\title{
DESENVOLVIMENTO DE TÉCNICA DE MEDIÇÃO E OBTENÇÃO DE DADOS EXPERIMENTAIS ENVOLVIDOS NO CICLO DE TRABALHO DOS COMPRESSORES HERMÉTICOS ALTERNATIVOS.
}

Marcelo Alexandre Real

Dissertação apresentada à Escola de Engenharia de São Carlos da Universidade de São Paulo, como parte dos requisitos para a obtenção do Título de Mestre em Engenharia Mecânica.

Orientador: Prof. Dr. Luiz Carlos Felicio

São Carlos

2005 
Para Luciana, minha mulher, pelo seu carinho, compreensão e incentivo durante minha jornada. À Julia, minha filha, pelas noites que a deixei sem companhia em suas brincadeiras. Ao meu pai e aos meus sogros pelo apoio. Em memória de minha mãe, sempre presente em minha vida. 


\section{AGRADECIMENTOS}

A Tecumseh do Brasil Ltda. na figura do Srs. Leonelo A. Calciolari e Enio S. Freitas pela significativa contribuição e apoio para desenvolvimento do trabalho.

Aos meus amigos, em especial Eduardo A. G. Pereira, pelo seu apoio e cooperação para realização dessa dissertação, a Sérgio Bertachini pelo incentivo durante minha trajetória e a Paulo $\mathrm{H}$. Domingues pelo suporte para realização do trabalho.

Ao professor Doutor Luiz Carlos Felício, pelos ensinamentos e fundamental contribuição para o desenvolvimento do projeto.

A Escola de Engenharia de São Carlos - EESC USP - por colocar a minha disposição sua estrutura.

A Professora Mariângela Tassinari de Figueiredo - IFSC USP - pelos seus ensinamentos e dedicação. 
"O que prevemos raramente ocorre; o que menos esperamos geralmente acontece." 


\section{RESUMO}

Real, M. A. (2005). Desenvolvimento de técnica de medição e obtenção de dados experimentais envolvidos no ciclo de trabalho dos compressores herméticos alternativos. Dissertação de Mestrado - Escola de Engenharia de São Carlos, Universidade de São Paulo, São Carlos 2005.

Essa dissertação desenvolve e faz uso de uma técnica de medição com objetivo de obter dados experimentais envolvidos no ciclo de trabalho dos compressores herméticos alternativos, largamente utilizados nos sistemas de refrigeração. O trabalho mostra o comportamento das válvulas de admissão e descarga durante o funcionamento do compressor, as pressões no cilindro, na sucção, na descarga e também a variação de rotação do eixo durante um ciclo de compressão completo. Todas as características mensuradas estão referenciadas à posição angular do eixo do compressor, o que permitiu monitorar todos os eventos em função do seu deslocamento angular. Para o desenvolvimento desse trabalho foi necessário planejar um sistema de medição robusto, não vulnerável aos fatores ambientais, presentes dentro da carcaça do compressor. A limitação do espaço físico foi um fator de grande importância na escolha dos sensores, assim como a velocidade de resposta dos instrumentos, pois um ciclo de compressão tem período menor que 0,020 segundos. A coleta dos dados e a análise dos sinais foram realizadas com o auxilio de hardware apropriado e software especialmente desenvolvido.

Palavras-chave: Compressor hermético; válvulas; medidas de pressões; deslocamento de válvula; sensores; sistema de aquisição de dados. 


\section{ABSTRACT}

Real, M. A. (2005). Development of techniques to measure and extract experimental data of hermetic compressor work cycle. M.Sc Dissertation Escola de Engenharia de São Carlos, Universidade de São Paulo, São Carlos 2005.

In this dissertation it is developed and applied measurement methods to obtain experimental data of a hermetic compressor work cycle, widely used in the refrigeration systems. This work shows the suction and discharge valve behaviors, the pressure in the cylinder, as well as in the discharge and suction chambers, and also crankshaft rotation variation during a complete compression cycle. All the measurements are reference to crankshaft angular position of compressor which allows to verify the events as a function of the crankshaft angular displacement. For the development of this work it was necessary to plan a reliability measure system, not affected by environmental factors inside the housing of compressor. The inner space limitation was an important feature for choosing the sensors as well as their time response, since the period compression cycle is less than 0.020 seconds. The data acquisition and signal analysis were done with appropriate hardware and it was developed a specific software.

Keywords: Hermetic compressor; valve; pressure measurement; valve displacement; sensors; data acquisition system 


\section{LISTA DE FIGURAS}

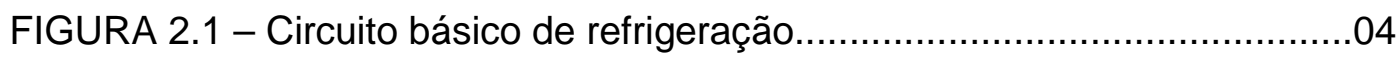

FIGURA 2.2 - Foto de um compressor hermético...............................................

FIGURA 2.3 - Foto de um compressor hermético em corte..............................07

FIGURA 3.1 - Sistema de válvula utilizado em compressores........................17

FIGURA 4.1 - Esquema detalhando a instrumentação utilizada.......................23

FIGURA 4.2 - Sensor de pressão ETL-76M-190-500A ….............................25

FIGURA 4.3 - Bancada para verificação dos sensores de pressão a

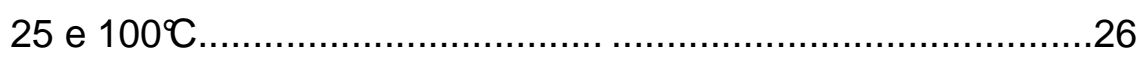

FIGURA 4.4 - Curva de resposta do sensor V109 (sucção) -

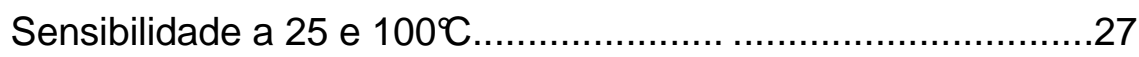

FIGURA 4.5 - Curva de resposta do sensor V110 (cilindro) -

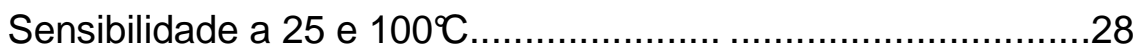

FIGURA 4.6 - Curva de resposta do sensor V111 (descarga) -

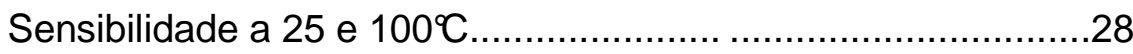

FIGURA 4.7 - Modelo de transiente de pressão..........................................29

FIGURA 4.8 - Espectro do transiente da figura 4.7 considerando

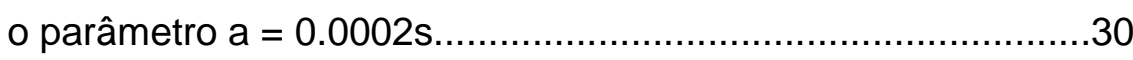

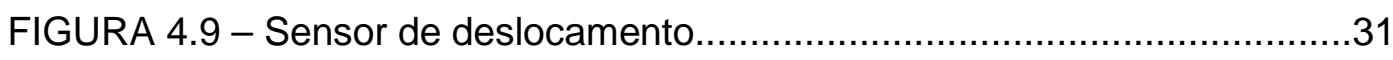

FIGURA 4.10 - Bancada utilizada para conhecer a resposta dos sensores

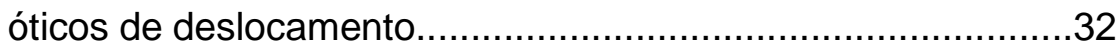

FIGURA 4.11 - Verificação em claro do sensor de deslocamento......................33

FIGURA 4.12 - Verificação em escuro do sensor de deslocamento...................33

FIGURA 4.13 - Gráfico para determinação da sensibilidade Sensor de deslocamento RC100

FIGURA 4.14 - Gráfico para determinação da sensibilidade -

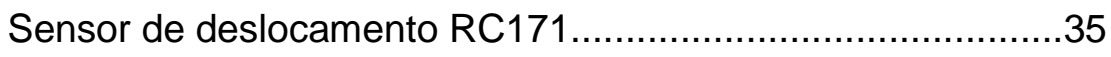

FIGURA 4.15 - Bancada para verificar o efeito da flexão da válvula sobre o sensor de deslocamento............................................36

FIGURA 4.16 - Efeito da flexão da válvula sobre o sensor RC 171................38

FIGURA 4.17 - Correto alinhamento do sensor de deslocamento para alvos inclinados 
FIGURA 4.19 - Gráfico para determinação da sensibilidade na região linear (Região de trabalho) do sensor RC171..........................40

FIGURA 4.20 - Sensor de deslocamento angular (encoder).

FIGURA 4.21 - Posicionamento dos sensores de pressão nas câmaras de admissão e descarga....................................................42

FIGURA 4.22 - Posicionamento do sensor de pressão no cilindro. 43

FIGURA 4.23 - Dimensionamento do furo conector para pressão no cilindro

FIGURA 4.24 - Esquema básico do furo conector utilizado na modelagem.....44

FIGURA 4.25 - Montagem dos sensores de deslocamento. .47

FIGURA 4.26 - Vedação utilizada na passagem dos cabos dos sensores de deslocamento.

FIGURA 4.27 - Montagem e ajuste do sensor de deslocamento angular (encoder)

FIGURA 4.28 - Montagem do termopar junto a câmara de descarga................50

FIGURA 4.29 - Montagem do tubo de passagem dos cabos elétricos.

FIGURA 4.30 - Montagem geral do compressor instrumentado dentro da

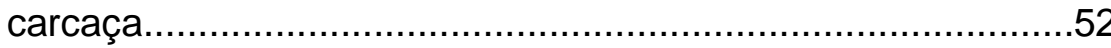

FIGURA 4.31 - Sistema de aquisição de dados.............................................53

FIGURA 4.32 - Estrutura do software de aquisição e dados.............................54

FIGURA 4.33 - Painel frontal do software de aquisição e dados.......................55

FIGURA 4.34 - Influência do filtro sobre o sinal medido................................57

FIGURA 5.1 - Relação de amplitudes: pressão no sensor/pressão no cilindro.

FIGURA 5.2 - Gráfico da fase do sinal medido através do furo adaptador.......61

FIGURA 5.3 - Comparação do sinal amostrado com o sinal corrigido teoricamente em função do comprimento do furo 62

FIGURA 5.4 - Influência do furo adaptador sobre o sinal medido. .63

FIGURA 5.5 - Comparação entre as medidas de pressão usando cabeçotes distintos.

FIGURA 5.6 - Comportamento das pressões durante o ciclo de compressão de um compressor hermético.

FIGURA 5.7 - Determinação do deslocamento do pistão em um sistema biela-manivela 
FIGURA 5.8 - Variação da pressão do cilindro comparada ao deslocamento do pistão.

FIGURA 5.9 - Diagrama das pressões contra o volume de um compressor hermético.

FIGURA 5.10 - FFT do sinal da pressão de sucção.. 69

FIGURA 5.11 - FFT do sinal da pressão de descarga.

FIGURA 5.12 - Repetição das leituras do comportamento de pressão durante o ciclo.

FIGURA 5.13 - Registro da abertura da válvula de sucção em relação a posição angular do eixo do compressor, durante um ciclo de compressão

FIGURA 5.14 - Abertura da válvula de sucção em função do tempo, durante uma revolução.

FIGURA 5.15 - Trecho ampliado que ilustra as oscilações da válvula de sucção na admissão.

FIGURA 5.16 - Comportamento das pressões durante abertura da válvula de sucção.

FIGURA 5.17 - Transformada de Fourier da abertura válvula de sucção. 74

FIGURA 5.18 - Repetibilidade das leituras da abertura da válvula de Sucção. .75

FIGURA 5.19 - Abertura da válvula de descarga em relação a posição angular do eixo do compressor durante um ciclo. .76

FIGURA 5.20 - Abertura da válvula de descarga em função do tempo, durante um ciclo.

FIGURA 5.21 - Trecho ampliado ilustrando a ausência de oscilações na válvula de descarga.

FIGURA 5.22 - Comportamento das pressões durante a abertura da válvula de descarga, em um ciclo.

FIGURA 5.23 - FFT da abertura da válvula de descarga .79

FIGURA 5.24 - Repetibilidade das leituras da abertura da válvula de Descarga. .80

FIGURA 5.25 - Temperatura do compressor hermético em funcionamento representado em gráfico de barras. 
FIGURA 5.26 - Método empregado para determinar velocidade do eixo de

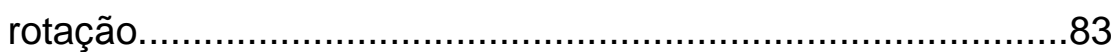

FIGURA 5.27 - Discretização do sinal do encoder (sensor de deslocamento angular).........................................................

FIGURA 5.28 - Variação da rotação durante o ciclo de compressão.................85

FIGURA 5.29 - Variação da rotação e pressão no cilindro durante um ciclo....85

FIGURA 5.30 - Variação da rotação e deslocamento do pistão durante um ciclo.

FIGURA 5.31 - Repetibilidade das leituras do perfil de velocidade durante o ciclo. 


\section{SUMÁRIO}

RESUMO

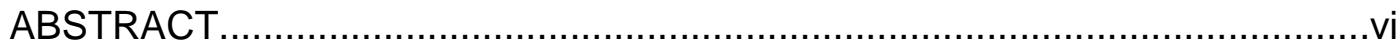

LISTA DE FIGURAS................................................................................

1 - INTRODUÇÃO

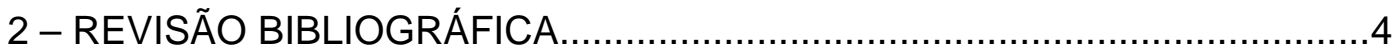

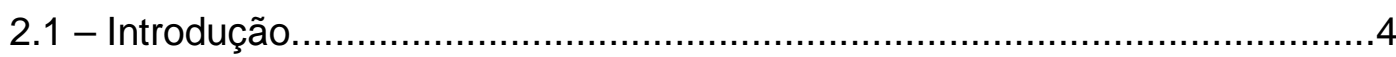

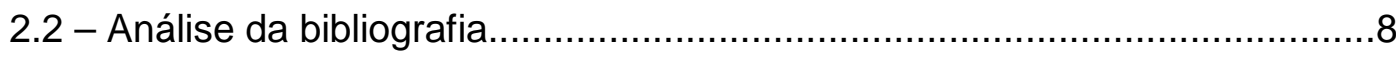

3 - OBJETIVO.

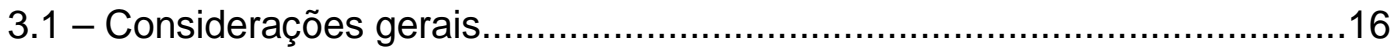

3.2 - Justificativa para o presente trabalho...............................................18

3.3 - Objetivos e contribuição dessa dissertação...........................................20

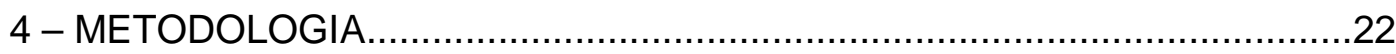

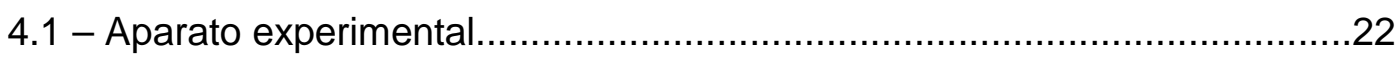

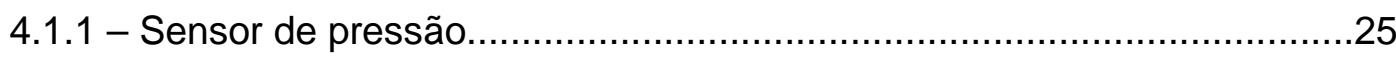

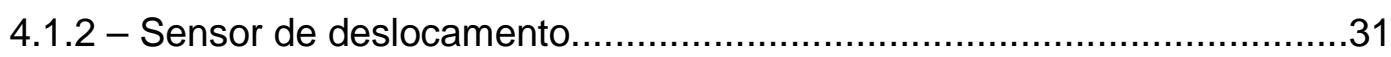

4.1.3 - Sensor de deslocamento angular...................................................

4.1.4 - Sensor de temperatura.............................................................

4.2 - Montagem .

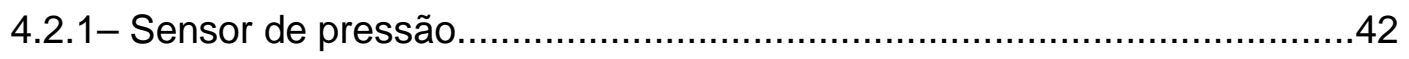

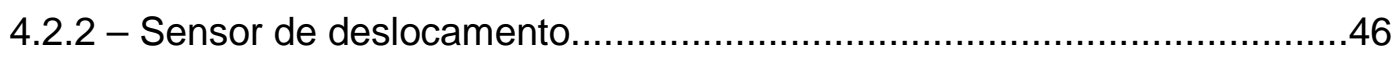

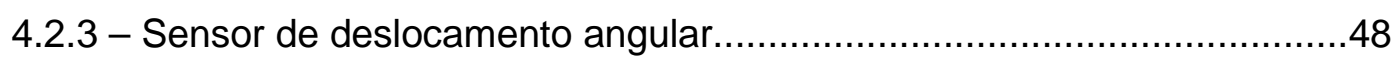

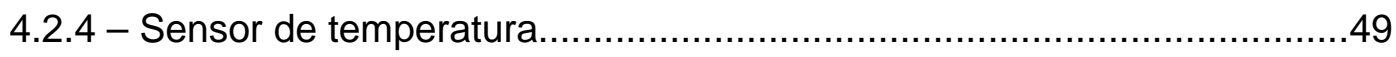

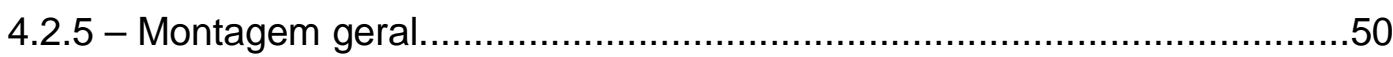

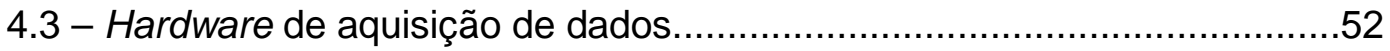

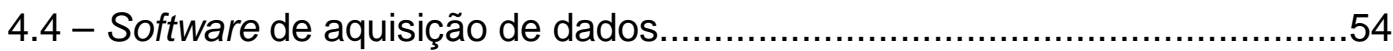

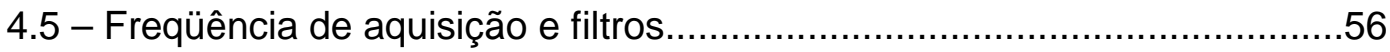


5 - RESULTADOS E DISCUSSÕES

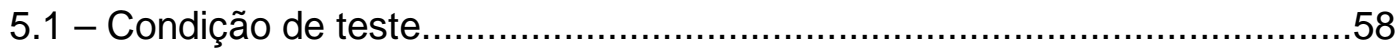

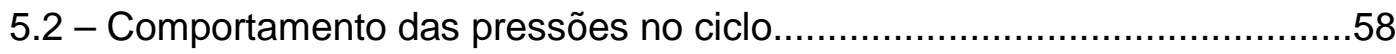

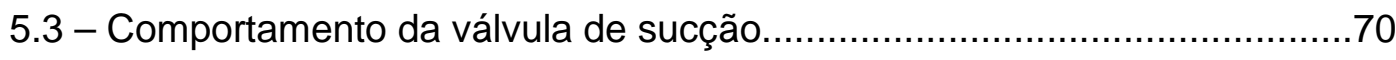

5.4 - Comportamento da válvula de descarga ...............................................76

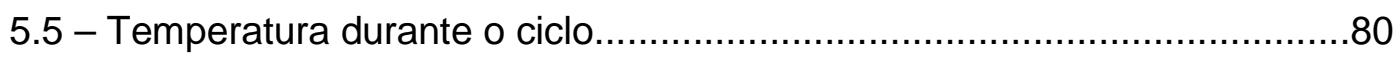

5.6 - Variação de rotação no ciclo.............................................................82

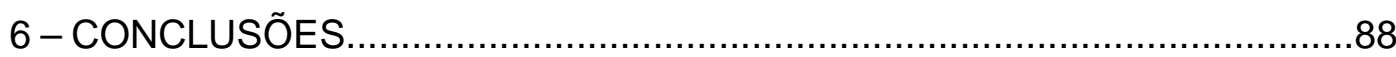

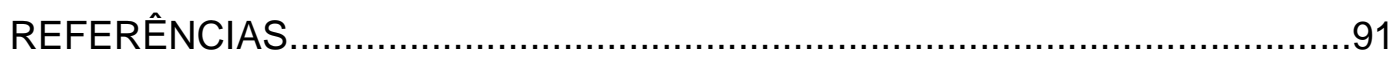

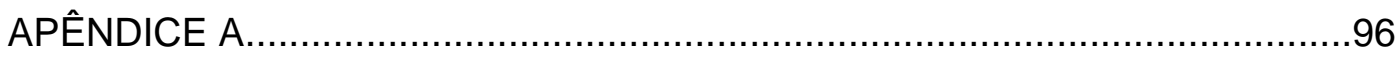

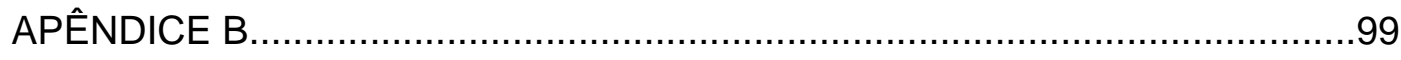




\section{INTRODUÇÃO}

O processo de remover calor de um corpo é bastante antigo, data do tempo dos egípcios, gregos e romanos. Na Grécia clássica eram utilizados escravos para o transporte de neve das montanhas que, armazenadas em palha, eram utilizadas nos meses quentes de verão. Os egípcios colocavam vasos, confeccionados de material poroso, cheios de água, fora de suas casas durante a noite. $O$ vento frio do deserto resfriava a água pela evaporação da umidade.

Atualmente existem meios para produzir refrigeração em qualquer estação do ano, mas foi a partir de 1923 com o advento da unidade mecânica que a refrigeração tomou seu grande impulso.

Nos primórdios da refrigeração mecânica, o equipamento utilizado, além de volumoso e dispendioso, não era muito eficiente. Este equipamento requeria a presença de um mecânico ou um engenheiro de operação, a postos durante todo o tempo. Isto limitava o uso da refrigeração a pequenas aplicações como fábricas de gelo e de empacotamento de carne, além de requerer grandes depósitos de armazenamento.

No espaço de apenas algumas décadas, a refrigeração tornou-se uma indústria gigantesca e de rápida expansão, como é atualmente. Este progresso explosivo aconteceu como resultado de diversos fatores. Primeiramente, o desenvolvimento de métodos de fabricação de precisão tornou possível produzir, em curto prazo de tempo, equipamentos mais eficientes. Isto, mais o desenvolvimento de refrigerantes "seguros" e a invenção de motor elétrico, viabilizou a pequena unidade de refrigeração (DOSSAT, 1984).

Após a Segunda Guerra Mundial, a Tecumseh Products Company lançou no mercado o compressor hermético, amplamente utilizado nas pequenas unidades de refrigeração, o qual é hoje usado em múltiplas aplicações como refrigeradores e congeladores domésticos, aparelhos de ar condicionado e instalações comerciais.

Atualmente há poucas casas ou estabelecimentos comerciais que não possuam um ou mais conjuntos de refrigeração de qualquer gênero. 
Acostumados com o uso da refrigeração, desconhecemos sua importância no desenvolvimento da sociedade. Não seria possível, por exemplo, sem a refrigeração, preservar e transportar gêneros alimentícios em quantidade suficiente para sustentar a sempre crescente população urbana. $O$ condicionamento de ar também é fundamental à sociedade; ele cria ambientes agradáveis, permite que as pessoas obtenham o seu melhor desempenho 0 que contribui para aumentar a eficiência e a economia.

Hoje a sociedade exige cada vez mais equipamentos de refrigeração eficientes, que economizam energia, e possuam baixo índice de ruído e vibração.

Dentre os fatores que influenciam a eficiência, o índice de ruído e vibração de um sistema de refrigeração, o compressor tem uma importância capital.

Por essa razão, esse trabalho tem como foco de estudo o compressor hermético. Através de dados experimentais, tais como, o funcionamento das válvulas de admissão e descarga, as pressões do sistema, os pulsos de pressão e a variação de rotação durante um ciclo completo de compressão, procura-se entender melhor o funcionamento do compressor, para assim, fornecer resultados que possam contribuir para 0 desenvolvimento de compressores mais eficientes e de melhor qualidade.

Essa dissertação desenvolve e faz uso de uma técnica de medição com objetivo de obter dados experimentais envolvidos no ciclo de trabalho dos compressores herméticos alternativos. Todas as características mensuradas estão referenciadas à posição angular do eixo do compressor, o que permitiu monitorar todos os eventos em função do seu deslocamento angular.

Para o desenvolvimento desse trabalho foi planejado um sistema de medição robusto, não vulnerável aos fatores ambientais, presentes dentro da carcaça do compressor, tais como: compatibilidade química e eletromagnética, temperatura e pressão. Durante a escolha e montagem dos sensores, às limitações do espaço físico impostas pelo objeto em estudo e a velocidade do evento monitorado, menor que 0,020 segundos, também foram avaliados. A coleta dos dados e a análise dos sinais foram realizadas com o auxilio de hardware apropriado e o desenvolvimento de um software específico. 
O sistema de medição utilizado mostrou-se bastante robusto atingindo plenamente os objetivos propostos nessa dissertação.

A maior ênfase desse trabalho de mestrado está na aplicação de técnicas de medição, montagem de uma bancada experimental, realização dos ensaios, levantamento de dados e na análise e interpretação dos resultados. 


\section{REVISÃO BIBLIOGRÁFICA}

\section{1 - INTRODUÇÃO}

Um circuito de refrigeração é composto por:

- Fluido refrigerante;

- Condensador;

- Válvula de expansão ou tubo capilar;

- Evaporador;

- Compressor hermético.

A figura 2.1 ilustra, de forma esquemática, o circuito básico de refrigeração, mostrando as posições relativas entre seus componentes.

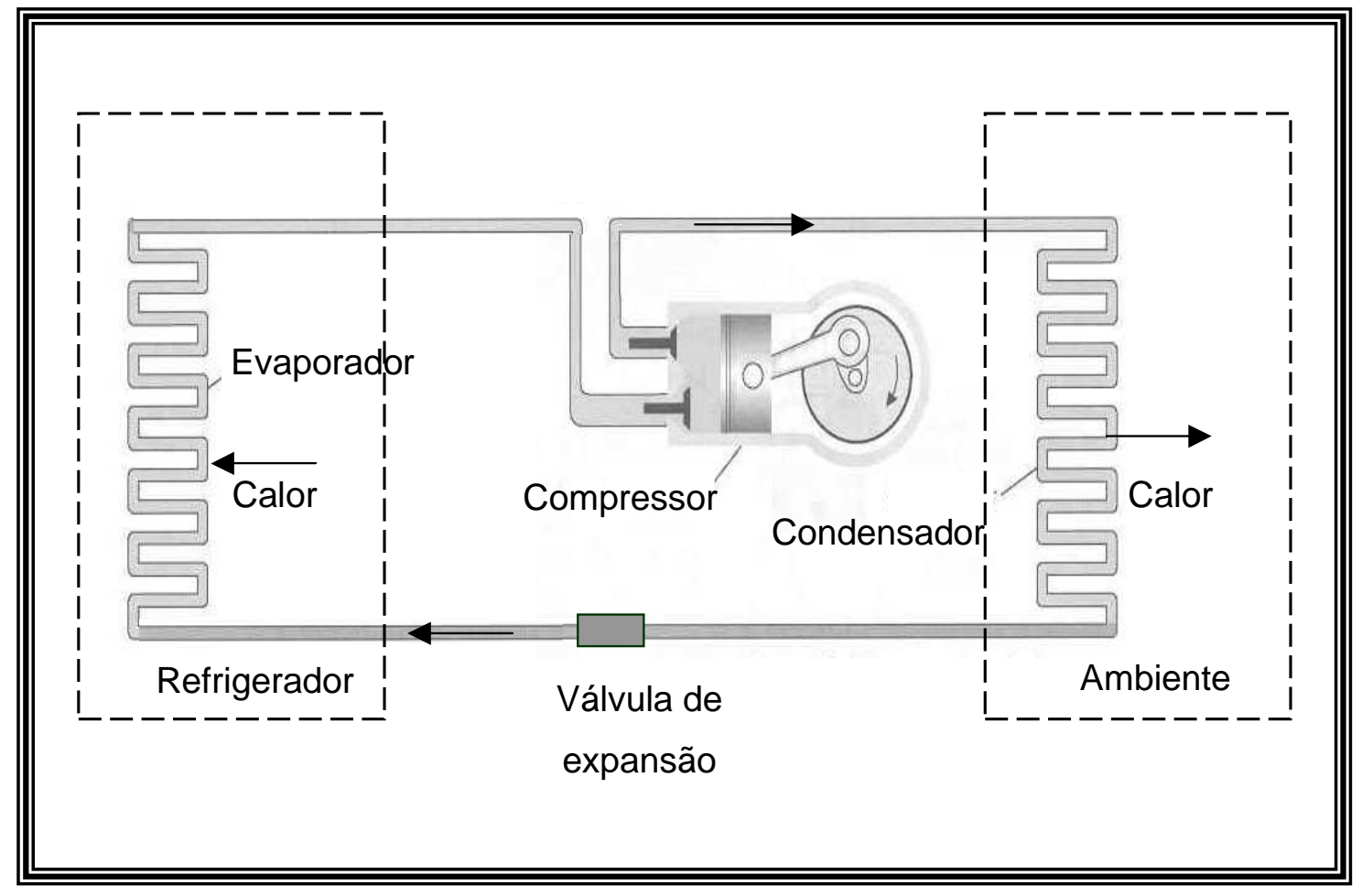

Figura 2.1 - Circuito básico de refrigeração - fonte: Física 1 - LTC 
O fluido refrigerante é qualquer fluido que age como agente refrigerante (térmico), pela absorção de calor de outro corpo ou substância. Com relação ao ciclo de compressão do vapor, o refrigerante é o fluido de trabalho do ciclo que, alternadamente, vaporiza e condensa quando absorve e cede calor, respectivamente. Para ser adequado para o uso como refrigerante no ciclo de compressão do vapor, um fluido deve possuir certas propriedades químicas, físicas e termodinâmicas que o tornem além de seguro, econômico para uso.

O condensador é uma superfície de transmissão de calor. O calor do vapor refrigerante quente é transferido, através das paredes do condensador, para o meio de condensação. Como resultado, o vapor refrigerante é primeiro resfriado ao ponto de saturação e, então, condensado no estado líquido.

A válvula de expansão ou tubo capilar é um dispositivo que, através da restrição da vazão, possue a função de regular a quantidade de refrigerante que chega ao evaporador. Com isso obtem-se a queda de pressão necessária para permitir, ao refrigerante, vaporizar sob a pressão baixa no evaporador e, simultaneamente, condensar sob uma pressão elevada no condensador. Dessa forma, a válvula de expansão divide o sistema em duas seções de pressão: 0 lado de alta e o lado de baixa.

O evaporador é qualquer superfície de transmissão de calor na qual o fluido refrigerante é vaporizado com o objetivo de remover calor de um ambiente ou produto refrigerado. Devido às diversas aplicações na refrigeração mecânica, os evaporadores são fabricados em grandes variedades de tipos, formas e tamanhos (DOSSAT, 1984).

Conforme já foi dito, o compressor é o principal componente do sistema de refrigeração. Para o serviço de refrigeração, comumente são usados três tipos de compressores: alternativo, rotativo, centrífugos. Os tipos alternativos e rotativos são compressores de deslocamento positivo, nos quais a compressão do vapor é efetuada mecanicamente por meio de um elemento de compressão. No compressor alternativo, o elemento de compressão do vapor é um pistão alternativo, enquanto no compressor rotativo, o elemento de compressão toma a forma de um rolo, aleta ou lóbulo. O compressor centrífugo, por outro lado, não possui elemento de compressão; nele a compressão do vapor é efetuada 
pela ação da força centrífuga que é desenvolvida quando o vapor é girado por um rotor em alta velocidade.

Cada um dos três tipos de compressores apresenta certas vantagens em seu próprio campo de uso. O tipo de compressor empregado em qualquer aplicação individual depende da dimensão, da natureza da instalação e do fluído refrigerante usado.

A maioria das aplicações de pequeno porte, tais como: refrigeradores, freezers, bebedouros e aparelhos de ar condicionado residencial utilizam compressores do tipo hermético alternativo. Ele é especialmente adaptável para o uso com refrigerantes que requeiram deslocamentos relativamente pequenos e com condensação a pressões relativamente altas.

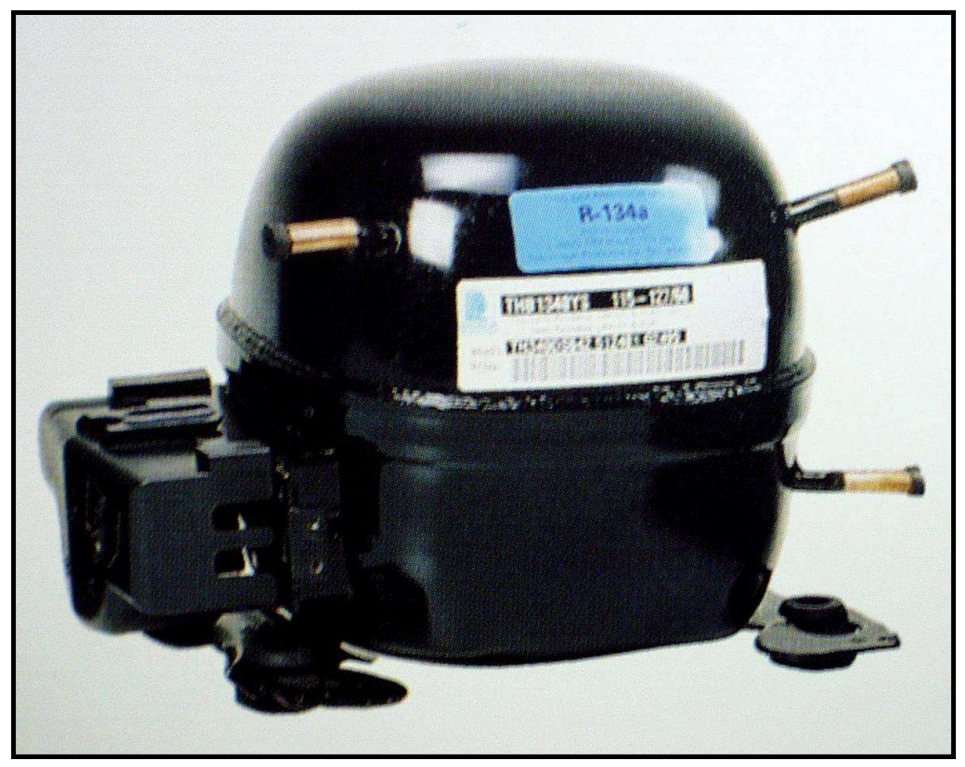

Figura 2.2 - Foto de um compressor hermético - Fonte catálogo geral Tecumseh do Brasil 2004

As figuras 2.2 e 2.3 mostram o compressor hermético alternativo. $\mathrm{O}$ compressor alternativo possue um pistão diretamente acionado por uma biela acoplado ao eixo da manivela que é movido pelo motor elétrico. 


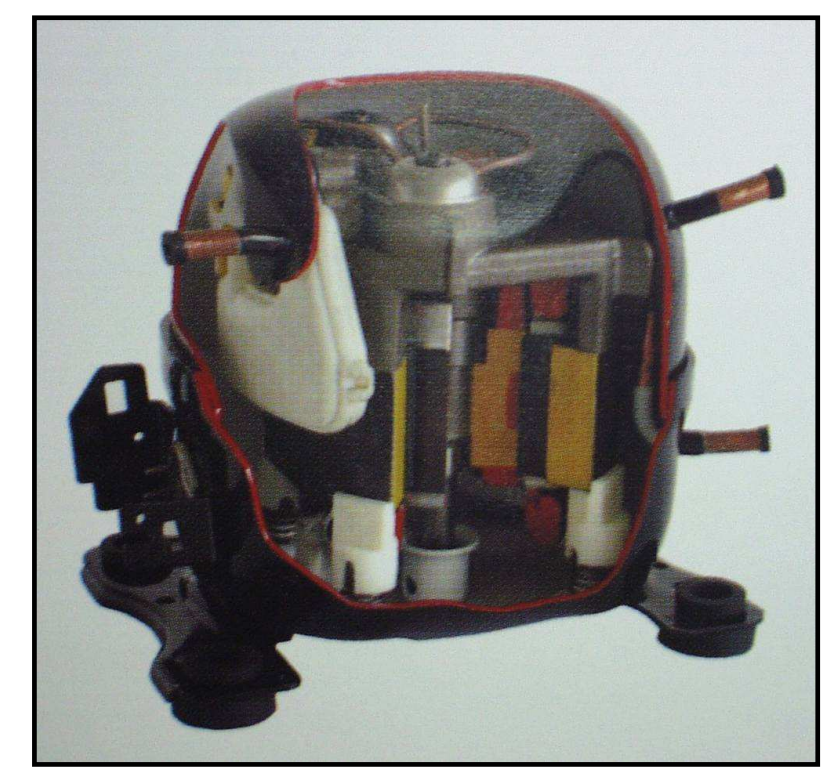

Figura 2.3 - Foto de um compressor hermético em corte - Fonte catálogo geral Tecumseh do Brasil 2004

Os movimentos alternativos do pistão são denominados avanço e retorno. Quando o pistão do compressor retorna, durante o tempo de admissão, um vapor de baixa pressão da tubulação de admissão é aspirado para o cilindro através das válvulas de sucção. Quando o pistão avança, o vapor de baixa pressão é comprimido e, então, descarregado como um fluido de alta pressão, através da válvula de descarga no momento que a pressão no cilindro - devido à restrição imposta pela válvula de expansão - passa a ser maior que a do condensador. O fluido chega, então, ao condensador onde é liquefeito por convecção (natural ou forçada), processo que cede calor ao ambiente, motivo pelo qual, além de liquefazer-se, resfria-se. Depois de liquefeito, o refrigerante passa pela válvula de expansão de onde se expande para o evaporador.

No evaporador o fluido volta a vaporizar-se, absorve o calor latente do meio externo ao evaporador e novamente retorna ao compressor para recomeçar um novo ciclo.

Através da observação do ciclo como um todo, pode-se notar que vários fatores influenciam na sua eficiência, mas é evidente a importância do compressor. 


\section{2 - ANÁLISE DA BIBLIOGRAFIA}

O compressor pode ser considerado como o coração do sistema de refrigeração. Ele é responsável pelas transformações físicas que ocorrem no fluido refrigerante, transformações estas que culminam no fenômeno da refrigeração.

Compressor, do latim compressor oris, é definido como "máquina alternativa ou rotativa que se usa para comprimir um fluido" (HOUAISS, 2001).

Hermético, do francês hermétique (1554), com origem do grego hermes, perfeitamente selado para impedir a entrada e saída do ar (HOUAISS, 2001).

O compressor hermético é constituído por um conjunto mecânico - corpo, eixo, pistão, biela, placa válvula, válvula de sucção e descarga, cabeçote, sistema de sucção e descarga - e por um conjunto elétrico - estator e rotor dentro de um mesmo compartimento (carcaça) perfeitamente selado. As ligações com a parte externa do compressor são feitas através dos tubos de sucção e descarga do gás refrigerante e do terminal hermético utilizado para conexão elétrica. Existe ainda um terceiro tubo utilizado para processo, através do qual é possível realizar a carga do fluido e/ou lubrificante ou, ainda, realizar vácuo no sistema de refrigeração.

O desempenho dos compressores está diretamente condicionado à eficiência das válvulas em admitir e entregar o fluido refrigerante ao seu destino. Uma vez entendida a dinâmica de uma válvula e sua influência no desempenho e confiabilidade dos compressores, este conhecimento assume grande importância nos desenvolvimentos de novos produtos. Por esta razão, por mais de cinco décadas, muitos pesquisadores têm tentado monitorar o funcionamento das válvulas e desenvolver modelos matemáticos para compreender e prever seu comportamento.

A influência dos pulsos de pressão nas linhas de descarga e sucção é apontada por Maclaren e Tramscheck (1972) como fator de grande importância no desempenho das válvulas. A válvula de sucção é muito sensível à fase do pulso de pressão durante seu fechamento, devido ao fato da diferença de pressão entre a câmara de sucção e o cilindro ser pequena na admissão, 
quando comparada à válvula de descarga. Entretanto, os pulsos de pressão na linha de descarga são mais severos devido à abertura mais rápida da válvula de descarga e, também, dado o maior diferencial de pressão ao qual a válvula está submetida.

Os pulsos de pressão são suficientemente grandes para causar uma inversão no diferencial de pressão através da válvula e, assim, gerar um fluxo reverso. As alterações no diferencial de pressão são rápidas e isso pode gerar o flutter da válvula - movimentos de abertura e fechamento desordenados das válvulas - que comprometem a eficiência volumétrica do compressor.

Nos compressores, as válvulas não estão sujeitas à vazão constante, mas variável devido ao movimento alternativo do pistão. Neste caso, o movimento da válvula pode tornar-se instável. Böswirth (1990) apresenta um modelo teórico para o flutter da válvula baseado na teoria clássica de estabilidade. O modelo foi testado em bancada experimental, fora do compressor, e apresentou bons resultados.

Killmann (1972) sugere especial atenção no projeto de válvula a fim de se evitar a condição de ressonância e o flutter da mesma. Assim como Killmann, Woollatt (1972) propõe a análise do movimento da válvula em função da posição angular do eixo de rotação dos compressores. Referenciado ao eixo de rotação é possível conhecer o comportamento da válvula durante todo um ciclo de compressão e, assim, conhecer os tempos de abertura das válvulas, a duração da abertura, o tempo de fechamento e a ocorrência de flutter da válvula em função da posição angular do eixo de rotação.

Bredesen (1974) desenvolveu um modelo teórico para calcular o comportamento das válvulas em condições de operação, levando em consideração os pulsos de pressão na linha de sucção e na descarga. Vários modelos foram criados para as válvulas de sucção e descarga, em sua grande maioria tratada como um sistema massa mola com um grau de liberdade. Um modelo bastante elaborado é apresentado por Buak (2002), no qual também se aplica um sistema de um grau de liberdade, mas com diversos tipos de nãolinearidades. Esse autor considera que cada válvula, sucção ou descarga, pode ter abertura não limitada ou pode possuir um limitador rígido ou flexível com ou sem massa e pode, também, apresentar ou não rebatimento. O modelo 
ainda leva em consideração as forças de atrito e contato nas válvulas e adota o fluxo compressivo do gás através delas, considerando os vazamentos na parede do cilindro para calcular sua pressão. Contudo os modelos teóricos exigem a validação experimental.

Há relatos na literatura em que são mensuradas todas as características que possam influenciar o comportamento das válvulas, em um único experimento, porém existem muitos trabalhos que contribuem de forma individual.

McConnell e Cohen (1972) desenvolveram um sistema para monitorar a velocidade instantânea do eixo de rotação do compressor durante um ciclo de funcionamento, utilizando: uma engrenagem em alumínio com 200 dentes, acoplada ao eixo de rotação do compressor e um sensor de proximidade de relutância variável. Os resultados evidenciaram ter havido variação na velocidade do eixo de rotação durante o ciclo de compressão, porém o artigo não mostra os valores encontrados. Na compressão do fluido foi detectada uma queda na velocidade do eixo, porém, durante a admissão, foi verificado aumento em sua velocidade. O sistema trabalhou da seguinte forma: cada vez que o dente da engrenagem passava pelo sensor, era produzido um pulso elétrico. Um conversor freqüência-voltagem convertia os pulsos e gerava uma voltagem proporcional à freqüência dos pulsos. A largura do dente da engrenagem e o ruído elétrico foram algumas dificuldades encontradas pelos autores.

No início dos trabalhos experimentais Speich (1972) sinalizou quais os sensores poderiam ser empregados para realizar a instrumentação necessária para entender o desempenho do ciclo de compressão e suas limitações. Muitos dos sensores sofreram a influência da temperatura e não apresentaram comportamento linear durante as medições. $O$ autor sugere que a correção deva ser feita através de uma pré-calibração dos sensores.

A aplicação dos sensores de pressão em compressores herméticos, em muitos casos, pode requerer a instalação de adaptadores devido à geometria do conjunto mecânico. A medida da pressão do cilindro, por exemplo, geralmente pede a utilização dos adaptadores. Uma vez encontrada a necessidade de uso, deve-se lembrar que os adaptadores podem afetar o 
comportamento dinâmico da pressão que chega ao sensor, podendo funcionar como um filtro das altas freqüências ou alterar a fase e a magnitude entre a pressão medida pelo sensor e a pressão verdadeira do cilindro.

Elson, Soedel (1972) e Buchholz (1978) trouxeram considerações importantes sobre o correto dimensionamento dos adaptadores com o objetivo de minimizar os seus efeitos sobre o sistema de medida.

O uso do adaptador para monitorar a pressão do cilindro também foi relatado nos ensaios experimentais realizados por Richardson, Gatecliff, Griner (1980). Ao adaptador foi acoplado um sensor piezelétrico com o objetivo de obter-se a resposta dinâmica da pressão do cilindro. Além da pressão do cilindro também foi realizado o monitoramento das pressões nas câmaras de sucção e descarga, feito de forma estática, por intermédio de um tubo que conectava as respectivas câmaras aos manômetros. O trabalho mensurou, também, o deslocamento da válvula de sucção e o deslocamento do pistão, através de um sensor de proximidade. A alimentação e o sinal dos sensores, bem como a passagem dos tubos conectados aos manômetros foram realizados através de conectores herméticos fixados na carcaça. Os sinais dos sensores foram conectados a um osciloscópio, apresentados e armazenados.

Com o aparecimento das placas de aquisições digitais acopladas aos microcomputadores, a manipulação dos sinais tornou-se mais fácil. Danqing, Qi e Xiangxing (1986), auxiliado por um computador, elaboraram e realizaram a aquisição dos dados experimentais de ciclo completo de compressão. Para isso foram utilizados: sensores de pressão posicionados no cilindro e câmaras de sucção e descarga; sensores de deslocamento indutivos para monitorar o funcionamento das válvulas e um sensor fotoelétrico para determinar a posição do ponto morto superior (menor distância entre o topo do pistão e a placa valvula). Com o auxílio de um software, o computador recebia o sinal do sensor fotoelétrico e disparava a aquisição dos dados. Dessa forma a coleta era feita a partir de um referencial, ponto morto superior, podendo assim, gerar as curvas de pressão em função da posição angular do eixo, bem como os deslocamentos das válvulas. Foi relatada a presença de ruídos aleatórios nos sinais dos sensores que gerou erros de precisão nas leituras, que obrigou especial cuidado no tratamento nos dados experimentais. 
Além dos ruídos elétricos, Kim e Soedel (1996) reportaram que muitos sensores de pressão são sensíveis à temperatura e isso pode gerar mudança na sensibilidade e na linearidade do sensor. Outra característica, apontada pelos autores, é que os sensores que são utilizados para monitorar as variações dinâmicas de pressão são submetidos a uma calibração estática.

As informações dinâmicas dos sensores, em sua grande maioria, são fornecidas pelo fabricante devido à dificuldade de realizar-se a calibração dinâmica.

Kim e Soedel também relataram a influência do incorreto alinhamento do sensor que referencia a posição angular do eixo de rotação, gerando informações imprecisas quanto à correta posição do pistão.

Perkovich, Kuehn e Ramsey (1994) no ensaio experimental empregaram os sensores de pressão tipo diafragma, sensores de proximidade para monitorar o movimento das válvulas e um sensor magnético para detectar a posição do pistão.

A instrumentação empregada por Meiners, Zhou e Kim (1996) utiliza um sensor de contato elétrico para verificar a abertura e fechamento da válvula. $O$ sensor de contato consiste de um contato de cobre, eletricamente isolado do conjunto mecânico, colado no acento da válvula e de uma bateria 9 VDC. O princípio deste método de medida é a teoria elementar de um circuito elétrico. Como a maioria dos componentes do compressor é de metal, ao alimentar o circuito com a bateria, se a válvula estiver fechada, circula uma corrente elétrica e pode ser medida a diferença de potencial. No instante que a válvula se abre cessa a corrente e cai a tensão. O registro da tensão mostra o momento de abertura e fechamento das válvulas. Junto a esse sistema a posição do pistão também foi monitorada por um sensor magnético. As pressões nas câmaras de sucção, de descarga e no cilindro foram monitoradas através de sensores de pressão piezelétricos. Os seis sinais - três pressões, dois movimentos de válvula e sinal e posição do pistão - simultaneamente foram monitorados por meio de um analisador digital de sinal.

Em um outro experimento, a mesma metodologia foi utilizada por Joo, Oh, Kim (2000), para verificar o comportamento da válvula. As vantagens 
apontadas por esses autores, foi o baixo custo do sensor e a mínima interferência no conjunto.

Este sistema, como qualquer outro, apresenta vantagens e desvantagens. A maior desvantagem é o fato de o sinal apenas mostrar se a válvula está aberta ou fechada. Se ocorrer flutter na válvula onde não exista contato com acento, este fato não será percebido pelo sensor. Outro efeito negativo é não ser possível a mensuração do deslocamento parcial.

Uma nova técnica para monitorar as válvulas nos compressores foi aplicada por Ludu, Betto e Regner (2000). Esses pesquisadores utilizaram dois endoscópios usando um fino feixe de fibras ópticas, para gravar em vídeo, o movimento das válvulas de sucção e descarga. Foram utilizados sensores piezelétricos de alta precisão para medir a pressão dinâmica na câmara de sucção, de descarga e no cilindro e, também, um sensor para determinar a posição do pistão. Foi capturada também, uma imagem para cada grau de giro do eixo de rotação. Os autores relataram ter sido boa a qualidade das imagens obtidas, sendo claramente visível o movimento das válvulas. Os resultados da investigação utilizando vídeo endoscópio foram as seqüências de imagens digitais que mostraram o movimento da válvula. Esses vídeos foram tratados por software específicos e, assim, foi possível mensurar as aberturas das válvulas.

Os sensores utilizando a tecnologia da fibra óptica foram também empregados por Prasad e Woollatt (2000). Nesses sensores foram utilizados feixes de fibras para transmitir luz e receber a luz refletida das superfícies monitoradas. A intensidade da luz refletida é proporcional à distância entre a ponta do sensor e o objeto medido. O trabalho não aponta o monitoramento das pressões e da posição do pistão.

Rigola, et al (2002), mais interessados em estudar o diagrama pressãovolume prepararam uma instrumentação para monitorar as pressões de descarga, de sucção e do cilindro. Um sensor de posição angular (encoder) foi utilizado para referenciar a posição do pistão. Foram empregados sensores de pressão piezos-resistivos, o que possibilitou verificarem as pressões estáticas (médias) e dinâmicas do sistema. Os autores usaram uma carcaça especial que permitiu a instalação de conectores herméticos para a alimentação dos 
sensores e adquirir os sinais. Para processar e analisar os sinais foi utilizado um sistema de aquisição de dados acoplado a um microcomputador.

Outra forma para analisar o movimento da válvula é através da técnica de vibrometria laser. Este método foi empregado por Buligan, Paone, Revel e Tomasini (2002 - 2003) em um compressor comercial utilizado na refrigeração doméstica. Para medir o movimento das válvulas pela vibrometria laser, elas necessitam estar oticamente acessíveis. Para isso, a carcaça do compressor e o cabeçote, receberam uma janela transparente de modo a possibilitar o acesso do laser sem alterar os volumes. Ambas as janelas foram seladas para prevenir vazamentos.

Os problemas apontados pelos autores, com relação à esta técnica são: primeiramente a dispersão e a reflexão da luz incidente pelas janelas e pelo óleo; reflexão da luz pelas janelas poderia permitir que o vibrômetro medisse o movimento do conjunto mecânico e não o movimento da válvula. A solução apontada pelos autores (op.cit) para o primeiro problema, foi melhorar a rugosidade das janelas para diminuir a dispersão dos raios e posicionar a fonte de laser não ortogonalmente à válvula. Com isso a luz refletida pela janela não atinge mais o sensor, mas somente a luz refletida pela válvula. Segundo problema - as partículas de óleo no gás e o filme de óleo formado sobre as janelas, também poderiam comprometer o acesso óptico e refletir a luz sobe o sensor. A solução foi criar um anteparo para proteger o feixe dentro da carcaça do compressor.

Outras características devem ser levadas em consideração, tais como a distância focal e o índice de refração. O compressor trabalhando com o fluido refrigerante possui um índice de refração diferente do índice do ar. Esse fato afeta a sensibilidade da vibrometria, então, os dados de velocidade necessitam ser ajustados. Os valores encontrados com o método da vibrometria foram comparados pelos autores (op.cit) aos valores encontrados pelo método do endoscópio e mostraram concordância satisfatória.

Todos os trabalhos citados na revisão bibliográfica mostraram muitas possibilidades de instrumentação que auxiliaram na definição da proposta dessa dissertação. 
A metodologia proposta no presente trabalho utiliza sensores de deslocamento óptico para monitorar os deslocamentos das válvulas de sucção e descarga, sensores de pressão piezo-resistivos para monitoramento das pressões estáticas e dinâmicas até $2500 \mathrm{~Hz}$ na câmara de sucção, descarga e no cilindro e um sensor de posição angular (encoder) com 2000 traços por revolução, para verificar a posição angular e, conseqüentemente, a do pistão. A informação gerada pelo encoder também será usada para medir a variação de velocidade do compressor, durante um ciclo de compressão. Será empregado um sistema de aquisição de dados que com o auxilio de um computador permitirá o registro e o controle das medições. 


\section{OBJETIVO}

\section{1 - CONSIDERAÇÕES GERAIS}

O sistema de refrigeração pode ser considerado uma máquina térmica que opera ao revés. A máquina recebe trabalho para extrair certa quantidade de calor do refrigerador e transferi-lo ao ambiente.

A eficiência do sistema de refrigeração está diretamente ligada à eficiência do seu compressor. No projeto dos compressores, as válvulas de admissão e descarga são um dos fatores mais importantes a serem considerados. O desempenho desse equipamento é determinado pela eficácia com que as válvulas podem admitir e entregar o fluido a seu destino. Dessa forma, é de grande importância conhecer o ciclo de trabalho dos compressores herméticos alternativos, em especial, o funcionamento das válvulas de sucção e descarga.

Com essas informações, é possível maximizar a eficiência dos sistemas de refrigeração, bem como evitar instabilidades de pressão que possam vir causar indesejáveis vibrações no conjunto mecânico com significativo aumento nos níveis de ruído.

As válvulas de sucção e descarga são acionadas pelo diferencial de pressão entre o cilindro e o cabeçote devido ao movimento alternativo do pistão.

A válvula de sucção é responsável pela admissão do fluido para dentro do cilindro e a válvula de descarga, pela distribuição do fluido para o sistema de refrigeração.

$\mathrm{Na}$ figura 3.1 está ilustrado um sistema de válvulas utilizado em compressores herméticos alternativos. 


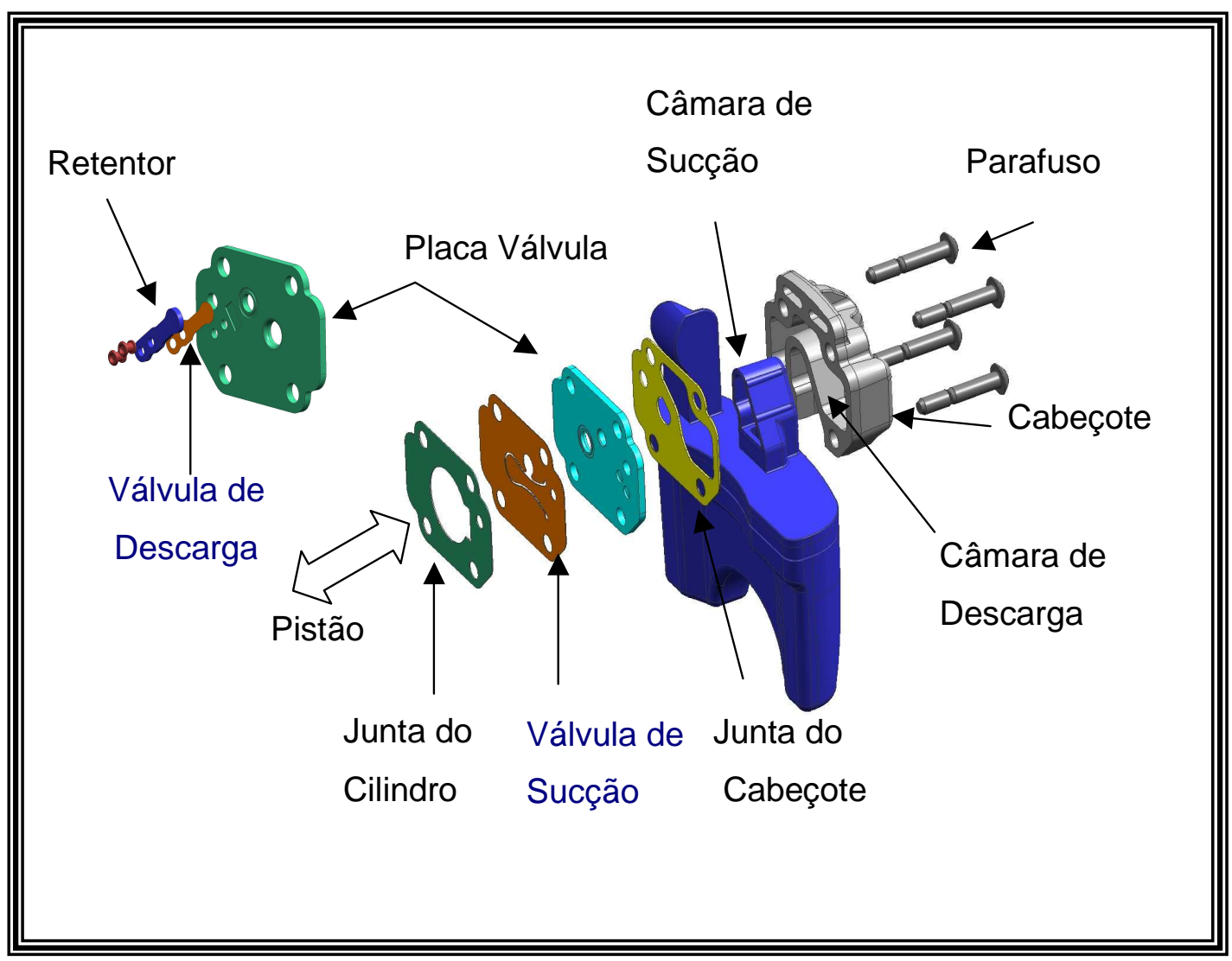

Figura 3.1 - Sistema de válvula utilizado em compressores - Fonte Tecumseh do Brasil

A perda por atrito sofrida pelo vapor que flui através das válvulas e passagens do compressor é, sobretudo, função da velocidade do vapor, pois, ela aumenta quando a velocidade do vapor aumenta. Portanto, a fim de minimizar as perdas por atrito, a válvula deve ser projetada para prover a maior abertura com o menor esforço possível. As válvulas devem ser localizadas de modo a garantir o fluxo retilíneo do vapor através das válvulas e passagens do compressor. Em todos os casos, as aberturas das válvulas devem ser suficientemente grandes para manter a velocidade do vapor dentro dos limites máximos. A velocidade do vapor permissível pode ser definida como aquela velocidade acima da qual o aumento no efeito do atrito produzirá uma redução marcante na eficiência volumétrica do compressor e/ou aumento nos requisitos de potência do compressor. 
As válvulas devem ser projetadas para fechar rápida e firmemente. A fim de abrir com facilidade e fechar rapidamente, as válvulas devem ser construídas de material leve e projetadas para rápidas respostas dinâmicas. Elas precisam ser fortes e duráveis e devem ser acionadas automaticamente. Além disso, as válvulas devem ser projetadas para minimizar o efeito de retorno de fluxo ou flutuação durante o acionamento. Devem ainda, ser localizadas de modo que não elevem o volume do espaço morto do compressor ou espaço nocivo.

Para evitar o choque do pistão com as placas de válvulas, todos os compressores alternativos são projetados de forma tal que, quando o pistão estiver no auge do deslocamento, haja uma pequena folga entre o topo do pistão e a placa de válvula. O volume dessa câmara é chamado volume do espaço morto ou espaço nocivo.

As válvulas empregadas nos compressores de refrigeração podem ser classificadas em três tipos básicos: de gatilho, de placa e anel e de flexão (DOSSAT, 1984). Todos os três tipos funcionam automaticamente, abrindo e fechando em resposta às diferenças de pressão causadas por mudanças na pressão do cilindro.

A válvula de flexão é amplamente usada em compressores menores. A válvula de flexão é uma fina lingüeta de aço, geralmente fixada firmemente em uma extremidade; enquanto a extremidade oposta, livre, permanece no acento da válvula. A extremidade livre da lingüeta flexiona para liberar ou restringir a passagem de fluxo devido ao diferencial de pressão ao qual esteja submetida.

\section{2 - JUSTIFICATIVA PARA O PRESENTE TRABALHO}

Para a escolha do tema do presente trabalho, inicialmente foram definidos critérios que permitissem 0 atendimento a premissas de ordem técnica e econômica, de forma que o resultado pudesse ter aplicação prática. Nesse contexto, tem-se uma breve descrição dos aspectos determinantes na definição. 
- Quanto ao equipamento: A escolha do equipamento foi direcionada para aquele que, em função das características do país/região, tivesse uso massivo por parte de todos os setores econômicos, em especial o residencial. Isso se deve ao fato que o uso do compressor hermético aplicado em refrigeradores está entre os 100 produtos de mais vendidos no Brasil (IBGE, 2003). Considerando a ampla gama de compressores aplicados à refrigeração existente no mercado, a pesquisa vai ser restrita aos modelos de baixa capacidade frigorífica, que são largamente aplicados em refrigeradores de uma porta e o mais acessível às diferentes camadas da sociedade. O compressor utilizado não é a última geração disponível ao mercado para assegurar o sigilo industrial.

- Quanto ao tema: $O$ presente trabalho justifica-se pela importância dos compressores herméticos alternativos. Esses equipamentos são amplamente utilizados na refrigeração doméstica e comercial, sendo indispensáveis em nosso cotidiano. Conhecer seu funcionamento, contribui para o desenvolvimento de equipamentos mais eficientes e robustos. A falha dos compressores causa a interrupção do ciclo de refrigeração, comprometendo a qualidade da conservação dos alimentos, causando sérios prejuízos à saúde pública e à economia.

Antes da definição final do tema, além dos aspectos descritos, procedeu-se a uma ampla pesquisa bibliográfica, com o intuito de conhecer o estado da arte sobre o assunto. Poucas publicações foram encontradas até o momento, o que indica a necessidade de avançar as pesquisas sobre o assunto. 


\subsection{OBJETIVOS E CONTRIBUIÇÕES DESSA DISSERTAÇÃO}

O trabalho proposto tem como objetivo, desenvolver uma técnica para obtenção de dados experimentais envolvidos no ciclo de trabalho dos compressores herméticos alternativos para conhecer as seguintes características:

i. Os comportamentos dinâmicos das válvulas de sucção e descarga durante o ciclo de compressão;

ii. Monitorar a pressão no cilindro, na admissão e na descarga durante o ciclo;

iii. Identificar o tempo de abertura e fechamento das válvulas durante o ciclo do compressor;

iv. Verificar o funcionamento das válvulas e das pressões em função da posição angular do eixo de rotação do compressor;

v. Mensurar o diferencial de pressão e os deslocamentos das válvulas durante o funcionamento do compressor;

vi. Conhecer a variação de rotação do eixo durante o ciclo de compressão.

vii. Verificar as temperaturas médias em regiões especificas dentro do compressor.

Para atingir os objetivos serão necessários:

I. Idealizar um robusto sistema de medição, que não seja vulnerável aos agressivos fatores ambientais ao qual será submetido, tais como: pressão, temperatura, compatibilidade química e eletromagnética;

II. Realizar a instrumentação em um compressor hermético;

III. Superar as limitações do espaço físico, devido ao tamanho do objeto em estudo;

IV. Não interferir e ou minimizar dentro do possível a interferência no sistema medido; 
V. Integrar hardware e desenvolver software que possibilitem a aquisição e o registro dos valores mensurados;

VI. Tratamento e análise dos dados coletados.

A obtenção desses resultados possibilitará avanços no conhecimento do ciclo de trabalho dos compressores herméticos, para assim, contribuir para o desenvolvimento de compressores mais eficientes e de melhor qualidade.

A aplicação desta técnica de medição em trabalhos futuros permitirá a obtenção de dados que possibilitará avanços no conhecimento do comportamento das válvulas. A vida útil das válvulas poderá ser prevista através de ensaios acelerados e também criar e validar modelos matemáticos que possam simular o sistema de válvulas dos compressores mencionados. A verificação do comportamento das válvulas poderá também contribuir para estudos sobre escoamento de fluidos em trabalhos que visem melhorar a eficiência volumétrica dos sistemas de refrigeração e, com isso, reduzir o consumo de energia elétrica.

Foge ao escopo desse trabalho a análise detalhada da adequação do projeto das válvulas em função dos resultados obtidos. 


\section{METODOLOGIA}

\subsection{APARATO EXPERIMENTAL}

O planejamento experimental foi realizado com objetivo de desenvolver uma técnica de medição para obter dados experimentais envolvidos no ciclo de trabalho dos compressores herméticos alternativos. A aplicação dessa técnica permite conhecer o comportamento das válvulas de admissão e descarga durante o funcionamento do compressor, as pressões no cilindro, na sucção, na descarga, as temperaturas e também a variação de rotação do eixo durante um ciclo de compressão completo. Todas as características mensuradas estão referenciadas à posição angular do eixo do compressor, o que permite monitorar todos os eventos em função do seu deslocamento angular.

Para o desenvolvimento desse trabalho foi necessário planejar um sistema de medição robusto, não vulnerável aos fatores ambientais, presentes dentro da carcaça do compressor. Foi preparada uma bancada experimental que utilizou os seguintes sensores:

I. Três sensores de pressão piezos-resistivos, localizados no cilindro, nas câmaras de sucção e de descarga;

II. Dois sensores de deslocamentos ópticos, sem contato, direcionados nas válvulas de descarga e de sucção, respectivamente;

III. Um sensor de deslocamento angular (encoder), fixado ao eixo de rotação do compressor.

IV. Cinco termopares localizados, na câmara de sucção, na câmara de descarga, na carcaça, no óleo e na entrada da câmara de admissão.

A limitação do espaço físico foi um fator de grande importância na escolha dos sensores, assim como a velocidade de resposta dos instrumentos, pois um ciclo de compressão tem período menor que 0,020 segundos. 
A figura 4.1 mostra em detalhes o esquema da instrumentação utilizada nesse trabalho.

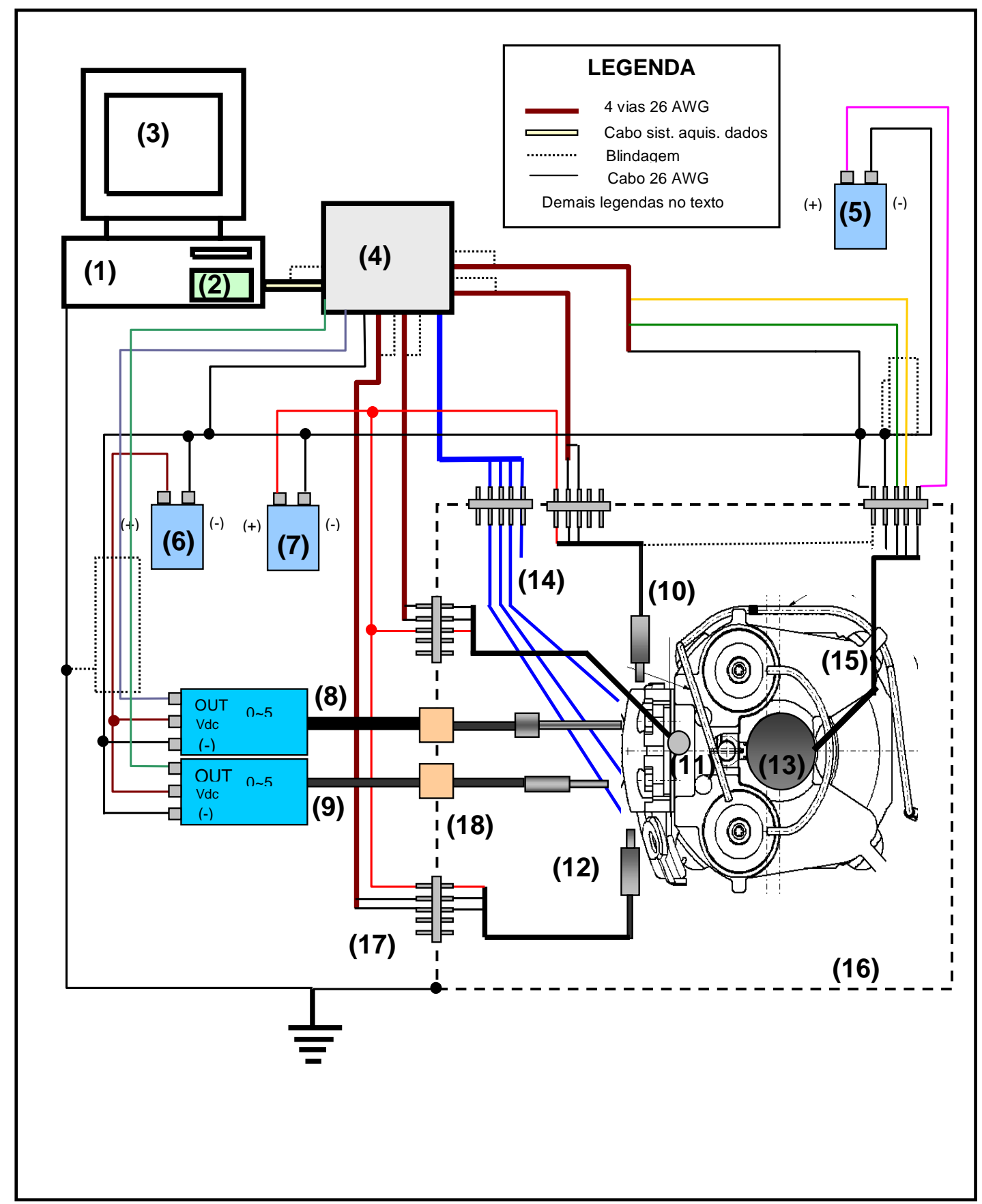

Figura 4.1 - Esquema detalhado da instrumentação utilizada. 


\section{Legenda da figura 4.1:}

1) Computador Dell dimension GX 280 - Processador Intel Pentium IV 3.0Ghz, memória RAM $512 \mathrm{MB}$;

2) Placa de aquisição de sinais marca National Instruments modelo $\mathrm{NI} \mathrm{PCl}$ 6251 - 16 bits, 1.250 .000 amostras/s;

3) Software Labview Versão 7.1 - National Instruments - para desenvolver o programa de controle e registro dos dados;

4) Condicionador de sinais composto por: Chassi SCXI 1000 com módulo SCXI1125 (Entrada Analógica) e bloco terminal SCXI 1313, módulo SCXI 1100 (Temperatura) com terminal bloco SCXI 1302 e conector 1180(Feedthrough) com terminal SCXI 1302;

5) Fonte de alimentação de 5 VDC, marca Incon Modelo FA 05-1, usado para alimentação do sensor de deslocamento angular;

6) Fonte de alimentação de 24 VDC, marca Incon Modelo FA 24-1, usado para alimentação do sensor de deslocamento;

7) Fonte de alimentação de 10VDC, marca Incon Modelo FA 10-1, usado para alimentação dos sensores de pressão;

8) Sensor de deslocamento óptico marca Philtec modelo RC 100 - válvula de descarga;

9) Sensor de deslocamento óptico marca Philtec modelo RC 171 - válvula de sucção;

10) Sensor de pressão marca Kulite modelo ETL-76M-500A para monitorar a pressão na câmara de sucção;

11) Sensor de pressão marca Kulite modelo ETL-76M-500A para monitorar a pressão na câmara de descarga;

12) Sensor de pressão marca Kulite modelo ETL-76M-500A para monitorar a pressão dentro do cilindro;

13) Sensor de deslocamento angular, encoder, marca Heidenhain modelo ERN 1020 2000_1; 
14)Termopares tipo T marca Omega modelo EXFF-TT-25 - cobre / constantan;

15)Compressor hermético utilizado em refrigeração doméstica;

16) Carcaça com flange: Dispositivo construído para garantir a vedação do compressor e que permitiu a montagem e a conexão dos sensores com o sistema de aquisição de dados;

17) Conector hermético;

\subsubsection{SENSOR DE PRESSÃO}

Os sensores de pressão utilizados foram do tipo piezos-resistivos modelo ETL-76M-190-500A, fabricados pela Kullite products Inc. Esse sensor é um dos menores transdutores micro-processados e amplificados atualmente disponível no mercado. Sua construção permite o uso em ambientes agressivos e apresenta grande acuracidade para faixas de temperaturas de $-40^{\circ} \mathrm{C}$ a $+120^{\circ} \mathrm{C}$. A completa especificação desse sens or encontra-se no apêndice $A$.

Estes sensores miniaturas são peças importantíssimas nessa instrumentação. As limitações do espaço físico e de volume morto são fundamentais para execução desse trabalho. A figura 4.2 mostra o sensor de pressão utilizado.

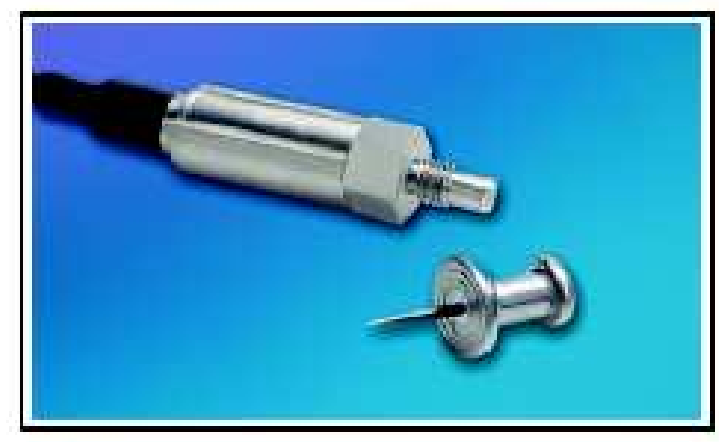

Figura 4.2 - Sensor de pressão ETL-76M-190-500A - Fonte: catalogo geral Kulite products Inc. 
Sabe-se que as temperaturas de determinadas regiões do compressor são mais elevadas que a temperatura ambiente, por exemplo, a temperatura no cilindro do compressor e na câmara de descarga. Houve uma suspeita sobre a possibilidade da temperatura causar efeitos interferentes e/ou modificantes nos transdutores de pressão. Assim, para assegurar a confiança nos valores medidos e investigar a influência da temperatura sobre os sensores de pressão, verificou-se na resposta dos a $25{ }^{\circ} \mathrm{C}$ e a $100^{\circ} \mathrm{C}$. Para realizar a verificação foi utilizado um padrão primário, com rastreabilidade ao INMETRO, marca PRESYS modelo PC507.

O aparato utilizado está ilustrado na figura 4.3.

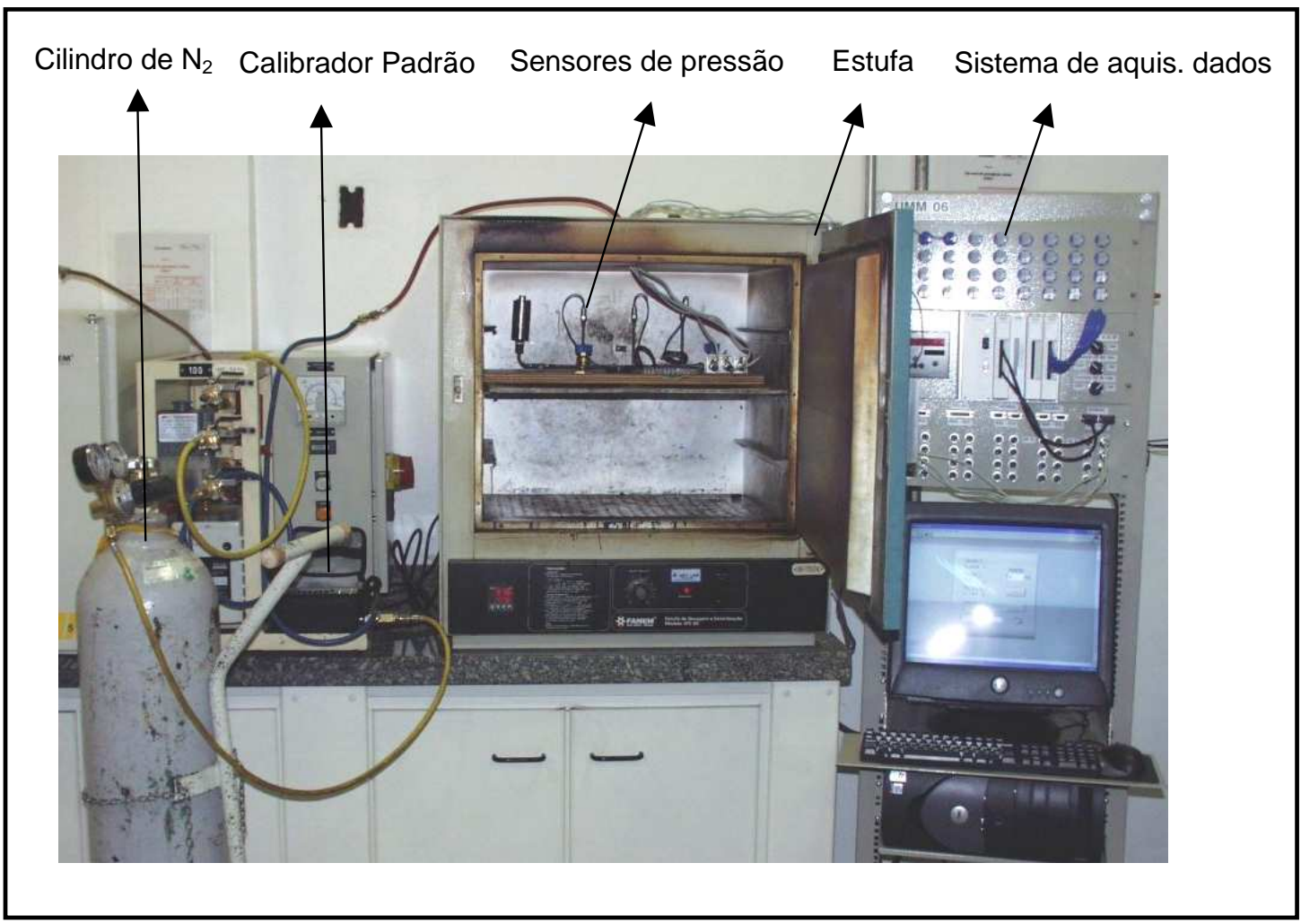

Figura 4.3 - Bancada para verificação dos sensores de pressão a 25 e 100 C.

Os valores encontrados estão na tabela 4.1. Com esses valores foram gerados gráficos da pressão contra a voltagem. Foi ajustada uma curva através de uma regressão linear pelos pontos medidos e encontrado a sensibilidade para cada sensor (figuras 4.4, 4.5 e 4.6). 


\begin{tabular}{|c|c|c|c|c|c|c|c|}
\hline \multicolumn{4}{|c|}{ Temperatura $25 \circ \mathrm{C}$} & \multicolumn{4}{|c|}{ Temperatura $100^{\circ} \mathrm{C}$} \\
\hline Pressão & Sensor & Sensor & Sensor & Pressão & Sensor & Sensor & Sensor \\
\hline \multirow{2}{*}{ Psia } & V109 & V110 & V111 & \multirow{2}{*}{$P s$} & V109 & V110 & V111 \\
\hline & (Volts) & (Volts) & (Volts) & & (Volts) & (Volts) & (Volts) \\
\hline 14,63 & 0,618 & 0,609 & 0,585 & 14,62 & 0,619 & 0,607 & 0,59 \\
\hline 26,99 & 0,729 & 0,721 & 0,697 & 27,10 & 0,731 & 0,722 & 0,701 \\
\hline 31,57 & 0,770 & 0,762 & 0,739 & 39,60 & 0,844 & 0,834 & 0,814 \\
\hline 38,74 & 0,834 & 0,827 & 0,804 & 50,00 & 0,937 & 0,927 & 0,908 \\
\hline 50,20 & 0,938 & 0,931 & 0,908 & 56,30 & 0,994 & 0,988 & 0,965 \\
\hline 56,30 & 0,993 & 0,986 & 0,963 & 64,00 & 1,063 & 1,057 & 1,035 \\
\hline 65,10 & 1,072 & 1,066 & 1,043 & 71,40 & 1,130 & 1,124 & 1,104 \\
\hline 71,80 & 1,132 & 1,126 & 1,1 & 79,10 & 1,199 & 1,193 & 1,173 \\
\hline 81,40 & 1,218 & 1,214 & 1,1 & 88,00 & 1,279 & 1,273 & 1,253 \\
\hline 98,70 & 1,374 & 1,369 & 1,348 & 97,50 & 1,364 & 1,358 & 1,338 \\
\hline 108,50 & 1,462 & 1,459 & 1,436 & 108,30 & 1,461 & 1,455 & 1,436 \\
\hline 118,40 & 1,551 & 1,548 & 1,526 & 119,30 & 1,560 & 1,554 & 1,534 \\
\hline 129,90 & 1,655 & 1,651 & 1,630 & 128,80 & 1,646 & 1,641 & 1,621 \\
\hline 141,90 & 1,763 & 1,760 & 1,738 & 136,50 & 1,715 & 1,71 & 1,689 \\
\hline 150,60 & 1,841 & 1,839 & 1,817 & 145,50 & 1,795 & 1,791 & 1,77 \\
\hline 160,40 & 1,929 & 1,927 & 1,906 & 156,80 & 1,896 & 1,892 & 1,872 \\
\hline 171,00 & 2,024 & 2,023 & 2,002 & 165,00 & 1,970 & 1,967 & 1,946 \\
\hline 183,40 & 2,136 & 2,135 & 2,114 & 175,30 & 2,063 & 2,059 & 2,039 \\
\hline 191,40 & 2,207 & 2,207 & 2,185 & 185,90 & 2,158 & 2,154 & 2,134 \\
\hline 201,00 & 2,294 & 2,295 & 2,273 & 197,30 & 2,260 & 2,257 & 2,236 \\
\hline 210,40 & 2,379 & 2,380 & 2,358 & 203,50 & 2,315 & 2,313 & 2,294 \\
\hline 217,20 & 2,439 & 2,440 & 2,419 & 213,40 & 2,404 & 2,402 & 2,382 \\
\hline 231,20 & 2,565 & 2,566 & 2,544 & 227,20 & 2,527 & 2,525 & 2,506 \\
\hline 240,50 & 2,648 & 2,649 & 2,628 & 237,00 & 2,616 & 2,614 & 2,594 \\
\hline
\end{tabular}

Tabela 4.1 - Resposta dos sensores de pressão.

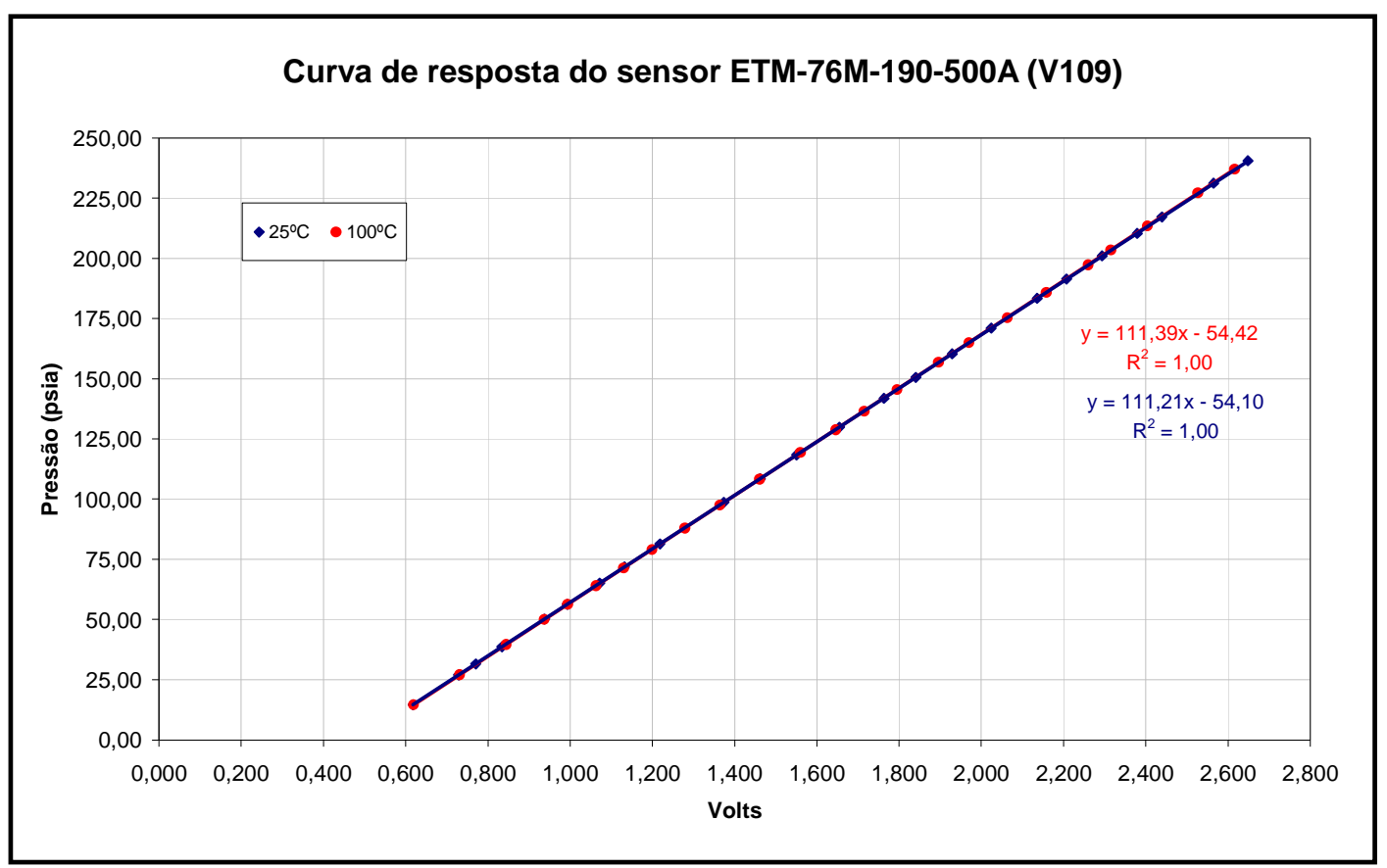

Figura 4.4 - Curva de resposta do sensor V109 (sucção) - Sensibilidade a 25 e $100{ }^{\circ}$. 


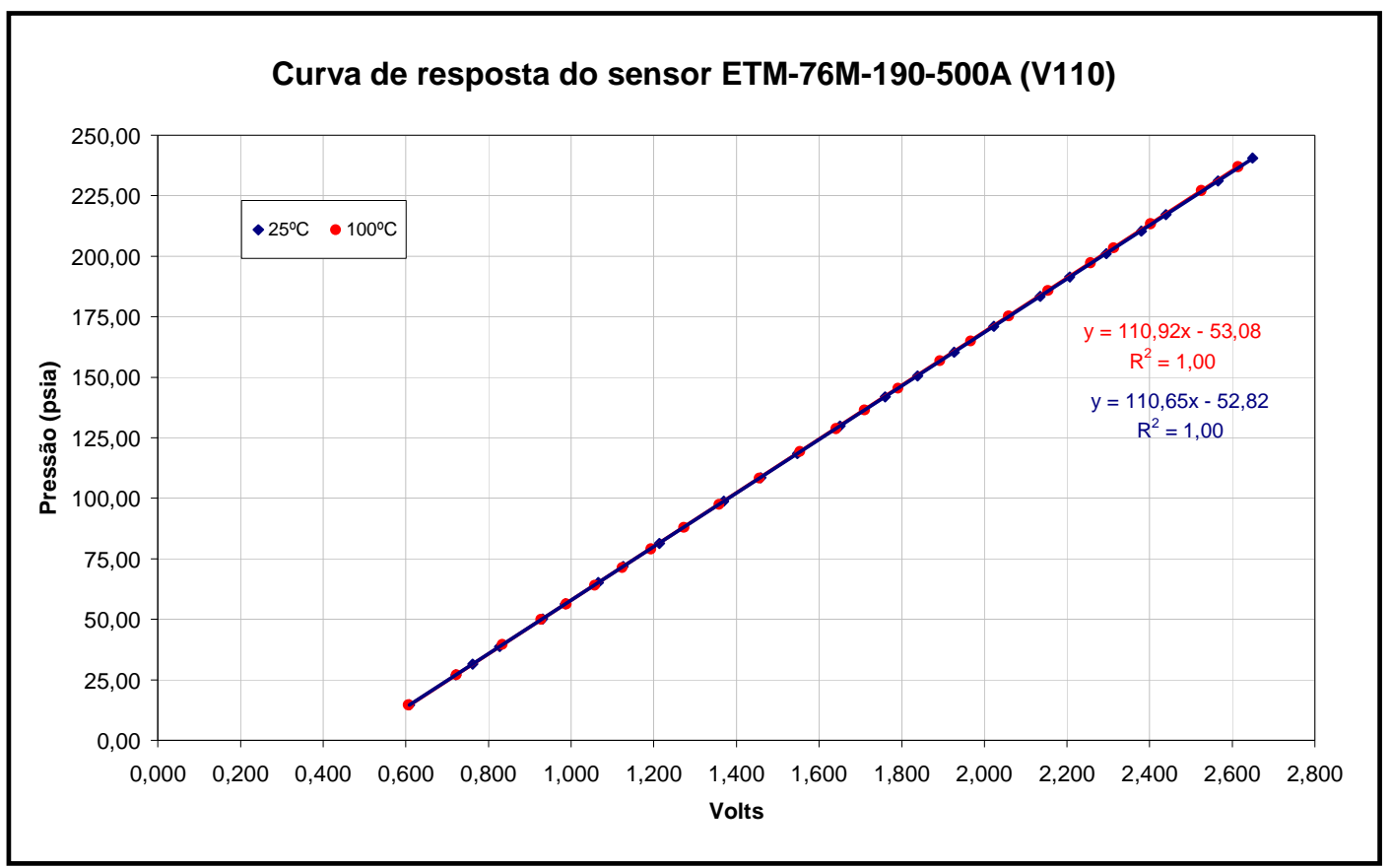

Figura 4.5 - Curva de resposta do sensor V110 (cilindro) - Sensibilidade a 25 e 100 C.

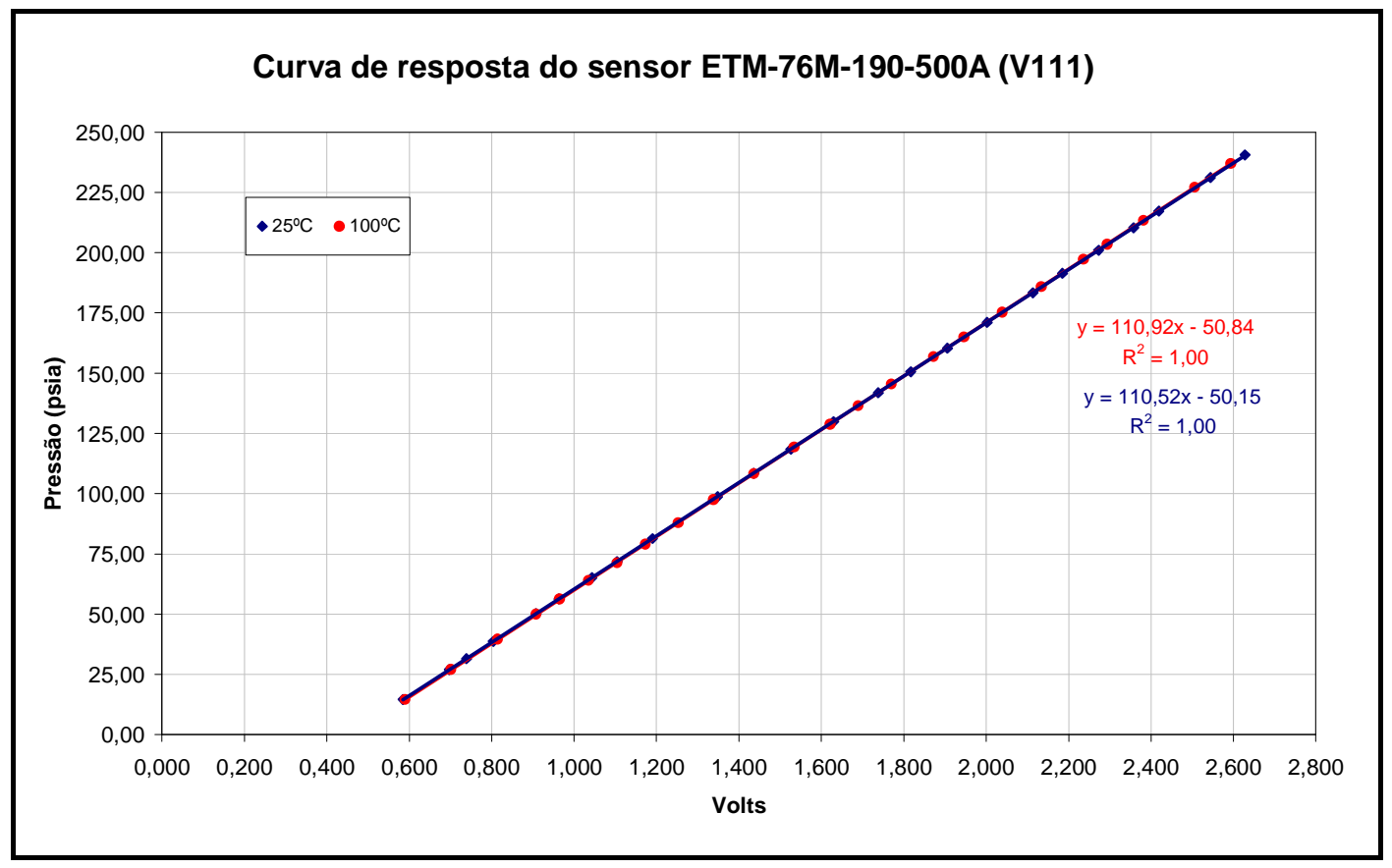

Figura 4.6 - Curva de resposta do sensor V111(descarga) - Sensibilidade a 25 e 100C. 
Após a analise das curvas verificou-se que os valores de sensibilidade encontrados a 25 e a $100^{\circ} \mathrm{C}$ estão dentro do erro do sensor, $\pm 0,25 \%$, portanto, pode-se dizer que a influência da temperatura sobre os sensores são completamente desprezíveis.

Outra característica importante dos sensores de pressão é a sua resposta dinâmica. Para esse modelo de sensor, o fabricante especifica uma resposta plana até $2500 \mathrm{~Hz}$. Esta característica refere-se à resposta em freqüência, isto é, regime permanente com entrada periódica. Neste trabalho é importante a capacidade de resposta à transientes. Assim, através desta propriedade e de uma modelagem matemática, procurou-se encontrar o menor tempo de um transiente que seria possível de ser medido pelo sensor.

O transiente de pressão adotado foi um pulso de duração $\boldsymbol{a}$, conforme ilustrado na figura 4.7.

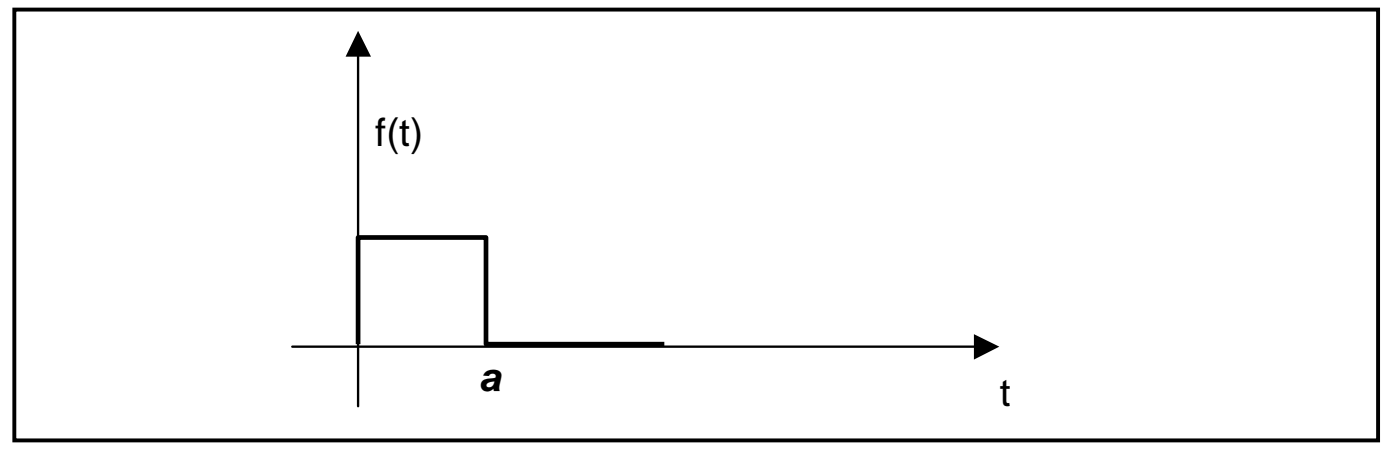

Figura 4.7 - Modelo de transiente de pressão.

Da figura pode-se definir $f(t)$ como sendo:

$f(t)=u(t)-u(t-a)$

Aplicando a Transformada de Laplace em cada termo vem:

$L[u(t)]=\frac{1}{S}$

$L[u(t-a)]=\frac{e^{a s}}{S}$ 


$$
F(S)=\frac{1}{S}-\frac{e^{a s}}{S}=\frac{1-e^{a s}}{S}
$$

Saindo do domínio de Laplace e indo para o domínio da freqüência,

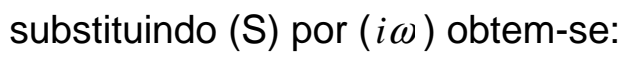

$$
F(i \omega)=\frac{1-e^{a i \omega}}{i \omega}
$$

Com auxilio do software Labview ${ }^{\circledR}$ é possível encontrar o menor transiente de tempo a para a freqüência de $2500 \mathrm{hz}$.

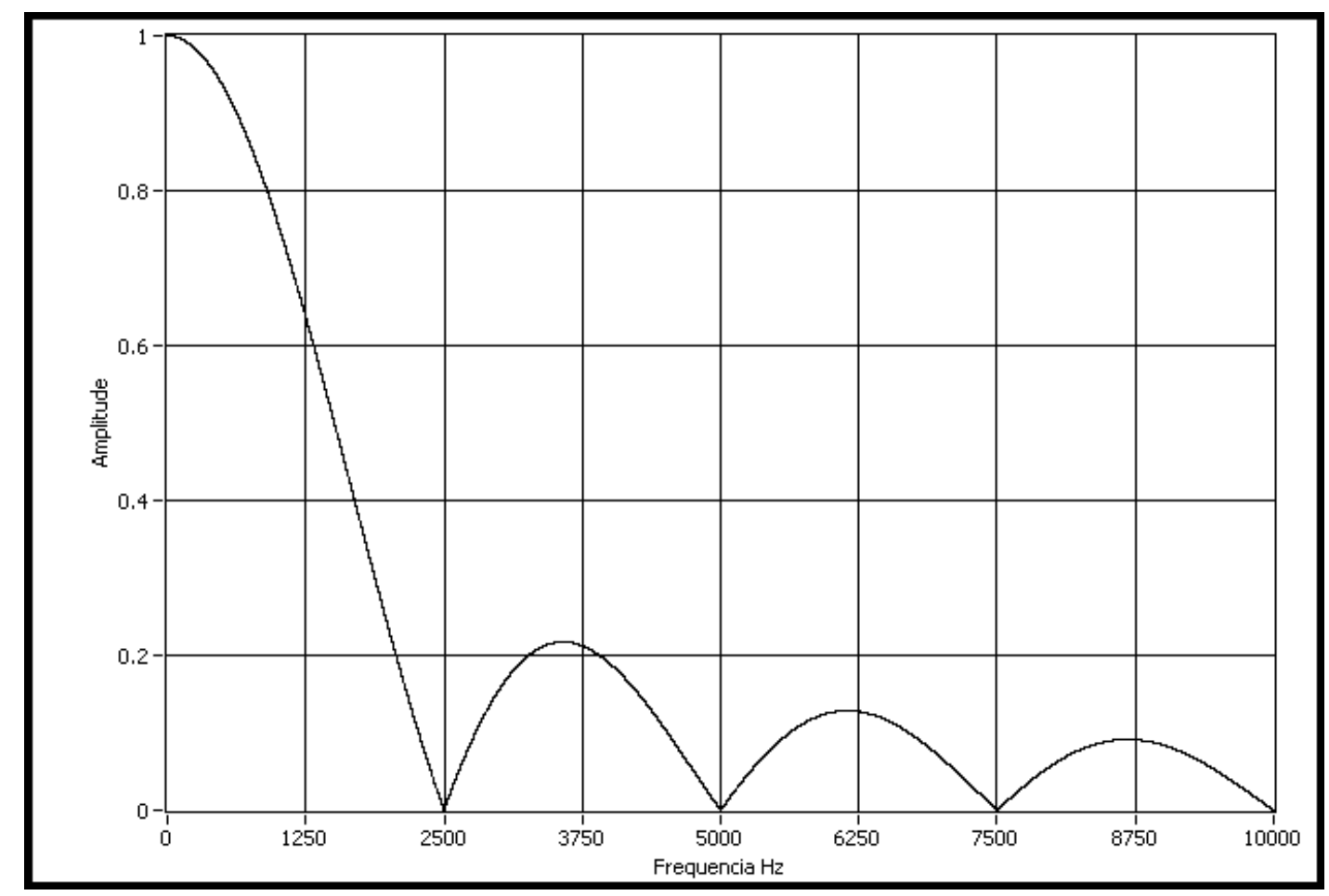

Figura 4.8 - Espectro do transiente da figura 4.7 considerando o parâmetro a $=0.0002$ s.

Essa modelagem possibilitou verificar que o sensor de pressão possui uma resposta bastante aceitável para transientes de pressão que sai do zero, atinge um máximo e volta à zero em um intervalo de tempo da ordem de 0,0002s. Para o compressor, este intervalo de tempo significa um giro do seu 
eixo da ordem de $4^{\circ}$. Acredita-se que em $4^{\circ}$ a pressã o não realiza uma variação tão exigente como o pulso dado na figura $4.7, \mathrm{com} a=0,0002 \mathrm{~s}$

\subsubsection{SENSOR DE DESLOCAMENTO}

Os sensores empregados no presente trabalho são do tipo sem contato que utilizam um feixe de fibras ópticas para transmitir luz e receber a luz refletida da superfície do alvo a ser medido. A intensidade da luz refletida é proporcional a distância entre a ponta do sensor e o objeto medido. Um sinal analógico de 0 a 5 Vdc é gerado pelo sensor proporcional à distância. A figura 4.9 mostra o sensor de deslocamento utilizado.

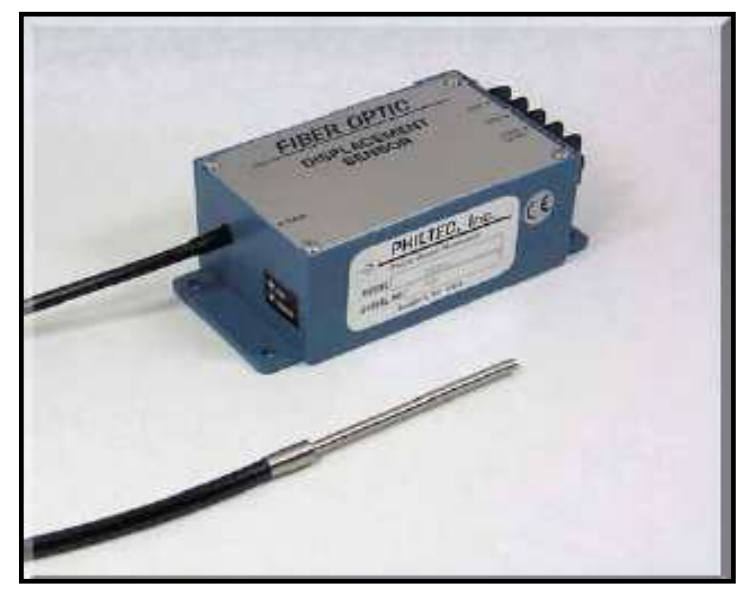

Figura 4.9 - Sensor de deslocamento - Fonte: Catálogo geral Philtec Inc. - 2002.

As vantagens da utilização desse tipo de sensor para a monitoração dos sistemas de válvulas em compressores herméticos, podem ser apontadas como:

i. Não requer nenhum tipo de fixação no elemento a ser medido. Neste caso em especial, devido a sua pequena massa das válvulas, qualquer conexão certamente ocasionará total alteração ao sistema medido;

ii. A forte indução eletromagnética do motor elétrico dos compressores pode interferir nas características de outros tipos de sensores, como por exemplo, os sensores de indução. 
iii. São sensores compactos e permitem medições dentro de ambientes agressivos com a presença de fluidos sob pressão e temperatura. Possuem resposta em freqüência plana até $20 \mathrm{kHz}$.

Foram utilizados dois modelos de sensores de deslocamento: o primeiro modelo RC 171 para medir deslocamentos de até 12,7mm (válvula de sucção) e um segundo modelo RC 100 para deslocamentos de até $5,1 \mathrm{~mm}$ (válvula de descarga).

Os sensores foram verificados utilizando um banco micrométrico Mitutoyo modelo 164-162. A figura 4.10 mostra a bancada utilizada para conhecer a curva de resposta dos sensores de deslocamento.

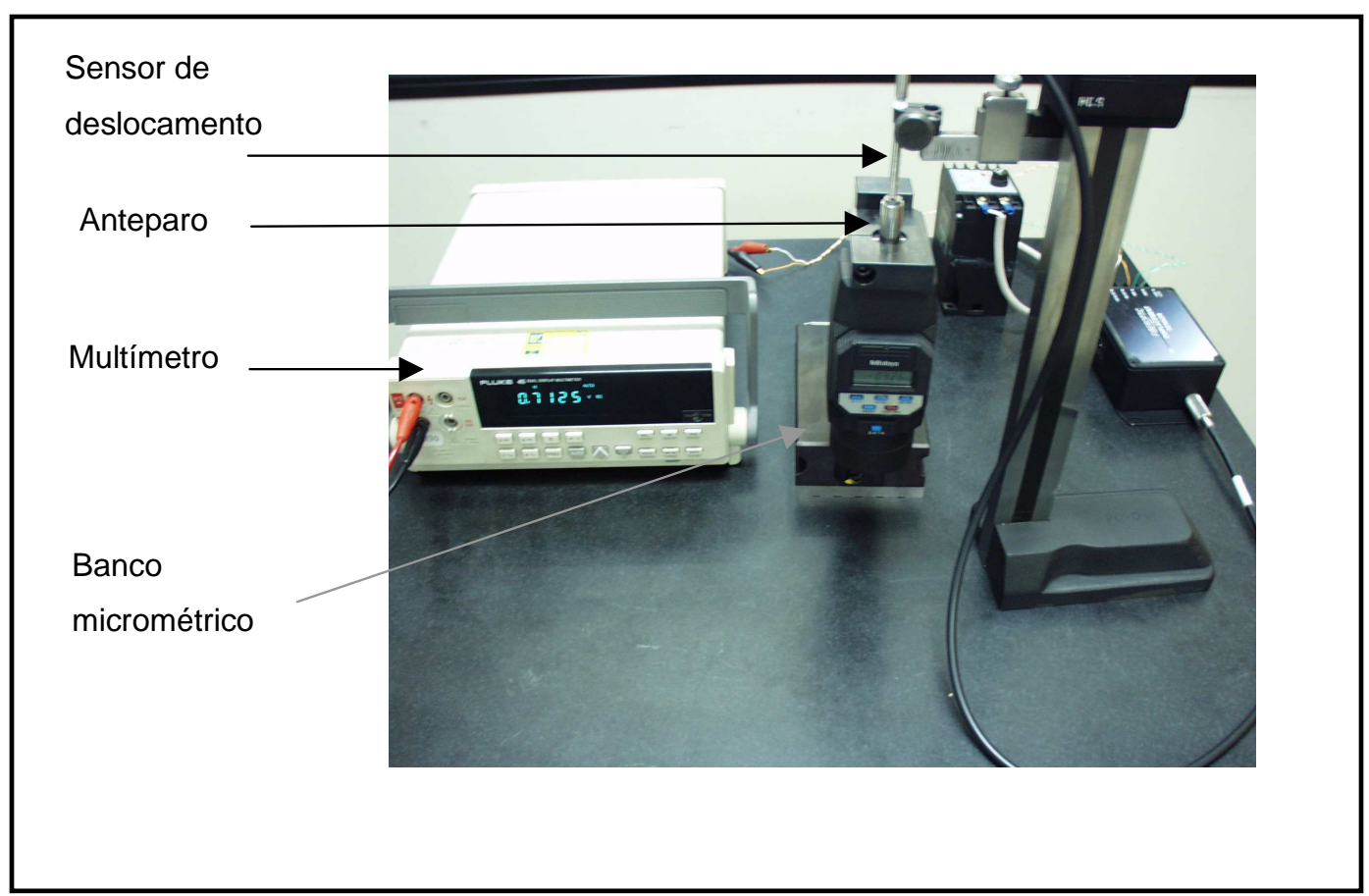

Figura 4.10 - Bancada utilizada para conhecer a resposta dos sensores óticos de deslocamento.

Por se tratar de um sensor ótico, três aspectos foram verificados durante a verificação. O primeiro foi quanto ao acabamento superficial do anteparo. Para minimizar o erro, foi recortada uma válvula e colada contra o anteparo do banco micrométrico. Dessa forma, a superfície de reflexão da luz na verificação dos sensores e na medição seriam praticamente as mesmas. A segunda 
característica observada foi que os sensores poderiam ser influenciados pelo nível de luminosidade aos quais os sensores de deslocamentos estariam expostos. Como os sensores seriam utilizados em um sistema hermético, sem a presença de luz, retirou-se a resposta do sensor em claro e escuro, podendo assim, verificar a influência da luz sobre os sensores. As figuras 4.11 e 4.12 mostram a verificação em claro e escuro.

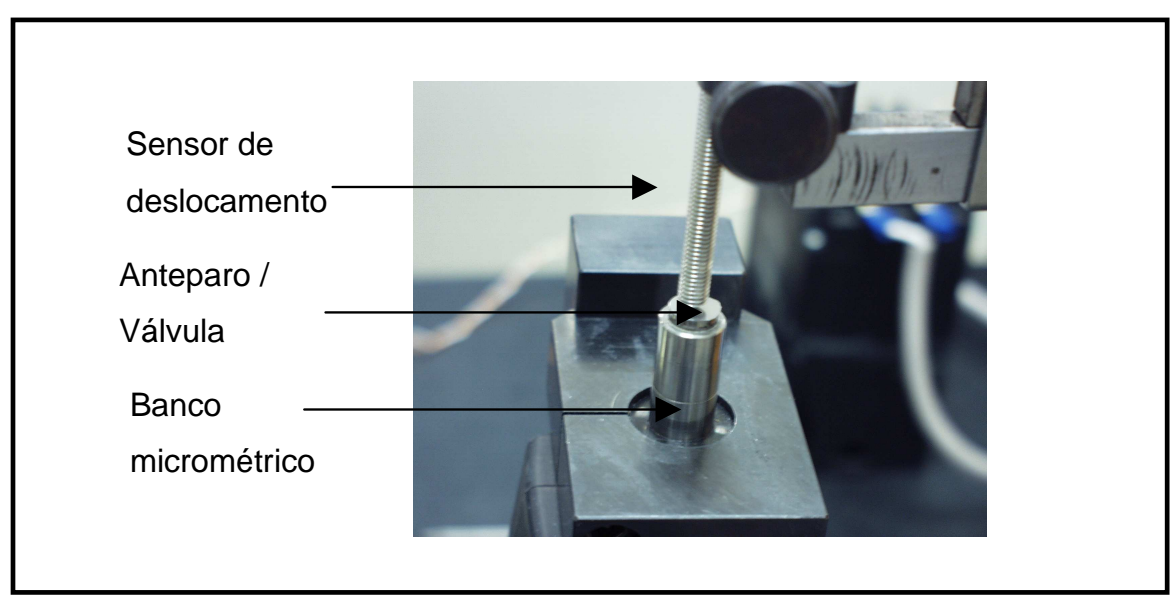

Figura 4.11 - Verificação em claro do sensor de deslocamento.

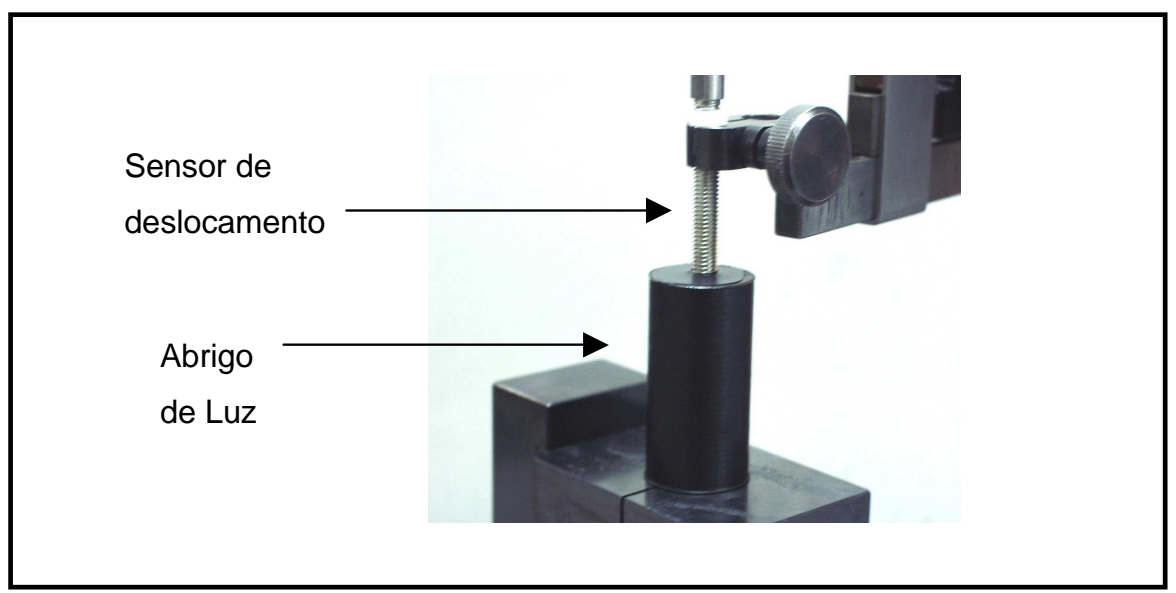

Figura 4.12 - Verificação em escuro do sensor de deslocamento.

Os valores encontrados estão indicados nas tabelas 4.2 e 4.3. 


\begin{tabular}{|c|c|c|c|c|c|c|c|c|c|c|c|}
\hline \multicolumn{12}{|c|}{ Curva de resposta do sensor de deslocamento RC 100} \\
\hline \multicolumn{6}{|c|}{ Resposta do sensor em claro } & \multicolumn{6}{|c|}{ Resposta do sensor em escuro } \\
\hline \multirow{2}{*}{\begin{tabular}{|c|} 
Distância \\
$(\mathrm{mm})$
\end{tabular}} & \multicolumn{2}{|c|}{ Avanço } & \multicolumn{2}{|c|}{ Retorno } & \multirow{2}{*}{\begin{tabular}{|c|} 
Média \\
Volts \\
\end{tabular}} & \multirow{2}{*}{$\begin{array}{c}\text { Distância } \\
(\mathrm{mm})\end{array}$} & \multicolumn{2}{|c|}{ Avanço } & \multicolumn{2}{|c|}{ Retorno } & \multirow{2}{*}{\begin{tabular}{|l} 
Média \\
Volts \\
\end{tabular}} \\
\hline & Volts & Volts & Volts & Volts & & & Volts & Volts & Volts & Volts & \\
\hline 0,000 & 0,547 & 542 & 0,545 & 2 & 0,544 & 0,000 & 0,489 & 0,483 & 0,483 & 35 & 0,485 \\
\hline & & & & & & & & & & & \\
\hline $0,($ & & & & & & & & & & & \\
\hline & & & & & & & & & & & \\
\hline & & & & & & & & & & & \\
\hline & & & & & & & & & & & \\
\hline & & 7 & 1,7 & & 1 , & & & 56 & & & \\
\hline 2,100 & & & 2,092 & & & & & & & & \\
\hline 2,400 & 66 & 35 & 2,464 & & & & & 91 & & & \\
\hline & 344 & 842 & 2,843 & 3 & & & & 2,862 & & $2, \varepsilon$ & \\
\hline & 213 & 3,212 & 3,213 & 3 & & & 3,224 & 3,222 & 3,225 & 3,2 & \\
\hline & & & & & & & & & & & \\
\hline & & & & & & & & & & & \\
\hline & & & 4,175 & & 4 & & & 4,150 & 4,1 & & \\
\hline 4,200 & 33 & 4,443 & 4,433 & 3 & 4,436 & & & 4,397 & 4,398 & $9 /$ & \\
\hline 4,500 & 660 & 4,659 & 4,659 & 4,659 & & & & 4,613 & 4,615 & 4,614 & 4,614 \\
\hline 4,800 & 4,853 & 4,853 & 4,853 & 853 & & & & 4,800 & 4,800 & 4,800 & 800 \\
\hline 5,100 & 5,020 & 5,019 & 5,019 & 5,020 & 5,020 & 5,100 & 4,959 & 4,958 & 4,959 & 4,958 & 4,959 \\
\hline
\end{tabular}

Tabela 4.2 - Resposta do sensor de deslocamento RC100.

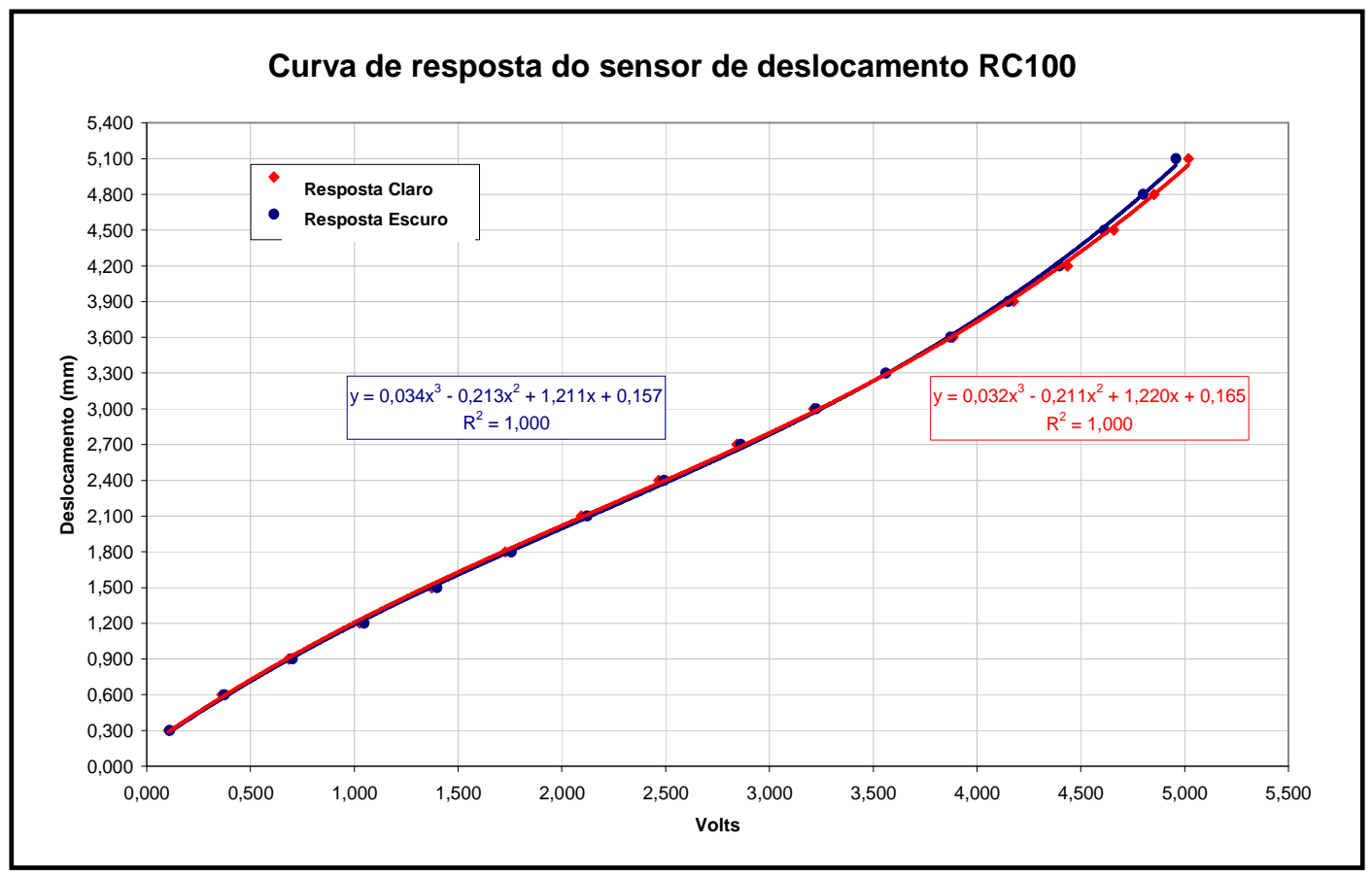

Figura 4.13 - Gráfico para determinação da sensibilidade - Sensor de deslocamento RC100. 


\begin{tabular}{|c|c|c|c|c|c|c|c|c|c|c|c|}
\hline \multicolumn{12}{|c|}{ Curva de resposta do sensor de deslocamento RC 171} \\
\hline \multicolumn{6}{|c|}{ Resposta do sensor em claro } & \multicolumn{6}{|c|}{ Resposta do sensor em escuro } \\
\hline \multirow{2}{*}{$\begin{array}{c}\text { Distância } \\
(\mathrm{mm}) \\
\end{array}$} & \multicolumn{2}{|c|}{ Avanço } & \multicolumn{2}{|c|}{ Retorno } & \multirow{2}{*}{\begin{tabular}{|c|} 
Média \\
Volts \\
\end{tabular}} & \multirow{2}{*}{\begin{tabular}{|c|} 
Distância \\
$(\mathrm{mm})$ \\
\end{tabular}} & \multicolumn{2}{|c|}{ Avanço } & \multicolumn{2}{|c|}{ Retorno } & \multirow{2}{*}{\begin{tabular}{|c|} 
Média \\
Volts \\
\end{tabular}} \\
\hline & Volts & Volts & Volts & Volts & & & Volts & Volts & Volts & Volts & \\
\hline 0,000 & 1,184 & \begin{tabular}{|l|}
1,177 \\
\end{tabular} & 1,175 & 1,174 & 1,178 & 0,000 & 1,098 & 1,092 & 1,091 & 1,087 & 092 \\
\hline 0,500 & 0,023 & 0,023 & 0,023 & 0,023 & 0,023 & & & & 0,019 & & \\
\hline 1,000 & 0,106 & 0,107 & 0,107 & & 0,107 & & 32 & & 0,082 & 0,081 & \\
\hline 1,500 & 0,257 & 0,257 & 0,257 & 0,258 & 0,257 & & 0,191 & 0,191 & 0,191 & 91 & \\
\hline 2, & 41 & 0,443 & 0,443 & 0,443 & 0,443 & & 0,327 & 0,328 & 0,328 & 27 & \\
\hline 2,500 & 0,653 & 0,654 & 0,654 & 0,6 & 0,654 & & 0,488 & 0,488 & 0,488 & 0,488 & \\
\hline 3,000 & 0,887 & 0,889 & 0,889 & 0,890 & 0,889 & & 0,672 & 0,672 & 0,672 & 0,672 & 72 \\
\hline 3,500 & 1,141 & 1,144 & 1,141 & 1,145 & & & 0,878 & 0,878 & 0,878 & 0,879 & \\
\hline 4,000 & 1,410 & 1,413 & 1,411 & 1,414 & & & & & 1,103 & & \\
\hline 4,500 & 1,689 & 1,691 & 1,691 & 1,693 & 1, & & & 1, & 1,344 & 1,347 & \\
\hline & & 1,9 & & & & & & & & & \\
\hline 5,500 & 2,259 & 2,262 & 2,260 & 2,264 & 2 & & 33 & 1,863 & 1,863 & 65 & \\
\hline 6 & 2,544 & 2,548 & 2,546 & 2,549 & 2,547 & & 33 & 2,133 & 2,133 & 35 & \\
\hline 6,500 & 2,825 & 2,828 & 2,827 & 2,830 & 2,828 & & 2,404 & 2,404 & 2,404 & 2,408 & \\
\hline 7,000 & 3,098 & 3,101 & 3,099 & 3,102 & 3,100 & 7 & 2,672 & 2,672 & 2,672 & 2,676 & 2,673 \\
\hline 7,500 & 3,357 & 3,361 & 3,360 & 3,361 & 3,360 & & 2,933 & 2,932 & 2,932 & 2,937 & 2,934 \\
\hline 8,000 & 3,604 & 3,606 & 3,605 & 3,608 & 3,606 & 0 & 3,183 & 3,182 & 3,182 & 3,187 & 3,184 \\
\hline 8,500 & 3,834 & 3,836 & 3,834 & 3,838 & 3,836 & 8,500 & 3,419 & 3,418 & 3,418 & 3,424 & 3,420 \\
\hline 9,000 & 4,045 & 4,050 & 4,045 & 4,049 & 4,047 & & 3,640 & 3,639 & 3,640 & 3,644 & 3,641 \\
\hline 9,500 & 4,239 & 4,242 & 4,239 & 4,242 & 4,241 & & 3,844 & 3,844 & 3,844 & 3,849 & \\
\hline 10,000 & 4,415 & 4,418 & 4,415 & 4,418 & 4,417 & & 4,031 & 4,031 & 4,031 & 4,036 & \\
\hline 10,500 & 4,572 & 4,575 & 4,572 & 4,574 & 4,573 & & 4,202 & 4,201 & 4,201 & 4,207 & 4,203 \\
\hline 11,000 & 4,713 & 4,715 & 4,713 & 4,715 & 4,714 & 11,000 & 4,356 & 4,361 & 4,356 & 4,361 & 4,359 \\
\hline 11,500 & 4,839 & 4,840 & 4,838 & 4,841 & 4,840 & 11,500 & 4,495 & 4,500 & 4,495 & 4,500 & 4,498 \\
\hline 12,000 & 4,949 & 4,952 & 4,950 & 4,952 & 4,951 & 12,000 & 4,620 & 4,623 & 4,620 & 4,625 & 4,622 \\
\hline
\end{tabular}

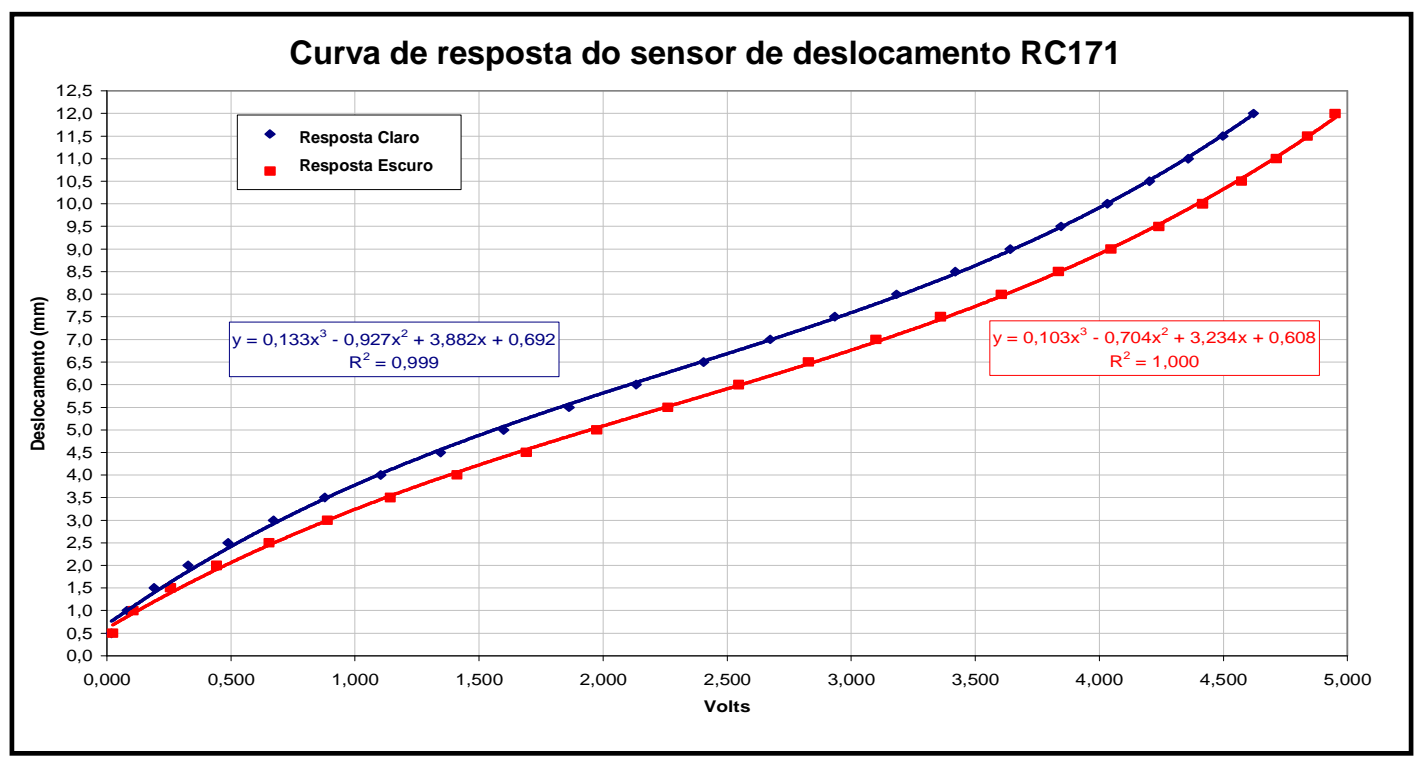

Figura 4.14 - Gráfico para determinação da sensibilidade - Sensor de deslocamento RC171. 
O sensor RC 100 apresentou uma diferença muito sutil em sua sensibilidade para as curvas de resposta em claro e escuro. Já o sensor RC 171 não produziu o mesmo resultado, pois as sensibilidades em claro e escuro são diferentes.

A terceira característica verificada foi quanto a flexão das válvulas. O princípio de funcionamento das válvulas empregadas nos compressores herméticos está baseado em sua flexão causada pelo diferencial de pressão. Ao fletir, o ângulo de incidência e reflexão da luz emitida pelo sensor é alterado. Esse fato pode comprometer a resposta do sensor. Para verificar o efeito da flexão, foi realizada uma nova verificação e comparada às já realizadas. A figura 4.15 ilustra a montagem utilizada.

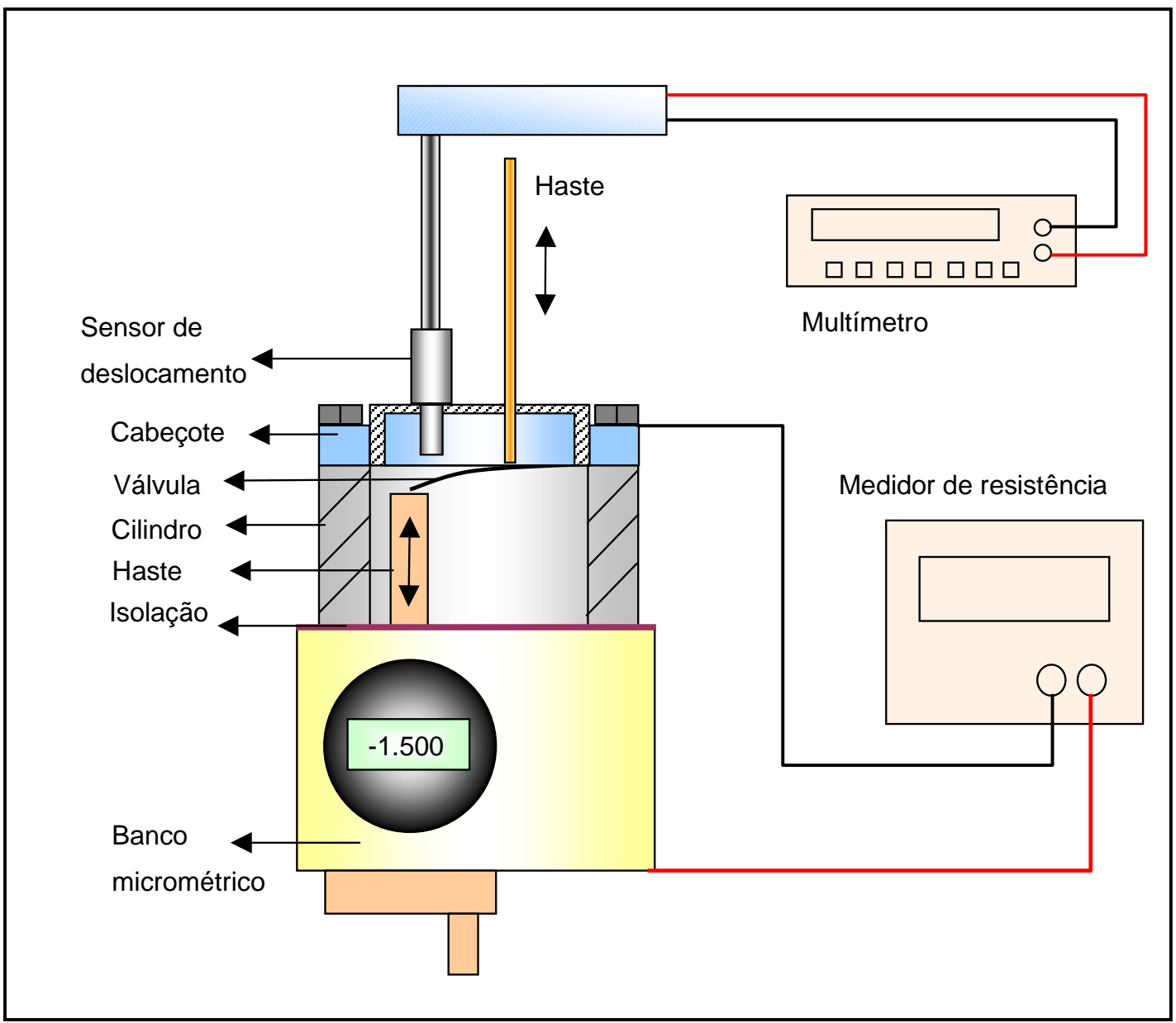

Figura 4.15 - Bancada para verificar o efeito da flexão da válvula sobre o sensor de deslocamento. 
Nessa verificação o sensor de deslocamento, RC 171, foi fixado no cabeçote. O cabeçote foi montado, junto com a válvula de sucção, no cilindro, que por sua vez, estava assentado sobre a base do banco micrométrico. Entre o cilindro e a base foi posicionada uma junta de isolação com objetivo de não permitir o contato elétrico do conjunto montado e o banco micrométrico Conectou-se um pólo do medidor de resistência ao cabeçote e o outro ao banco micrométrico. Essa isolação foi verificada, uma vez que o instrumento de medida acusou resistência infinita entre os pólos do aparelho quando a ponta do banco micrométrico estava afastada da válvula. Avançou-se a ponta do banco micrométrico até que esse atingisse a válvula, momento em que o medidor de resistência registrou contato, indicando sua posição inicial. Nesta posição, a válvula estava à 3,70 milímetros do sensor. Recuo-se a ponta do banco micrométrico a uma distância pré-determinada. Com auxilio de uma haste, também posicionada no cabeçote, a válvula foi fletida até tocar na ponta do banco, tomando um cuidado extremo para não causar outros tipos de deformação na válvula. Esse processo foi repetido para vários pontos e assim foi retirada uma curva de resposta. Os resultados estão apontados na tabela 4.4 e a comparação com a verificação inicial, onde o sensor estava posicionado perpendicularmente ao alvo, está indicada no figura 4.16.

\begin{tabular}{|c|c|c|c|c|c|c|c|c|}
\hline \multicolumn{10}{|c|}{ Resposta no Cabeçote - Sensor RC 171 } \\
\hline $\begin{array}{c}\text { Distância } \\
\text { Relativa }\end{array}$ & $\begin{array}{c}\text { Distância } \\
\text { Absoluta }\end{array}$ & $\begin{array}{c}\text { Volts } \\
\text { leitura 1 }\end{array}$ & $\begin{array}{c}\text { Volts } \\
\text { leitura 2 }\end{array}$ & $\begin{array}{c}\text { Volts } \\
\text { leitura 3 }\end{array}$ & $\begin{array}{c}\text { Volts } \\
\text { leitura 4 }\end{array}$ & $\begin{array}{c}\text { Volts } \\
\text { leitura 5 }\end{array}$ & Média & $\begin{array}{c}\text { Desvio } \\
\text { Padrão }\end{array}$ \\
\hline 0,00 & 3,70 & 0,89 & 0,87 & 0,87 & 0,88 & 0,86 & 0,874 & 0,01 \\
\hline 0,30 & 4,00 & 1,04 & 1,05 & 1,06 & 1,07 & 1,07 & 1,058 & 0,01 \\
\hline 0,60 & 4,30 & 1,21 & 1,21 & 1,22 & 1,21 & 1,21 & 1,212 & 0,00 \\
\hline 0,90 & 4,60 & 1,34 & 1,33 & 1,35 & 1,33 & 1,33 & 1,336 & 0,01 \\
\hline 1,20 & 4,90 & 1,46 & 1,47 & 1,45 & 1,43 & 1,44 & 1,450 & 0,02 \\
\hline 1,50 & 5,20 & 1,57 & 1,57 & 1,55 & 1,54 & 1,55 & 1,556 & 0,01 \\
\hline 1,80 & 5,50 & 1,66 & 1,67 & 1,64 & 1,64 & 1,63 & 1,648 & 0,02 \\
\hline 2,10 & 5,80 & 1,72 & 1,75 & 1,73 & 1,72 & 1,69 & 1,722 & 0,02 \\
\hline 2,40 & 6,10 & 1,83 & 1,83 & 1,84 & 1,79 & 1,77 & 1,812 & 0,03 \\
\hline 2,70 & 6,40 & 1,97 & 2,00 & 1,93 & 1,97 & 1,89 & 1,952 & 0,04 \\
\hline 3,00 & 6,70 & 2,12 & 2,11 & 2,06 & 2,1 & 2,05 & 2,088 & 0,03 \\
\hline 3,30 & 7,00 & 2,19 & 2,26 & 2,18 & 2,21 & 2,2 & 2,208 & 0,03 \\
\hline 3,60 & 7,30 & 2,41 & 2,4 & 2,4 & 2,38 & 2,38 & 2,394 & 0,01 \\
\hline 3,90 & 7,60 & 2,51 & 2,57 & 2,51 & 2,52 & 2,51 & 2,524 & 0,03 \\
\hline 4,20 & 7,90 & 2,71 & 2,69 & 2,67 & 2,69 & 2,67 & 2,686 & 0,02 \\
\hline 4,50 & 8,20 & 2,83 & 2,83 & 2,79 & 2,79 & 2,76 & 2,800 & 0,03 \\
\hline
\end{tabular}




\begin{tabular}{|c|c|c|c|c|c|c|c|c|}
\hline \multicolumn{10}{|c|}{ Resposta no Cabeçote - Sensor RC 171 } \\
\hline $\begin{array}{c}\text { Distância } \\
\text { Relativa }\end{array}$ & $\begin{array}{c}\text { Distância } \\
\text { Absoluta }\end{array}$ & $\begin{array}{c}\text { Volts } \\
\text { leitura 1 }\end{array}$ & $\begin{array}{c}\text { Volts } \\
\text { leitura 2 }\end{array}$ & $\begin{array}{c}\text { Volts } \\
\text { leitura 3 }\end{array}$ & $\begin{array}{c}\text { Volts } \\
\text { leitura 4 }\end{array}$ & $\begin{array}{c}\text { Volts } \\
\text { leitura 5 }\end{array}$ & Média & $\begin{array}{c}\text { Desvio } \\
\text { Padrão }\end{array}$ \\
\hline 4,80 & 8,50 & 2,9 & 2,92 & 2,87 & 2,91 & 2,81 & 2,882 & 0,04 \\
\hline 5,10 & 8,80 & 2,96 & 2,98 & 2,95 & 2,97 & 2,91 & 2,954 & 0,03 \\
\hline 5,40 & 9,10 & 3,04 & 3,05 & 3,03 & 3,04 & 2,98 & 3,028 & 0,03 \\
\hline 5,70 & 9,40 & 3,1 & 3,09 & 3,07 & 3,09 & 3,08 & 3,086 & 0,01 \\
\hline 6,00 & 9,70 & 3,16 & 3,18 & 3,16 & 3,19 & 3,19 & 3,176 & 0,02 \\
\hline 6,30 & 10,00 & 3,33 & 3,32 & 3,36 & 3,32 & 3,32 & 3,330 & 0,02 \\
\hline 6,60 & 10,30 & 3,42 & 3,42 & 3,43 & 3,42 & 3,43 & 3,424 & 0,01 \\
\hline 6,90 & 10,60 & 3,51 & 3,51 & 3,52 & 3,5 & 3,53 & 3,514 & 0,01 \\
\hline 7,10 & 10,80 & 3,68 & 3,72 & 3,71 & 3,72 & 3,70 & 3,706 & 0,02 \\
\hline 7,40 & 11,10 & 3,93 & 3,94 & 3,91 & 3,88 & 3,86 & 3,904 & 0,03 \\
\hline 7,70 & 11,40 & 4,16 & 4,17 & 4,19 & 4,18 & 4,16 & 4,172 & 0,01 \\
\hline 8,00 & 11,70 & 4,22 & 4,3 & 4,24 & 4,32 & 4,31 & 4,278 & 0,04 \\
\hline
\end{tabular}

Tabela 4.4 - Resposta do sensor de deslocamento RC171 montado no cabeçote.

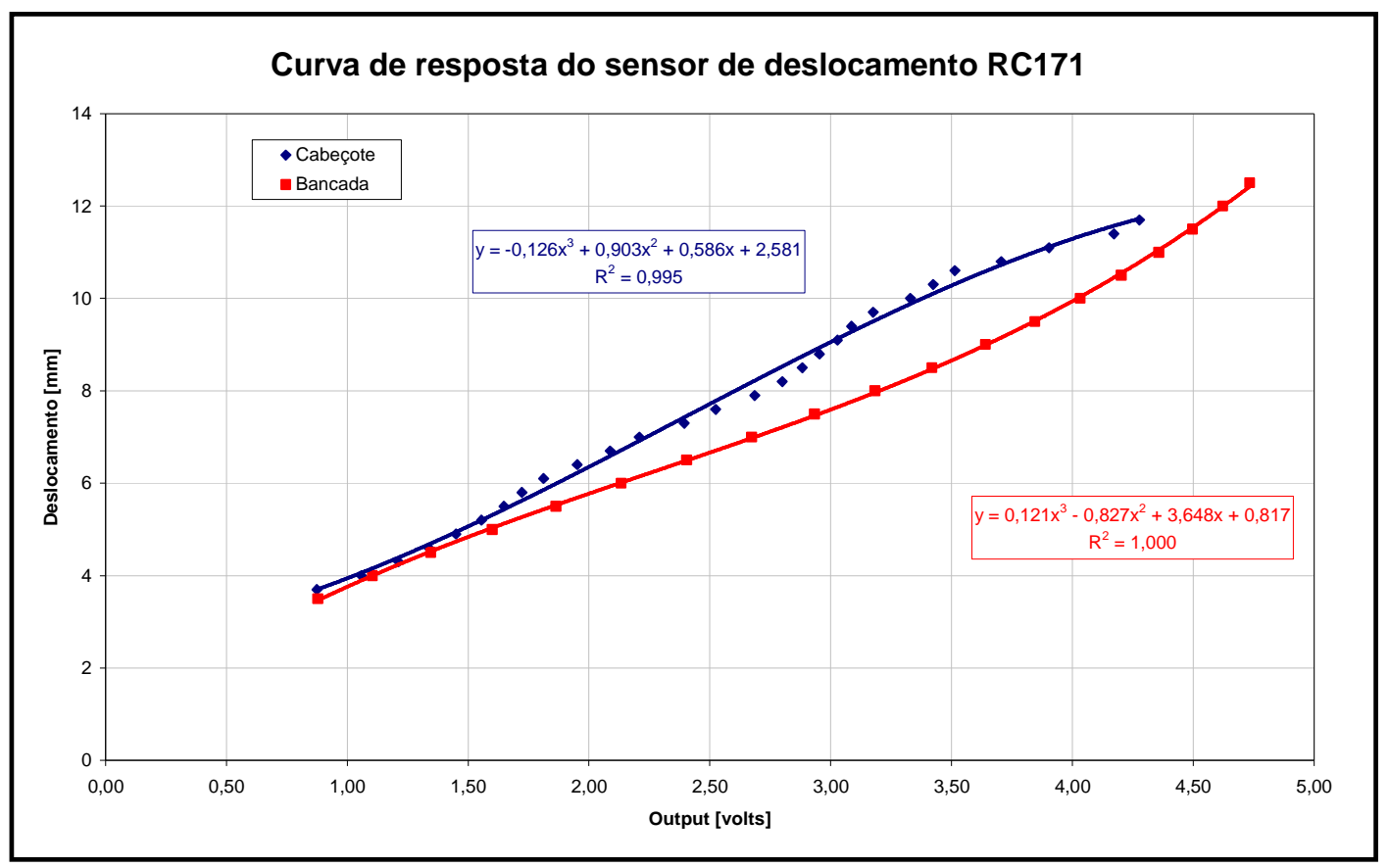

Figura 4.16 - Efeito da flexão da válvula sobre o sensor RC 171.

O segundo sensor modelo RC 100 é aplicado a válvula de descarga que possui um limitador de deslocamento. Dentro desse limite, o sensor obteve o mesmo comportamento da verificação inicial.

O fabricante dos sensores informa que os sensores de deslocamento modelo RC apresentam bons resultados quanto à flexão do alvo, para inclinações entre $\pm 10^{\circ}$, desde que observado o corr eto alinhamento dos feixes 
de fibras ópticas. A figura 4.17 mostra o correto alinhamento do sensor para alvos inclinados.

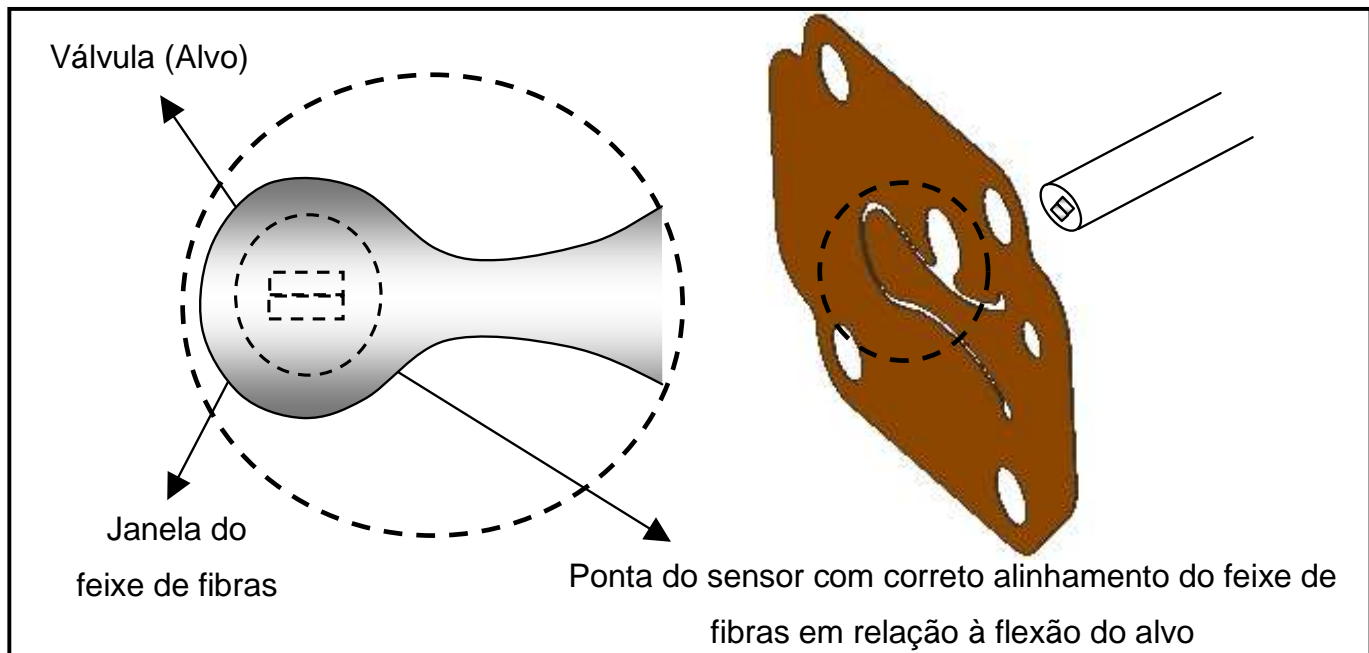

Figura 4.17 - Correto alinhamento do sensor de deslocamento para alvos inclinados.

Outra característica desses sensores é que eles não apresentam comportamento linear durante toda a faixa de leitura, mas se os deslocamentos medidos estiverem dentro de determinados limites, pode-se realizar uma regressão linear para determinar sua sensibilidade.

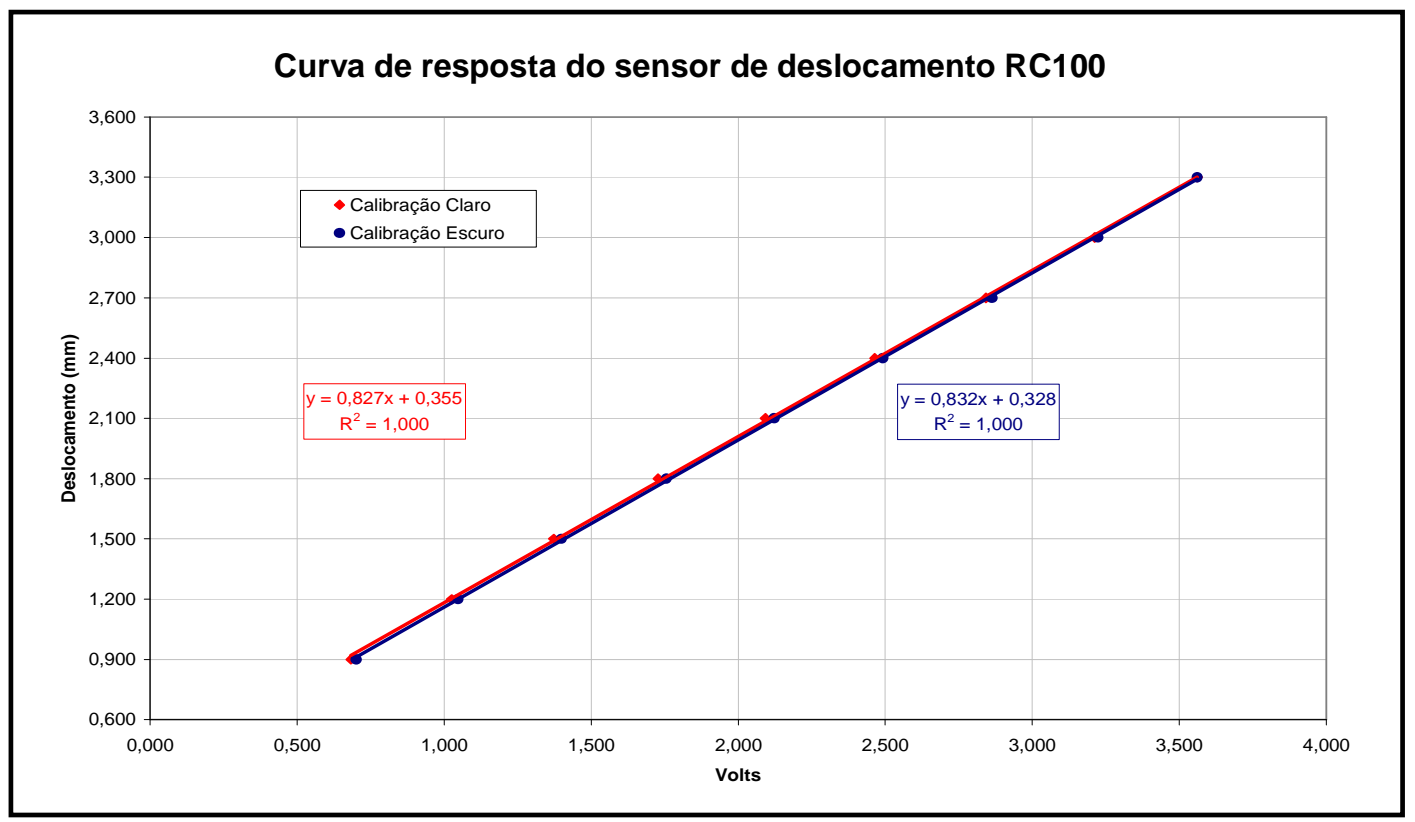

Figura 4.18 - Gráfico para determinação da sensibilidade na região linear (região de trabalho) do sensor RC100. 


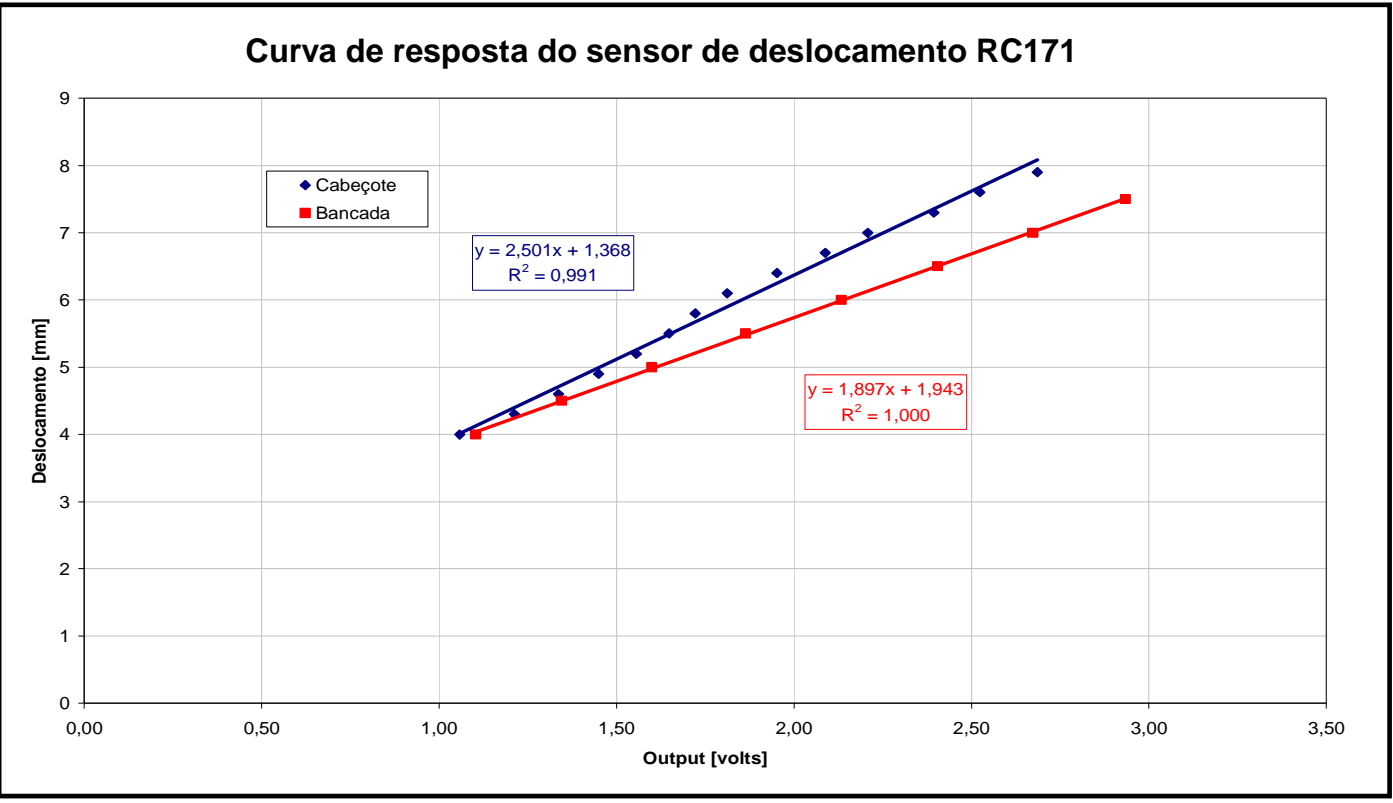

Figura 4.19 - Gráfico para determinação da sensibilidade na região linear (região de trabalho) do sensor RC 171.

Nesse trabalho foi utilizada a sensibilidade da região linear dos sensores em escuro, pois não há presença de luz dentro do compressor hermético e considerado a flexão da válvula.

\subsubsection{SENSOR DE DESLOCAMENTO ANGULAR}

A utilização do sensor de deslocamento angular, encoder, possibilitou correlacionar a posição do eixo do compressor com os demais eventos monitorados pelos sensores de pressão e deslocamento.

Foi utilizado um sensor marca HEIDENHAIN modelo ERN 1020-2000-01 que utiliza o princípio de varredura fotoelétrica. Nesse método, finas linhas impressas sobre um disco de acrílico, que ao girar sob a incidência de uma fonte de luz geram pulsos que são detectadas por fotocélulas. Um sinal de saída é gerado proporcional ao período da grade impressa no disco. O sensor utilizado é do tipo incremental, onde a informação de posição é obtida pela 
contagem das linhas individuais a partir de um ponto de origem. Uma vez que, uma referência absoluta é requerida, o disco graduado é provido de uma faixa adicional que é utilizada como referência. Dados adicionais da especificação desse sensor encontram-se no apêndice A. A figura 4.20 mostra o sensor de deslocamento angular utilizado.

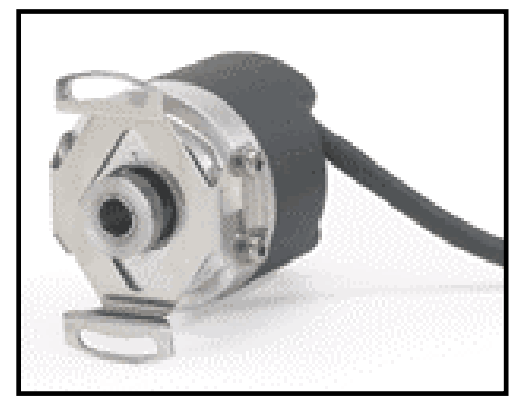

Figura 4.20 - Sensor de deslocamento angular (encoder) - fonte: catalogo geral Heidenhain.

O sensor utilizado possui 2000 linhas de medida e uma de referência. Dessa forma, um giro completo do eixo de rotação do compressor hermético foi subdividido em 2000 partes, portanto tem-se:

$$
\frac{360^{\circ}}{2000}=0,18^{\circ} / \text { linha }
$$

Como a precisão desse sensor é de $\pm \frac{1}{20}$ do período da linha tem-se a precisão de leitura de $0,18^{\circ} \pm 0,009^{\circ}$.

Esse sensor também foi utilizado para monitorar a variação de velocidade do eixo/pistão durante o ciclo.

\subsubsection{SENSOR DE TEMPERATURA}

Foram utilizados termopares tipo "T" - cobre / constatam - marca OMEGA código TFCC-015 e TFCP-015. Os termopares são compostos por dois fios metálicos de diferente material que quando unidos produzem uma diferença de potencial proporcional à temperatura ao qual a junção está submetida. Diferentes ligas e materiais podem ser empregados para confecção dos termopares. A escolha da liga a ser utilizada está diretamente 
relacionada com faixa temperatura a ser medida. Para os termopares tipo $T$ essa faixa é de $-270 \mathrm{a}+400^{\circ} \mathrm{C}$.

As medidas de temperaturas foram monitoradas nas seguintes regiões:

i. Entrada da câmara de admissão;

ii. Câmara de admissão;

iii. Câmara de descarga;

iv. Óleo;

v. Ambiente dentro da carcaça.

A verificação dos termopares foi realizada utilizando um calibrador modelo CAPPO 10 da ECIL.

\subsection{MONTAGEM}

\subsubsection{SENSOR DE PRESSÃO}

Os sensores de pressão foram montados em três regiões dentro do compressor: o primeiro junto à câmara de admissão, o segundo no cilindro e o terceiro na câmara de descarga. Os sensores de admissão e descarga foram instalados diretamente na região a ser medida, fazendo com que as pontas dos sensores ficassem faceando com as paredes das respectivas câmaras. Já para o sensor do cilindro, com todos os sensores montados no cabeçote, há necessidade de se utilizar furo conector. As figuras 4.21, 4.22 e 4.23 trazem os detalhes da fixação dos sensores de pressão.

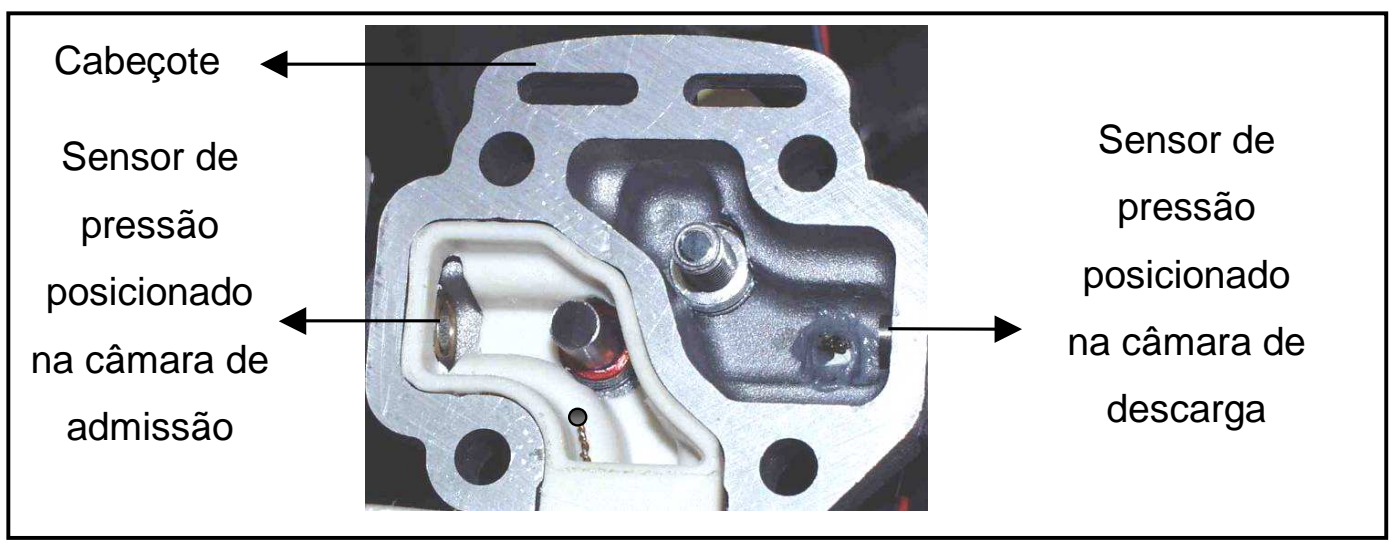

Figura 4.21 - Posicionamento dos sensores de pressão nas câmaras de admissão e descarga. 


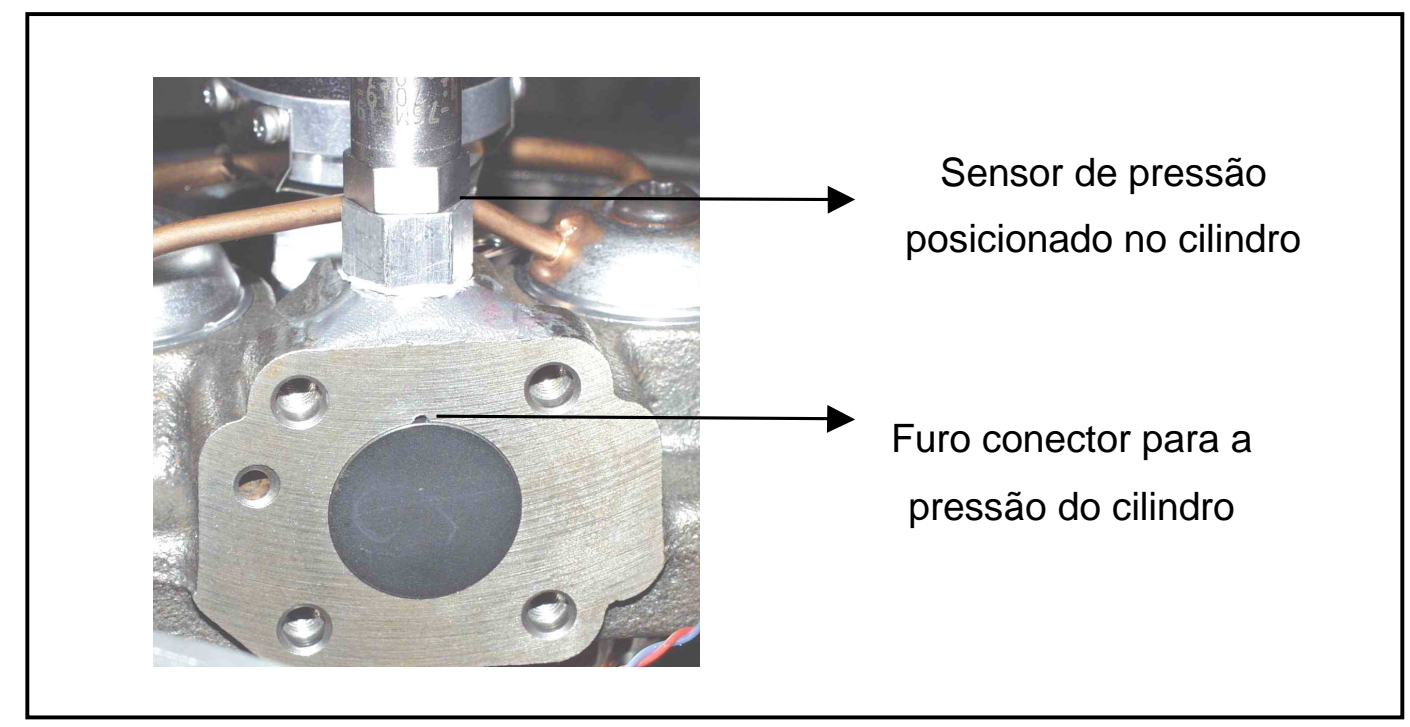

Figura 4.22 - Posicionamento do sensor de pressão no cilindro.

O furo conector foi posicionado na face do cilindro para que não fosse perdido o pico máximo de pressão dentro da câmara. A figura 4.23 mostra as dimensões do furo e estas devem ser consideradas para verificar a influência desta conexão sobre o sinal de pressão.

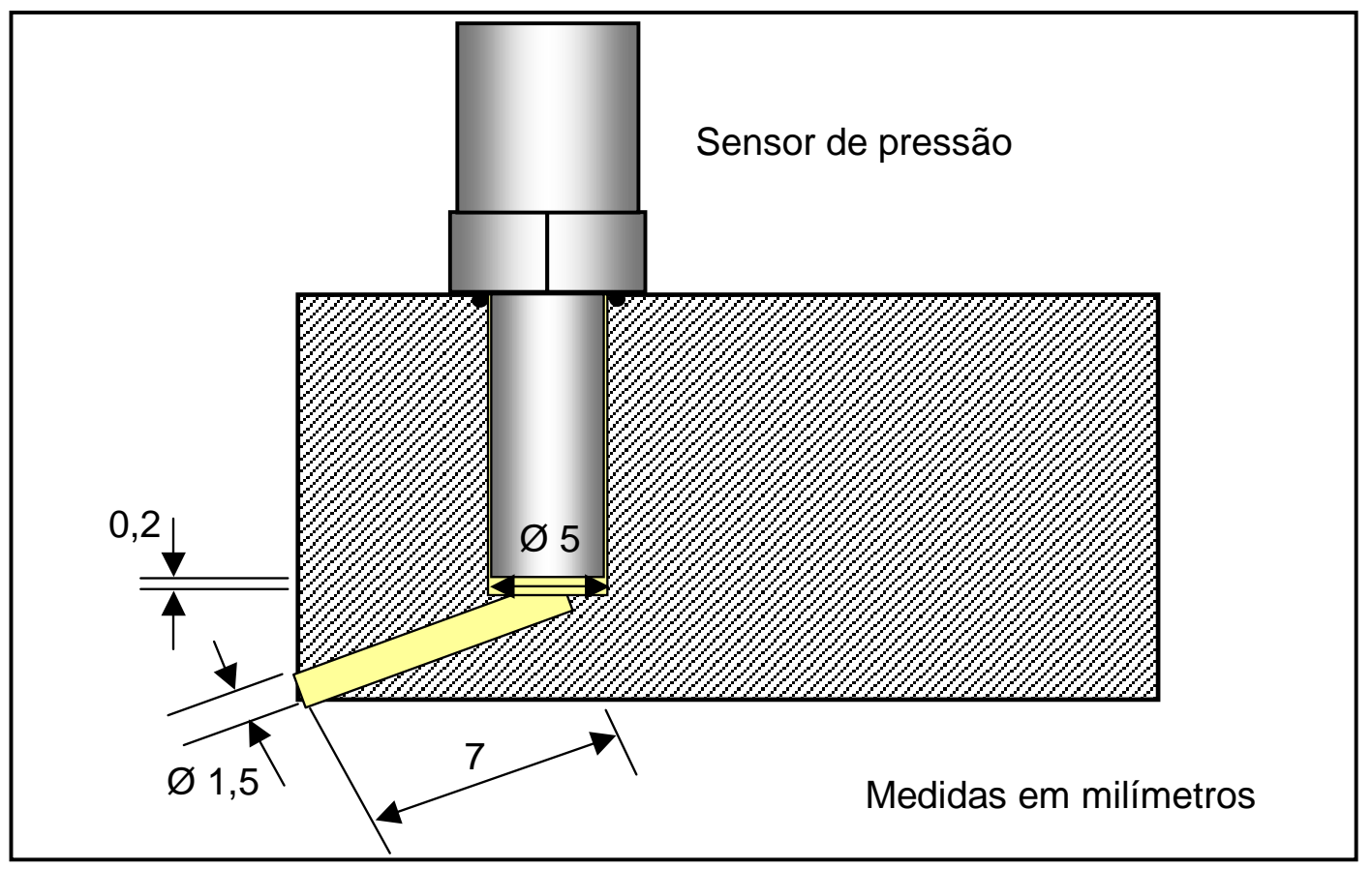

Figura 4.23 - Dimensionamento do furo conector para pressão do cilindro 
No estudo da influência do furo conector, dois métodos foram aplicados e comparados. O primeiro proposto por Elson, Soedel (1972) verifica a influência da freqüência de ressonância do furo conector sobre o sinal de pressão. Os parâmetros considerados estão listados na figura 4.24:

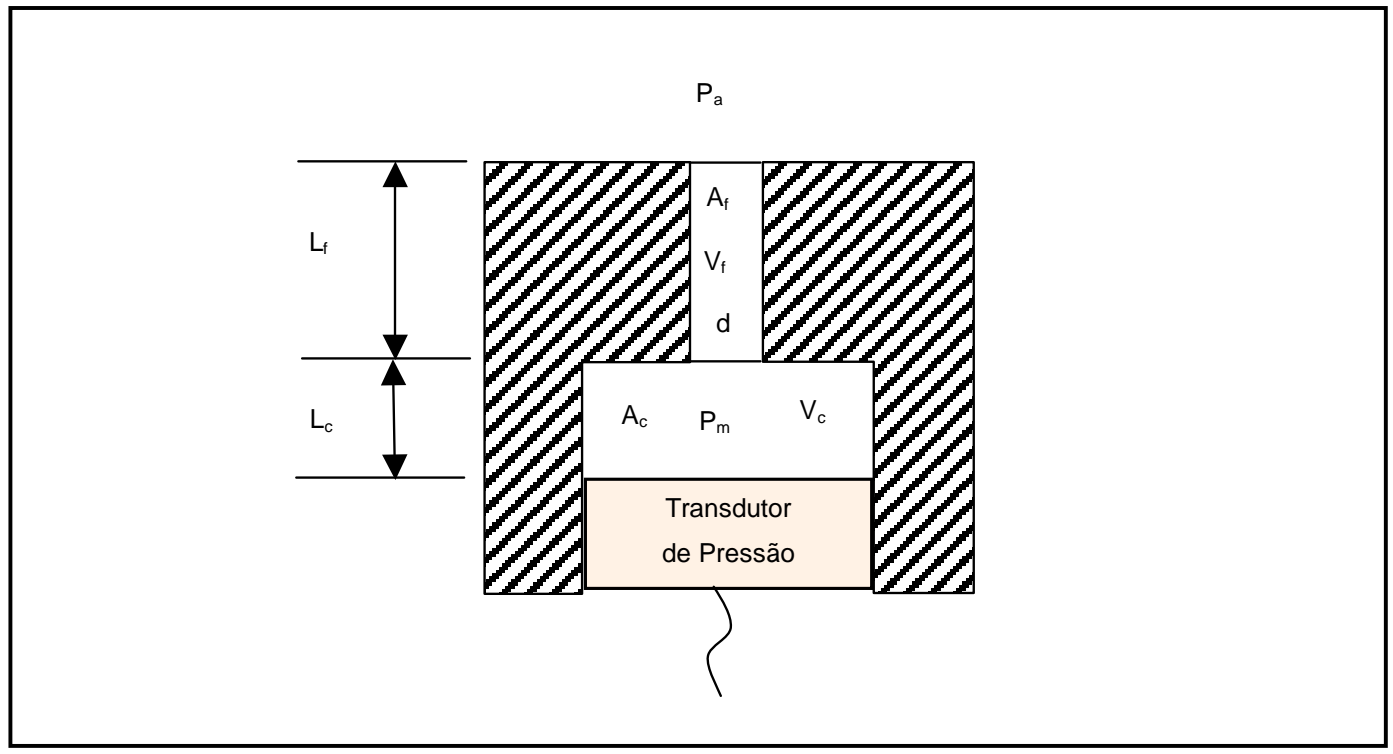

Figura 4.24 - Esquema básico do furo conector utilizado na modelagem

Onde:

$P_{a}=$ Pressão aplicada;

$P_{m}=$ Pressão medida;

$L_{f}=$ Comprimento do furo;

$L_{c}=$ Comprimento da câmara;

$A_{c}=$ Área da seção da câmara;

$A_{f}=$ Área da seção do furo;

$V_{c}=A_{c} \cdot L_{c}=$ Volume da câmara;

$V_{f}=A_{f} L_{f}=$ Volume do furo;

$d=$ Diâmetro do furo;

$R_{v}=V_{d} V_{f}=$ Razão entre volumes.

A freqüência natural não amortecida do furo conector, $\omega_{n}$, é dada pela equação:

$\omega_{n}=\frac{c}{L_{f} \cdot \sqrt{R_{v}+0.3905}}$

onde 
$c=$ velocidade do som

O erro máximo na freqüência $\omega_{n}$, apontada pelo autor está em 1,6\%.

Doebelin (1990) também aborda a tema. A freqüência natural não amortecida do furo conector é determinada pela equação:

$\omega_{n}=\frac{d \sqrt{\pi c^{2} / L_{f} V_{c}}}{2}$

O coeficiente de amortecimento do furo conector é dado por:

$\zeta=\frac{32 \mu \sqrt{V_{c} L_{f} / \pi}}{c \rho d^{3}}$

Onde:

$\rho=$ densidade do gás;

$\mu=$ viscosidade do gás.

Doebelin trás uma informação importantíssima a ser considerada no equacionamento 4.7 e 4.8. Se o volume do furo torna parte significante do sistema as seguintes fórmulas devem ser aplicadas para a determinação de $\omega_{n}$ e $\zeta$ :

$\omega_{n}=\frac{c}{L_{t} \cdot \sqrt{\frac{V_{c}}{V_{f}}+\frac{1}{2}}}$

$\zeta=\frac{16 \cdot \mu \cdot L_{t} \cdot \sqrt{\frac{V_{c}}{V_{f}}+\frac{1}{2}}}{c \cdot \rho \cdot d^{2}}$ 
A relação de amplitude, $R A(\omega)$, entre a pressão dentro do cilindro e a pressão medida pelo sensor pode ser obtida pela equação 4.11 :

$$
R A(\omega)=\frac{1}{\left.\left\{1-\left(\omega / \omega_{n}\right)^{2}\right]^{2}+\left(2 \zeta \omega / \omega_{n}\right)^{2}\right\}^{1 / 2}}
$$

A fase $\phi(\omega)$ é dada pela equação:

$$
\phi(\omega)=-\tan ^{-1} \frac{2 \zeta \omega / \omega_{2}}{1-\left(\omega / \omega_{n}\right)^{2}}
$$

Para um sistema ideal de medida, $R A(\omega)$, deve ser igual ao valor unitário e $\phi(\omega)$ deve ser igual a zero.

Outro aspecto a ser considerado no uso do furo conector é o atraso no sinal medido em função do comprimento do furo. Este atraso pode ser calculado utilizando a equação 4.13:

$$
\tau=\frac{L_{t}}{c}
$$

Assim, considerando as equações apresentadas acima, as dimensões do furo conector e as propriedades do fluido refrigerante, pode-se determinar a influência do furo conector no sinal do sensor de pressão do cilindro. Neste trabalho, esta determinação está desenvolvida no capitulo 5 , item 5.2 .

\subsubsection{SENSOR DE DESLOCAMENTO}

Os sensores de deslocamento foram montados junto ao cabeçote. A vedação deu-se pela rosca de fixação com o uso de fita de teflon. O sensor RC 100 foi posicionado a $2,5 \mathrm{~mm}$ de distância da válvula de descarga. Como a máxima abertura da válvula foi de $1 \mathrm{~mm}$, limitada pelo retentor, a válvula trabalhou a uma distância de $1,5 \mathrm{~mm}$ a $2,5 \mathrm{~mm}$. Assim, foi possível utilizar a região linear da sensibilidade do sensor conforme ilustra a figura 4.18 . 
Para que o sensor pudesse incidir a luz diretamente sobre a válvula foi necessário furar o retentor.

O sensor RC171 foi posicionado a uma distância de $3,7 \mathrm{~mm}$ da válvula de sucção, conforme a verificação realizada com o cabeçote. Essa válvula não possui um limitador, assim o sensor foi posicionado diretamente sobre à válvula. Para ambos os sensores foi realizado o correto alinhamento do feixe de fibras, com o objetivo de minimizar a influência da flexão da válvula sobre o sensor, figura 4.17. A figura 4.25 ilustra a montagem dos sensores de deslocamento.

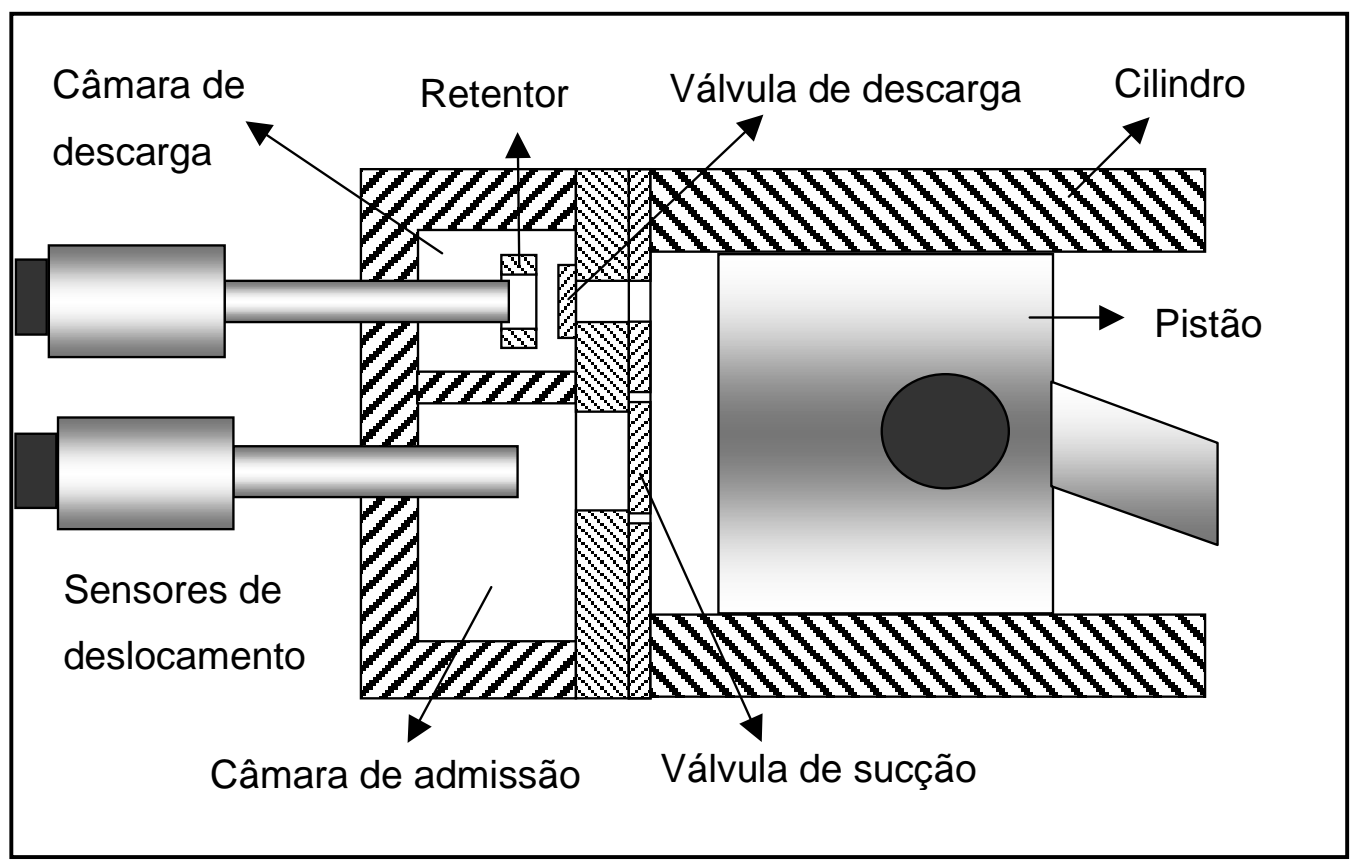

Figura 4.25 - Montagem dos sensores de deslocamento.

A vedação da ponta do sensor foi testada para evitar vazamentos durante o teste, uma vez que, a ponta está submetida à pressão do fluido refrigerante durante o funcionamento do compressor.

A passagem do cabo de fibras pela carcaça também necessitou de um cuidado especial com a vedação. Foram utilizados dois anéis de borracha, um no lado interno e outro no lado externo da carcaça, que foram prensados contra 
o cabo através das porcas de fixação. Todo o cuidado foi tomado para evitar vazamentos e também para não danificar o feixe de fibras ópticas do sensor. A figura 4.26 mostra a vedação utilizada na passagem dos cabos.

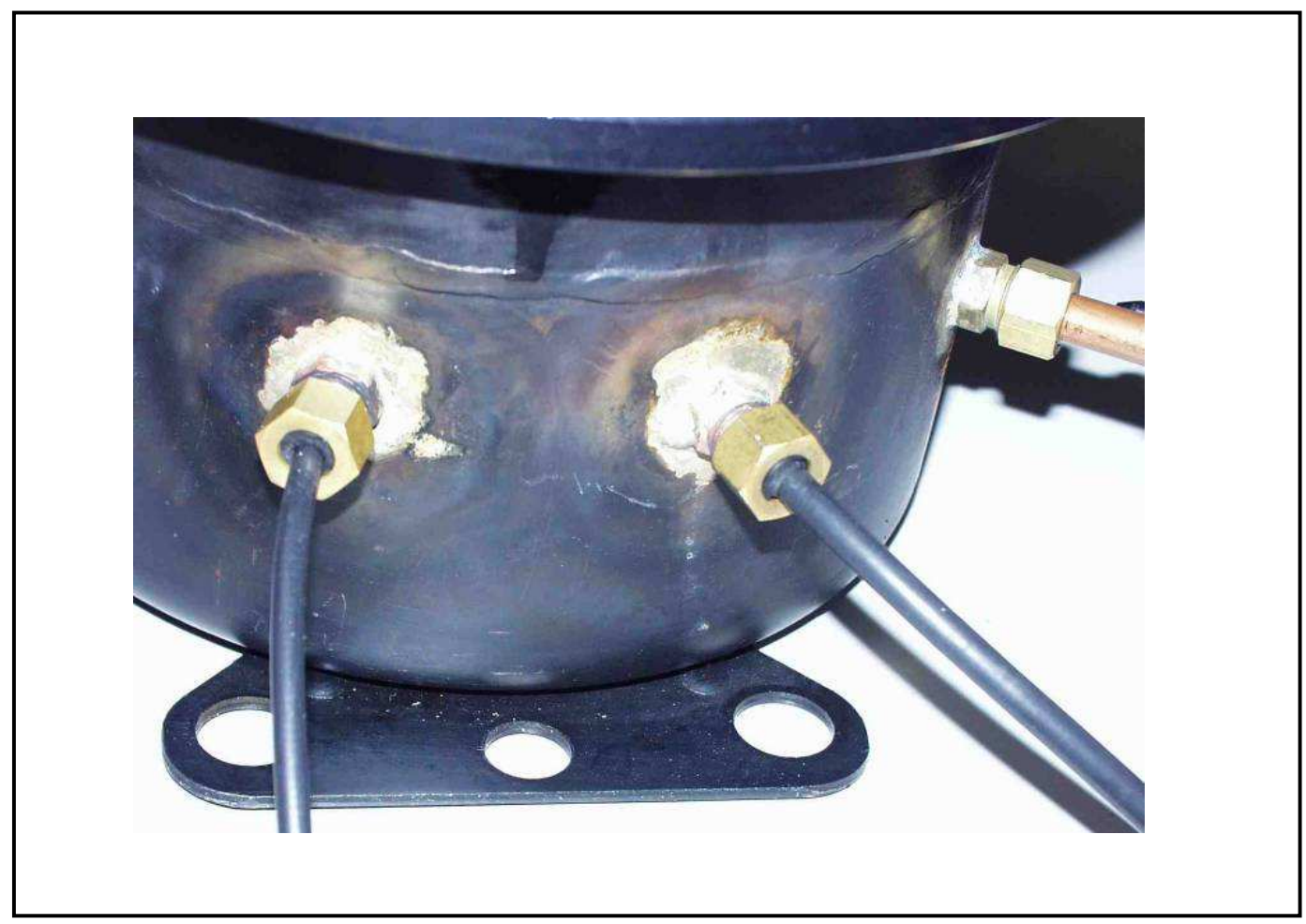

Figura 4.26 - Vedação utilizada na passagem dos cabos dos sensores de deslocamento.

\subsubsection{SENSOR DE DESLOCAMENTO ANGULAR}

A montagem do sensor de deslocamento angular é de fundamental importância para se ter a correta referência da posição angular do eixo de rotação do compressor. O primeiro passo foi confeccionar um conector, para fazer o acoplamento do encoder ao eixo. Em seguida, com o auxilio de um relógio comparador Mitutoyo modelo 2109F, posicionou-se o pistão na posição de ponto morto superior - menor distância entre o pistão e a placa válvula. Com um osciloscópio conectado ao sensor de deslocamento angular, girou-se o eixo do encoder até detectar o sinal de referência. Montou-se o encoder ao 
adaptador travando-o através dos parafusos de fixação do próprio sensor. O corpo do sensor também foi fixado junto ao conjunto mecânico do compressor. Após a montagem foi refeita a verificação do sinal. Essa montagem está ilustrada na figura 4.27 .

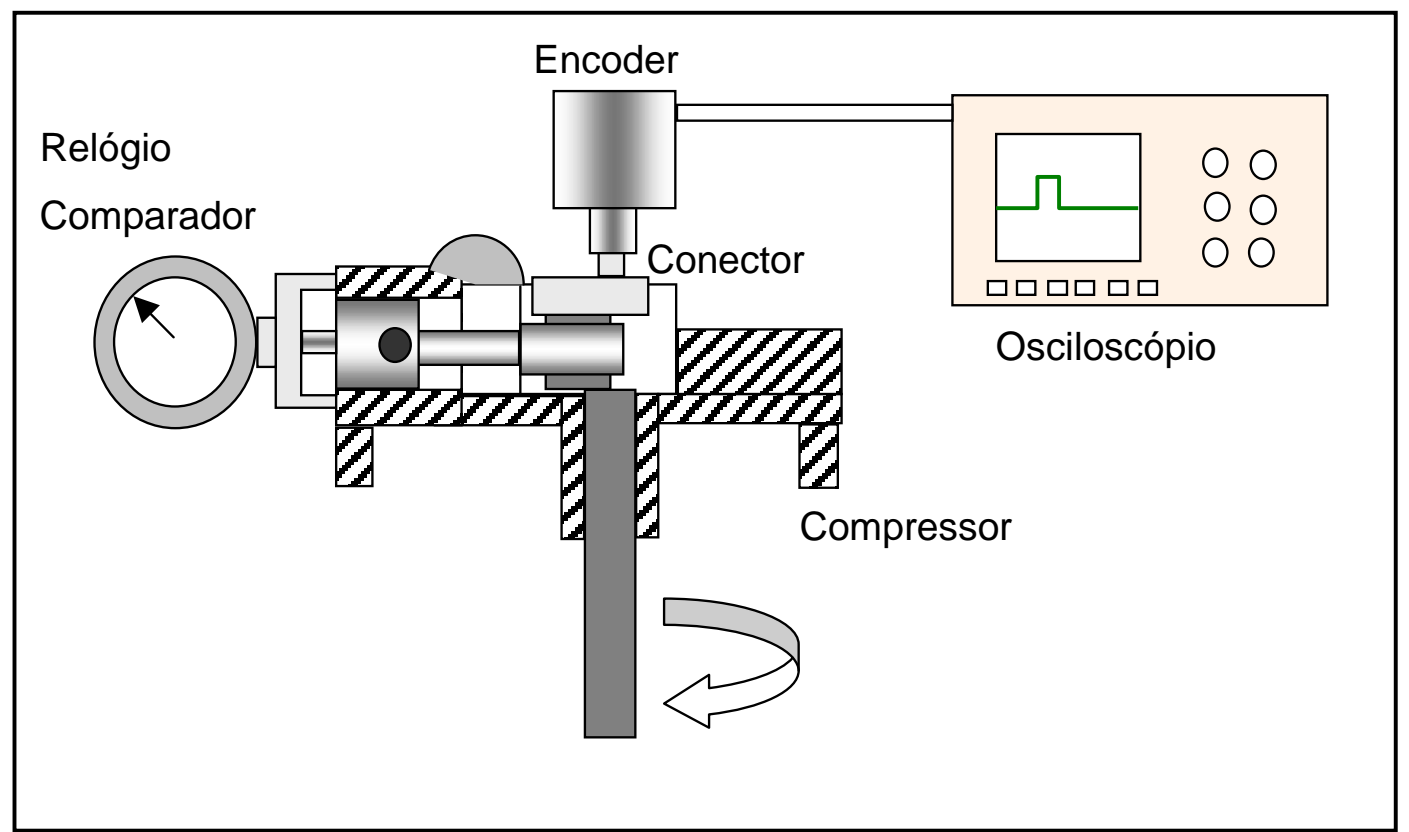

Figura 4.27 - Montagem e ajuste do sensor de deslocamento angular (encoder).

\subsubsection{SENSOR DE TEMPERATURA}

Os sensores de temperatura foram posicionados diretamente nas regiões a serem medidas. $O$ caráter mais importante dessa montagem foi a utilização do adesivo epóxi Loctite código 39917 para realizar a vedação e a fixação dos termopares Este adesivo tem cura rápida e permite a sua utilização em temperaturas de até $200^{\circ} \mathrm{C}$.

A junção dos termopares utilizados foi fundida com auxilio de uma fonte de tensão de corrente continua ajustada para 20 volts e mercúrio. Um pólo da fonte foi ligado ao recipiente contendo o mercúrio e o outro ao cabo do termopar. Ao mergulhar o cabo no mercúrio ocorreu a fusão dos cabos proporcionando uma junção de boa qualidade, com objetivo de melhorar a 
condição das medidas. A figura 4.28 mostra a montagem do termopar junto a câmara de descarga.

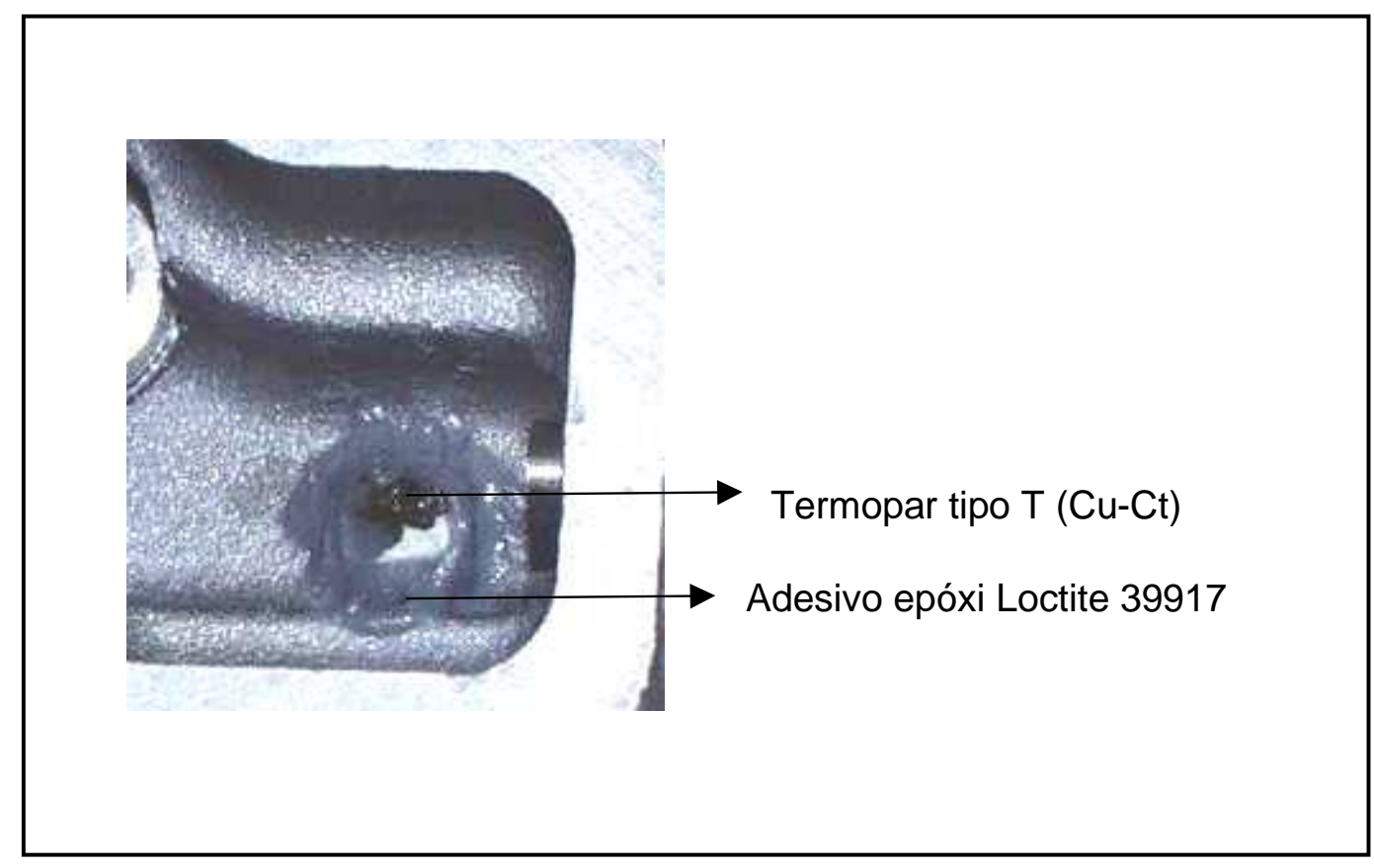

Figura 4.28 - Montagem do termopar junto à câmara de descarga.

\subsubsection{MONTAGEM GERAL}

Após a montagem individual de todos os sensores ao conjunto mecânico, fez-se necessário acomodar e posicionar o compressor dentro da carcaça. A carcaça foi planejada de forma a comportar internamente todos os sensores montados. Logo, houve necessidade de confeccionar uma carcaça especial, maior que a usual. No processo habitual de fabricação dos compressores herméticos, a carcaça e a tampa são soldadas com o objetivo de garantir seu fechamento, e assim,garantir sua hermeticidade. Já a empregada nessa instrumentação, o seu fechamento feito por parafusos e a estanqueidade foi garantida pelo uso de anel de vedação.

Outro detalhe importante foi a conexão elétrica entre o sistema de aquisição e os sensores. Com exceção dos sensores de deslocamento, utilizados para monitorar as válvulas, cujo sinal foi retirado pelo feixe de fibras 
ópticas, os demais sensores necessitaram ser alimentados e lidos através de fios que passavam através da carcaça, os quais apresentavam vazamento do fluido refrigerante entre $o$ isolante e o condutor. Para eliminar esse problema foi necessário confeccionar um tubo de passagem preenchido de resina epóxi. A figura 4.29 mostra a montagem do tubo.

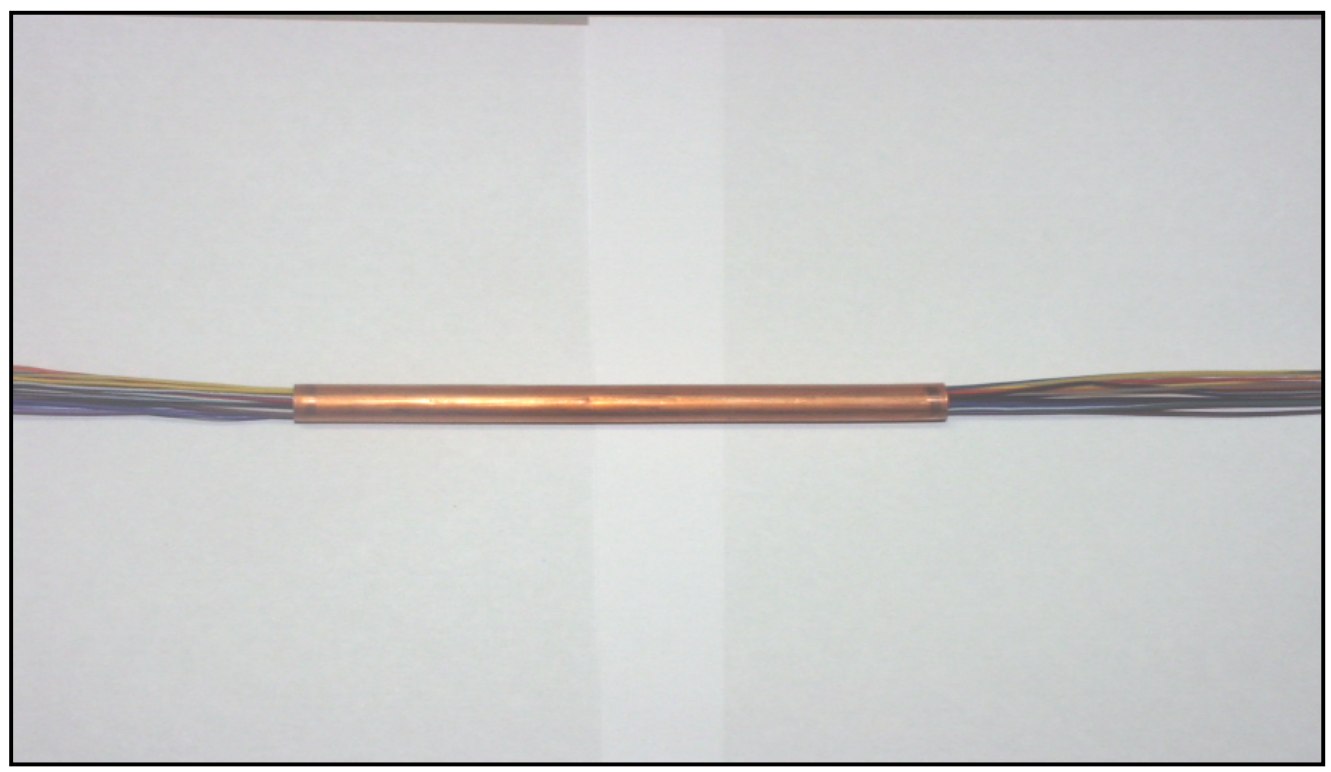

Figura 4.29 - Montagem do tubo de passagem dos cabos elétricos.

Após a montagem do tubo, o mesmo foi posicionado na carcaça através de conectores utilizados em montagens de sistemas hidráulicos. Dessa maneira foi garantido o não vazamento do fluido refrigerante pela utilização do tubo conector. O mesmo método foi empregado para se evitar vazamentos nos cabos dos termopares.

A figura 4.30 mostra a montagem geral do compressor dentro da carcaça. 


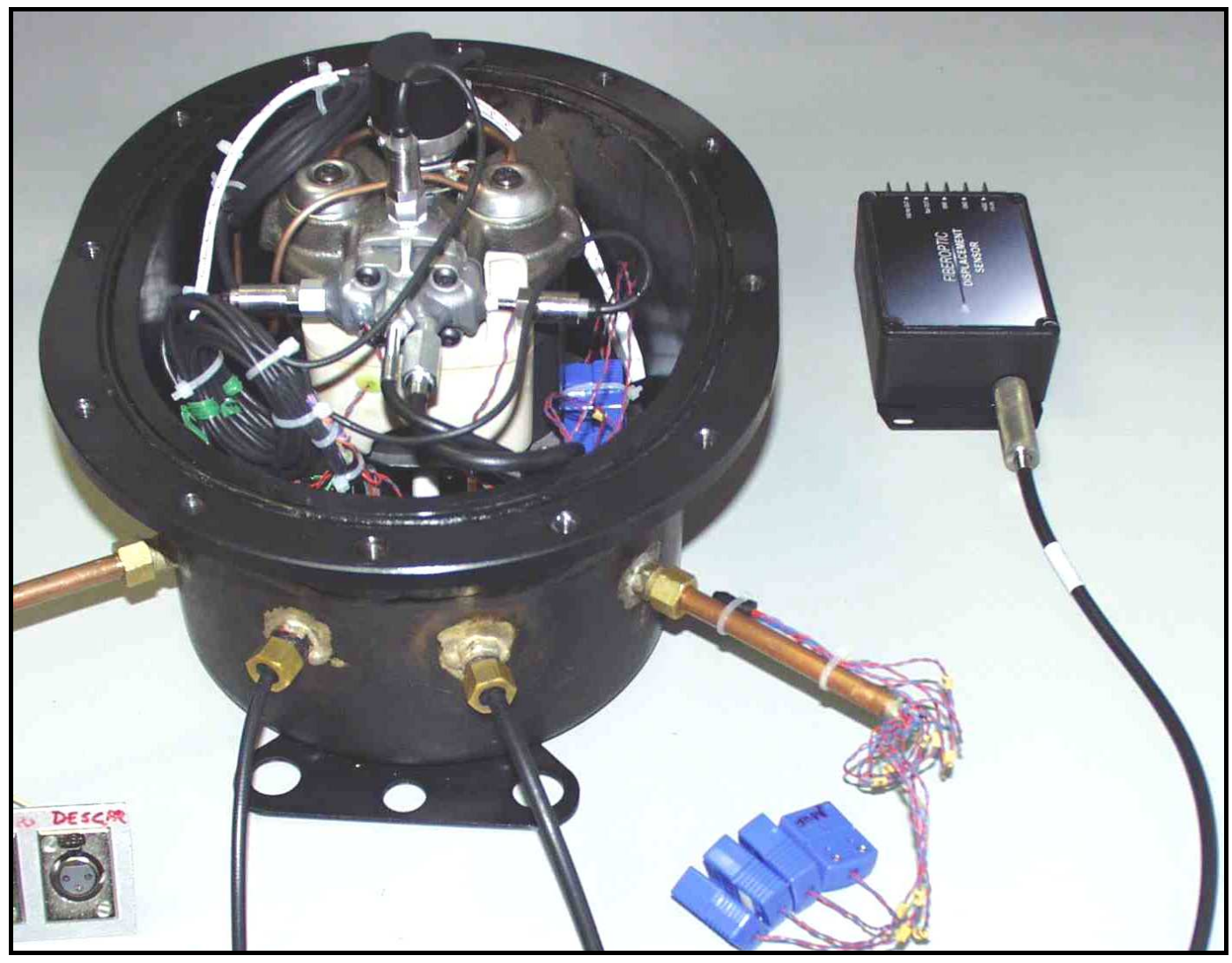

Figura 4.30 - Montagem geral do compressor instrumentado dentro da carcaça.

\subsection{HARDWARE DE AQUISIÇÃO DE DADOS}

Para realizar o monitoramento dos fenômenos propostos, foi utilizado um hardware de aquisição de dados composto por:

i. Computador Dell dimension GX 280 - Processador Intel Pentium IV - 3.0Ghz, memória RAM 512 MB;

ii. Placa de aquisição de sinais marca National Instruments modelo NI PCI 6251 - 16 bits, 1.250 .000 amostras/s;

iii. Chassi SCXI 1000 - National Instruments;

iv. Módulo SCXI1125 (Entrada Analógica) e bloco terminal SCXI 1313 - National Instruments; 
v. Módulo SCXI1102 (Temperatura) e bloco terminal SCXI 1300 National Instruments;

vi. Conector SCXI 1180 (Feedthrough) com terminal bloco SCXI 1302 - National Instruments;

vii. Cabos e conectores.

A figura 4.31 mostra a estrutura do sistema de aquisição de dados utilizado para realização do experimento.

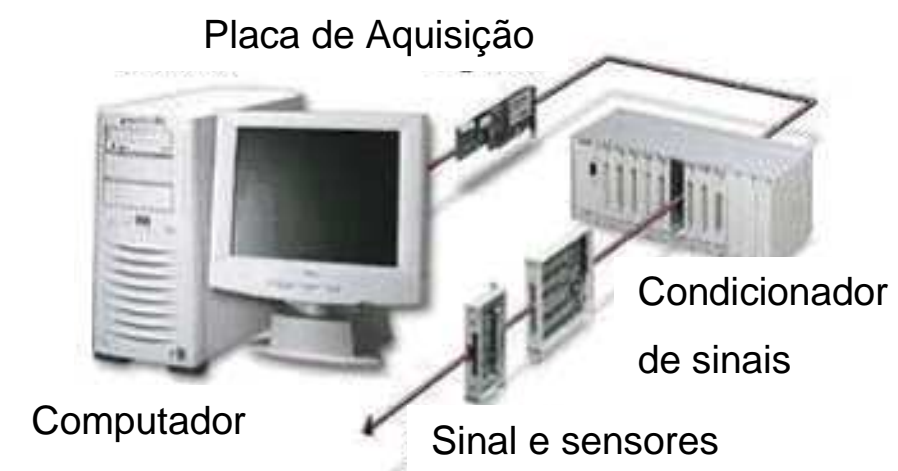

Figura 4.31 - Hardware de aquisição de dados. Fonte National Instruments.

Os sinais recebidos dos sensores foram conectados ao condicionador de sinal que é composto de:

i. Bloco terminal, onde propriamente foi realizada a conexão entre os sensores e o sistema;

ii. Módulo condicionador, onde foi possível aplicar filtros e ganhos;

iii. Chassi, que fez a interface com a placa de aquisição de dados.

A placa de aquisição de dados foi instalada no computador. Nela foi feita a conversão analógico/digital do sinal o que possibilitou o tratamento dos dados com o auxilio do próprio computador.

Dados complementares da especificação dos equipamentos utilizados no sistema de aquisição de dados estão listados no apêndice B. 


\subsection{SOFTWARE DE AQUISIÇÃO DE DADOS}

Outro fator de fundamental importância para o monitoramento do compressor foi a criação do software de aquisição de dados. O programa foi desenvolvido utilizando o software Labview ${ }^{\circledR}$ e pode ser representado esquematicamente pela figura 4.32 :

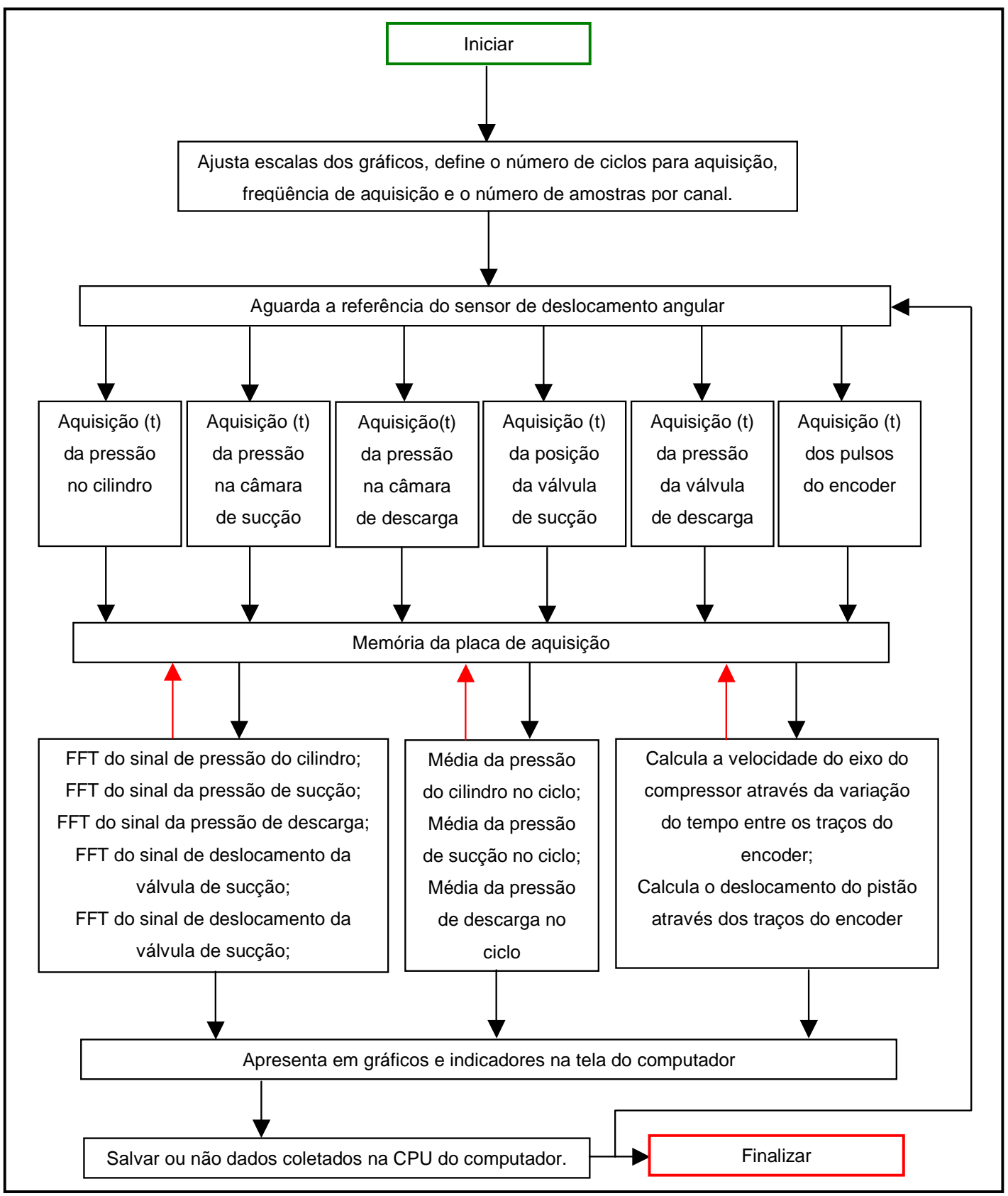

Figura 4.32 - Estrutura do software de aquisição de dados. 
Com a elaboração do software foi permitido:

i. Visualizar as medidas;

ii. Selecionar parâmetros de configuração do teste, tais como: sensibilidade dos sensores, número de amostras por canal, número de canais e a taxa de aquisição de dados;

iii. Gerenciar as tarefas da placa de aquisição de dados;

iv. Disparar aquisição;

v. Realizar cálculos matemáticos, tais como: média, FFT, deslocamento e a velocidade média;

vi. Sincronizar as leituras dos sensores de deslocamento e pressão com o sensor de deslocamento angular;

vii. Salvar dados em arquivo.

A figura 4.33 mostra o painel frontal do software criado para análise e aquisição dos dados.

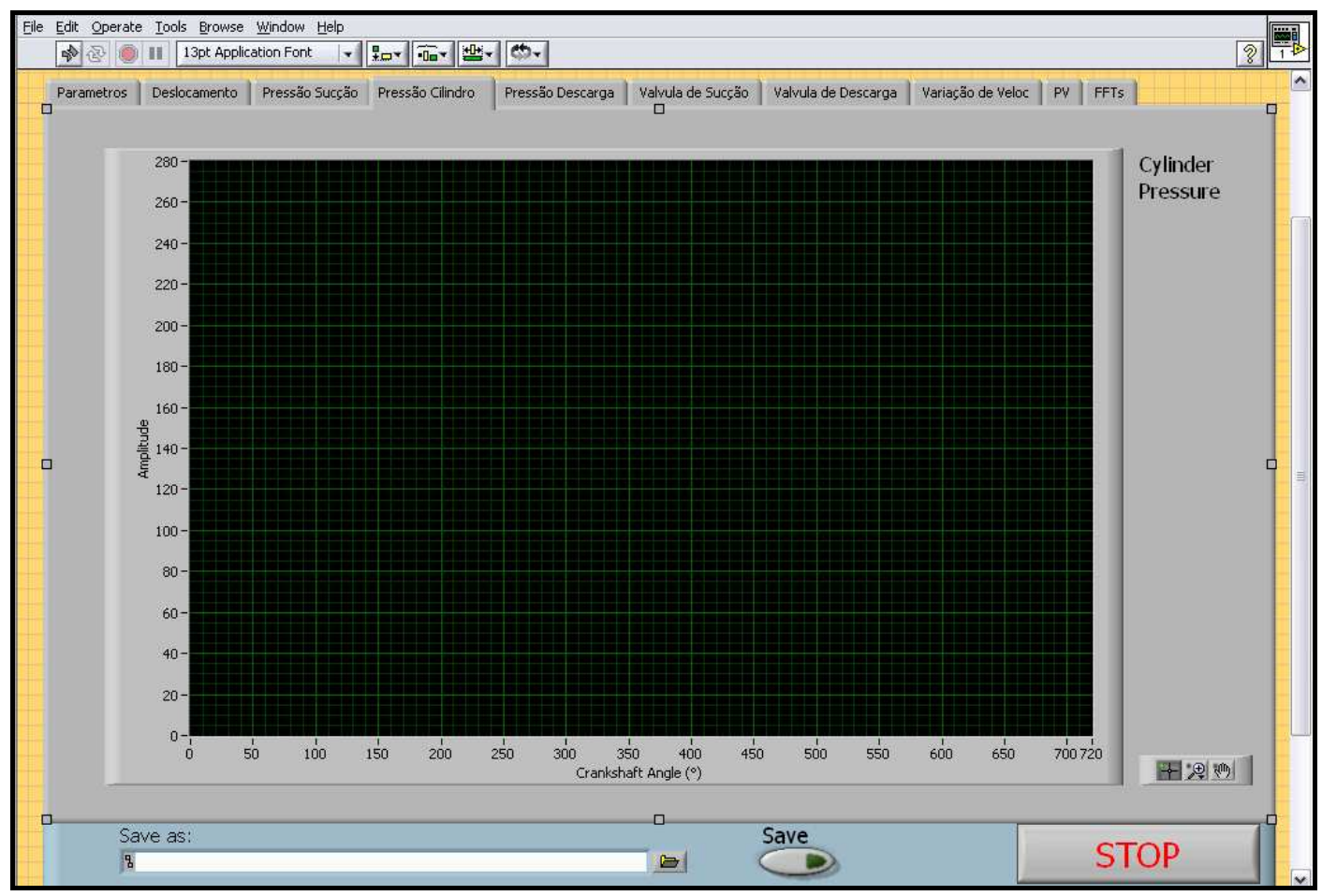

Figura 4.33 - Painel frontal do software de aquisição de dados. 


\subsection{FREQÜÊNCIA DE AQUISIÇÃO E FILTROS.}

A aquisição dos dados foi realizada de duas formas:

1. Taxa de aquisição variada: neste método a aquisição dos dados de pressão e deslocamento das válvulas, lidos pelos sensores, foram coletados pela placa de aquisição de dados em função do sinal do encoder, ou seja, o "sample clock" da placa foi disparado pelo pulso do encoder, garantido assim o sincronismo das medidas com a posição angular do eixo de rotação. Este método é denominado variado, pois se existir variação da velocidade durante o ciclo ocorrerá também uma variação na velocidade de aquisição dos dados, mantendo a correlação entre posição angular e dados medidos. $O$ encoder utilizado possui 2000 pulsos por revolução o que corresponde a uma taxa de aquisição ligeiramente menor que $120.000 \mathrm{~Hz}$ para compressores alimentados em $60 \mathrm{~Hz}$ e ligeiramente menor a $100.000 \mathrm{~Hz}$ para compressores em $50 \mathrm{~Hz}$, uma vez que os compressores não atingem a velocidade síncrona.

2. Taxa de aquisição fixa: neste método o "sample clock" da placa de aquisição é fixo, ou seja, pré-determinado pelo contador do equipamento e definido pelo software de aquisição. A taxa fixa faz-se necessária para os cálculos das FFT dos sinais de pressão e deslocamento das válvulas. A freqüência de aquisição utilizada neste método foi de $80.000 \mathrm{~Hz}$

A taxa de aquisição utilizada em ambos os casos, atenderam ao critério de NYQUIST, que pede a freqüência de aquisição maior que duas vezes a freqüência de corte do sinal medido, para se evitar perda na informação do sinal medido e "aliasing". Fligliola, R.S.; Beassley, D.E. (2000)

$\mathrm{Na}$ realização desse trabalho, foram utilizados filtros analógicos tipo "passa baixo" de $10000 \mathrm{~Hz}$, localizados no módulo SCXI1125, para as medidas de deslocamento das válvulas e das pressões do cilindro, sucção e descarga. 
$\mathrm{Na}$ figura 4.34 pode-se observar a influência do filtro utilizado sobre amplitude e a fase do sinal medido, através do software labview ${ }^{\circledR}$.

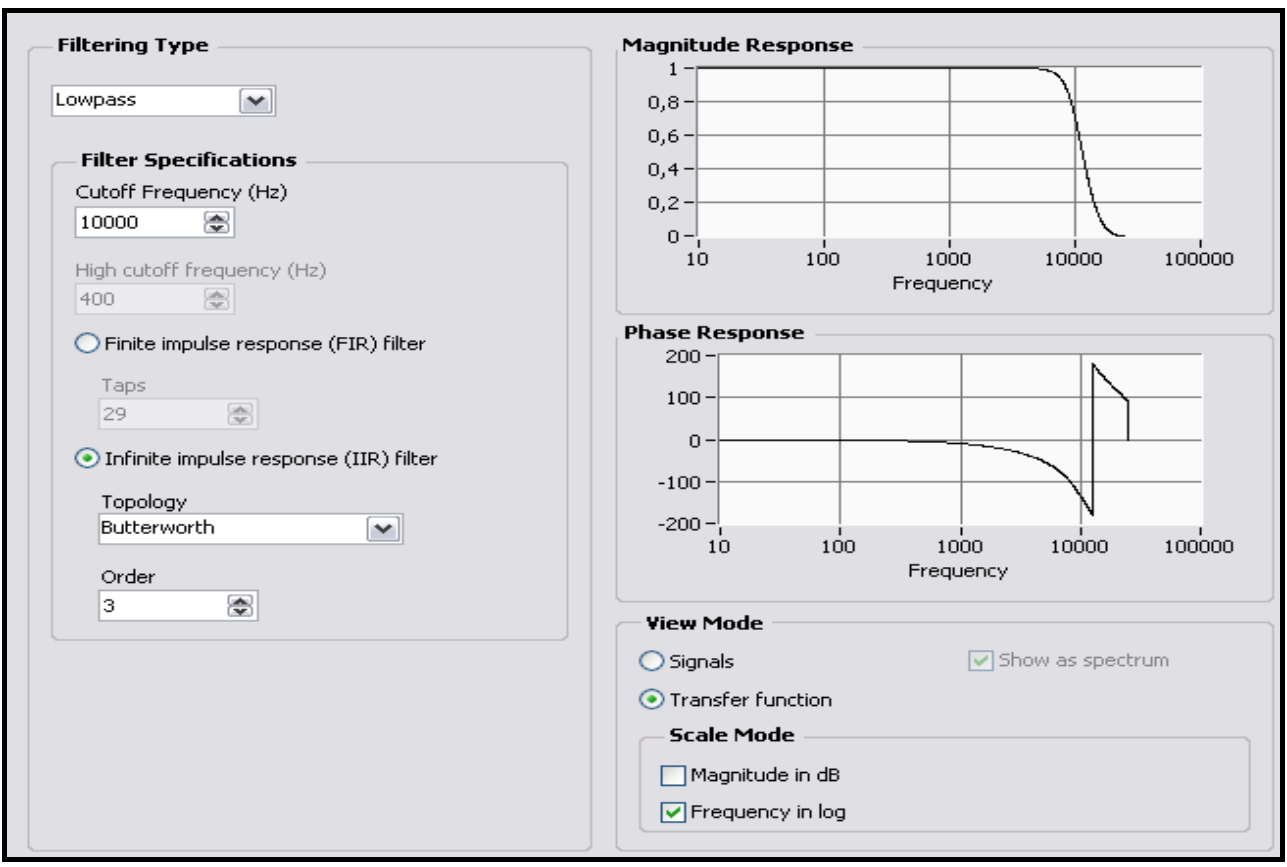

Figura 4.34 - Influência do filtro sobre o sinal medido.

Pode-se verificar que praticamente não existe influência do filtro sobre o sinal medido para freqüências até $2000 \mathrm{~Hz}$. Portanto, as análises utilizadas neste trabalho se limitarão a freqüência máxima de $2000 \mathrm{~Hz}$. 


\section{RESULTADOS E DISCUSSÕES}

\section{1 - CONDIÇÃO DE TESTE}

As características de funcionamento dos compressores herméticos são fortemente influenciadas por suas condições de operação, como por exemplo, a pressão de admissão, a pressão de descarga e a temperatura. $O$ comportamento dinâmico das válvulas de sucção e descarga é afetado pela variação desses parâmetros. Por esses motivos, os testes foram executados em condições pré-determinadas, especificadas pela norma ANSI-ASHRAE 231993 (temperatura do fluido refrigerante na saída do condensador e entrada do evaporador $32^{\circ} \mathrm{C}$ e temperatura de condensação $55^{\circ} \mathrm{C}$ ) em um calorímetro construído para trabalhar de acordo com a norma ANSI-ASHRAE 41.9-1988. Dessa maneira foi possível estabelecer um padrão para a realização dos ensaios experimentais e assim garantir as condições de teste para a realização das medidas.

\section{2 - COMPORTAMENTO DAS PRESSÕES NO CICLO.}

A primeira característica a ser verificada, antes de qualquer consideração sobre as medidas de pressões, é a influência do furo adaptador no sinal de pressão do cilindro. Nas câmaras de sucção e de descarga os sensores foram posicionados diretamente na região desejada. Por limitação de espaço físico, foi impossível posicionar o sensor de pressão do cilindro diretamente no topo do pistão, conforme discutido no capítulo 4.

Dois aspectos de fundamental importância devem ser levados em consideração sobre a medida de pressão: a relação entre a pressão efetiva dentro do cilindro e a pressão na face do sensor após percorrer o furo adaptador e a modificação da fase do sinal, também devido a influência do 
furo. Para encontrar a relação entre a amplitude do sinal medido, a pressão real e a modificação de fase, três parâmetros físicos necessitam ser conhecidos:

- A velocidade do som no fluido refrigerante;

- A densidade do fluido;

- A viscosidade do fluido refrigerante.

Estes parâmetros foram determinados com auxílio de um software específico REFRIPOP. Os dados de entrada para a determinação desses valores foram a pressão dentro do cilindro e a temperatura.

A grande dificuldade encontrada para a obtenção desses dados deve-se ao fato da pressão e da temperatura não permanecerem fixos durante todo o ciclo. Observando as equações 4.9 e 4.10 , pode-se observar que tais parâmetros podem alterar a freqüência natural e o amortecimento do sistema e consequentemente a relação de amplitudes e a fase do sinal conforme indica as equações 4.11 e 4.12 .

A pressão no cilindro durante o ciclo de compressão foi extraída diretamente pelo sensor posicionado no cilindro. A temperatura no cilindro não pode ser mensurada, pois o termopar não possui resposta dinâmica para monitorar a variação de temperatura durante o ciclo. Com as informações dos termopares posicionados na câmara de admissão e na câmara de descarga, pôde-se ter uma idéia da variação de temperatura do fluido dentro do cilindro. Com os dados de pressão e temperatura encontrou-se freqüência natural e o coeficiente de amortecimento para vários pontos durante o ciclo, extraindo o valor máximo e mínimo. Dessa forma foi avaliada a influência desses valores na resposta do furo adaptador, consequentemente sobre o sinal de pressão.

A figura 5.1 mostra a influência da máxima e mínima freqüência natural do adaptador sobre o sinal de pressão. 


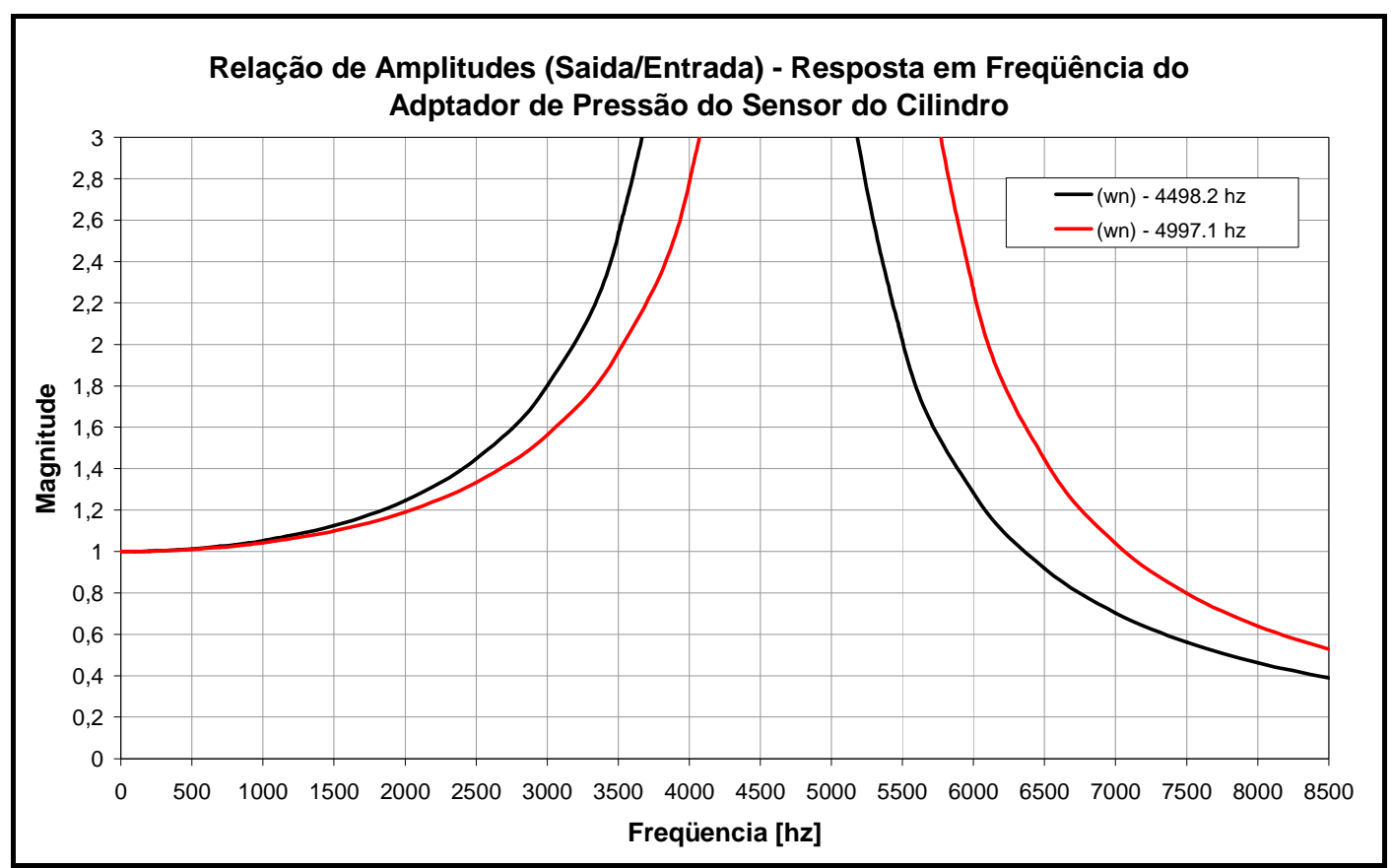

Figura 5.1 - Relação de amplitudes: pressão no sensor /pressão no cilindro.

O máximo valor da freqüência natural do sistema encontrado foi de 4997,1hz e mínimo valor encontrado para a freqüência natural foi de 4498,2 hz.

É verificado que quanto maior a freqüência natural do furo adaptador, menor é a influência sobre o sinal medido. A tabela 5.1 ilustra esta consideração.

\begin{tabular}{|c|c|c|c|c|c|c|}
\hline \multirow{2}{*}{$\begin{array}{c}\text { Freqüência } \\
\text { Natural }\end{array}$} & \multicolumn{5}{|c|}{ Alteração na amplitude do sinal medido (\%) } \\
\cline { 2 - 7 } & $100 \mathrm{hz}$ & $500 \mathrm{hz}$ & $1000 \mathrm{hz}$ & $1500 \mathrm{hz}$ & $2000 \mathrm{hz}$ & $2500 \mathrm{hz}$ \\
\hline$(4498.2 \mathrm{hz})$ & 0.05 & 1,2 & 5,2 & 12,5 & 26,4 & 44,7 \\
\hline$(4997.1 \mathrm{hz})$ & 0.04 & 1,0 & 4,2 & 9,9 & 19,1 & 33,6 \\
\hline
\end{tabular}

Tabela 5.1 - Alteração na amplitude do sinal medido em função da freqüência natural do adaptador.

Pode-se observar na tabela 5.1 que acima de $1000 \mathrm{~Hz}$ a influência do furo adaptador sobre o sinal medido apresenta alterações significativas.

A mesma análise sobre a influencia dos parâmetros físicos devido a pressão e temperatura foi feita para a fase do sinal de pressão do cilindro. A figura 5.2 mostra a alteração da fase em função da freqüência. 


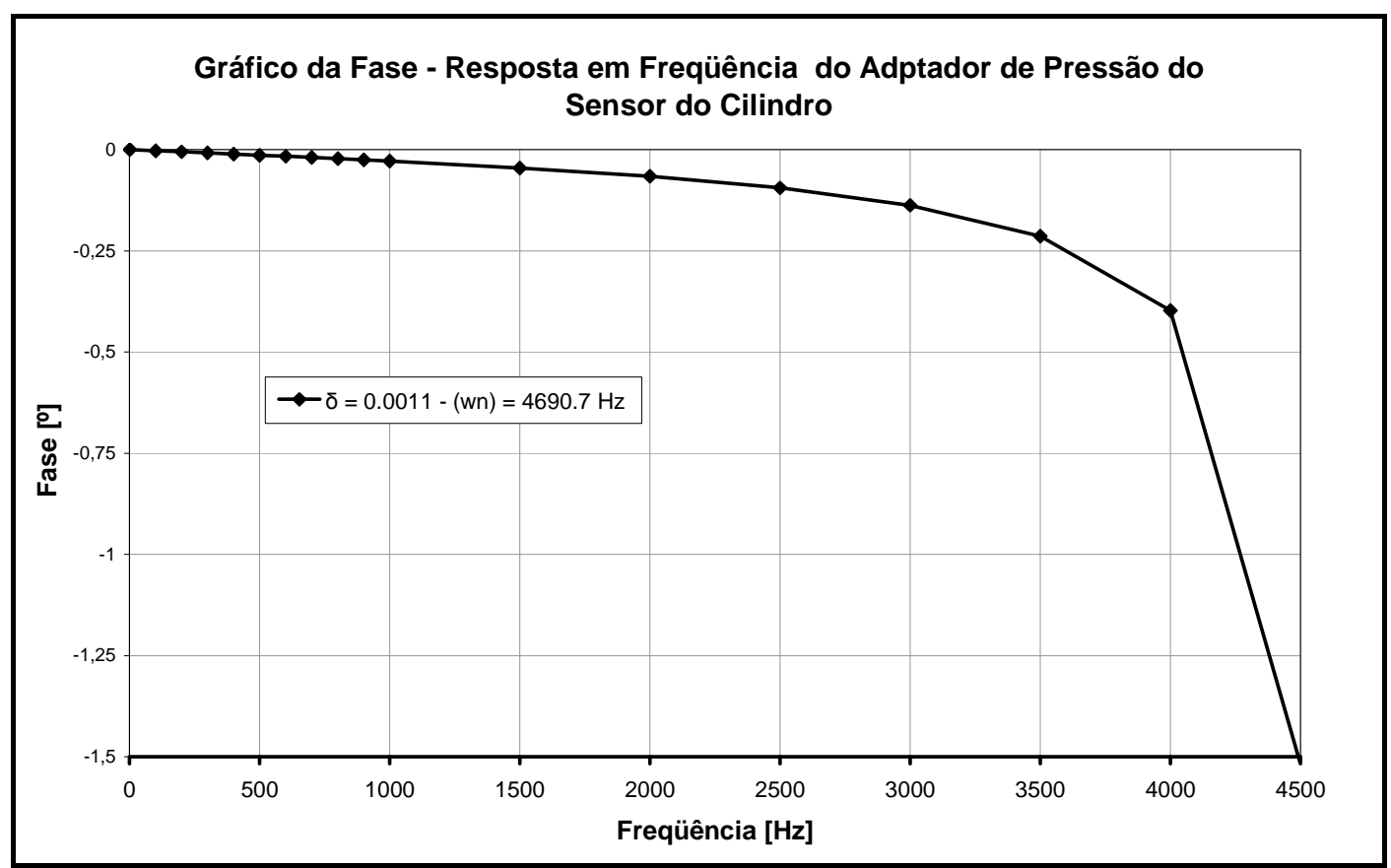

Figura 5.2 - Gráfico da fase do sinal medido através do furo adaptador.

O sistema não apresenta amortecimento considerável. O maior fator de amortecimento encontrado no ciclo é de 0,0011. Pode-se verificar que apesar de pequena, existe influência do furo adaptador sobre o sinal medido para transientes de alta freqüência. .

A terceira característica estudada no sinal de pressão do cilindro foi o atraso na resposta do sensor devido ao comprimento do furo. A equação 4.13 mostra que o atraso no sinal é inversamente proporcional a velocidade do som no fluido refrigerante. A exemplo dos estudos da amplitude e da fase foi levado em consideração a velocidade máxima e o mínima de propagação do som dentro do ciclo de compressão. A velocidade máxima encontrada foi de 184,3 $\mathrm{m} / \mathrm{s}$ e o valor mínimo de $165,9 \mathrm{~m} / \mathrm{s}$. Utilizando a equação 4.13 obtem-se um atraso máximo e mínimo de:

$$
\begin{aligned}
& \tau=\frac{L_{t}}{c}=\frac{0,007}{184,3}=3,8 \times 10^{-5} \text { segundos (para } c \text { máximo); } \\
& \tau=\frac{L_{t}}{c}=\frac{0,007}{165,9}=4,2 \times 10^{-5} \text { segundos (para } c \text { mínimo). }
\end{aligned}
$$


Para um ciclo compressão de $60 \mathrm{hz}$ tem-se $1 / 60 \mathrm{~s}=0.0167 \mathrm{~s}$ por ciclo de compressão. Dividindo esse tempo por $360^{\circ}$, uma volt a completa do eixo, obtém-se:

$$
0,0167 \mathrm{~s} / 360^{\circ}=4,6 \times 10^{-5} \text { segundos por grau de rotação do eixo } \text {. }
$$

Dividindo as equações 5.1 e 5.2 pela equação 5.3 tem-se um atraso mínimo de $0,8^{\circ}$ para velocidade de $184,3 \mathrm{~m} / \mathrm{s}$ e um at raso máximo de 0,9 para velocidade de $165,9 \mathrm{~m} / \mathrm{s}$.

O mesmo desenvolvimento vale para a freqüência de $50 \mathrm{hz}$. Nessa condição temos um atraso mínimo de $1,2^{\circ}$ e um máximo de $1,3^{\circ}$.

Diante destes números pode-se dizer que existe um atraso no sinal de pressão em função da freqüência de funcionamento do compressor. A figura 5.3 mostra a correção do sinal de pressão realizada devido ao comprimento do furo adaptador.

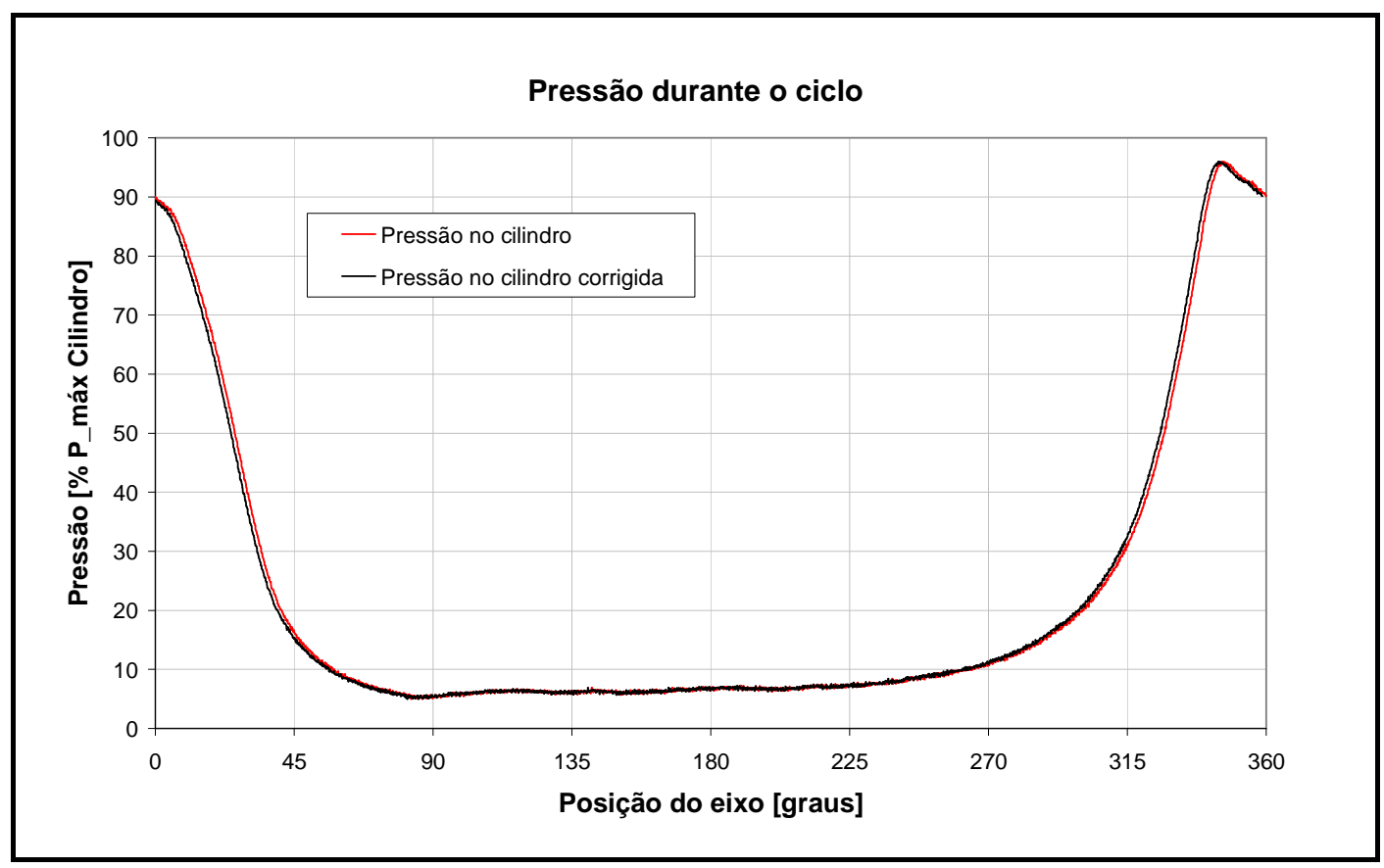

Figura 5.3 - Comparação do sinal amostrado com o sinal corrigido teoricamente em função do comprimento do furo. 
Com o objetivo de ampliar o estudo da influência do furo conector sobre o sinal de pressão no cilindro, foi preparado um segundo cabeçote, semelhante ao primeiro, mas sem a montagem dos sensores de deslocamento das válvulas, o que possibilitou a montagem de um segundo sensor de pressão aplicado diretamente no topo do pistão. Dessa forma foi possível comparar experimentalmente o efeito do furo conector sobre o sinal medido, conforme ilustrado no gráfico 5.4 .

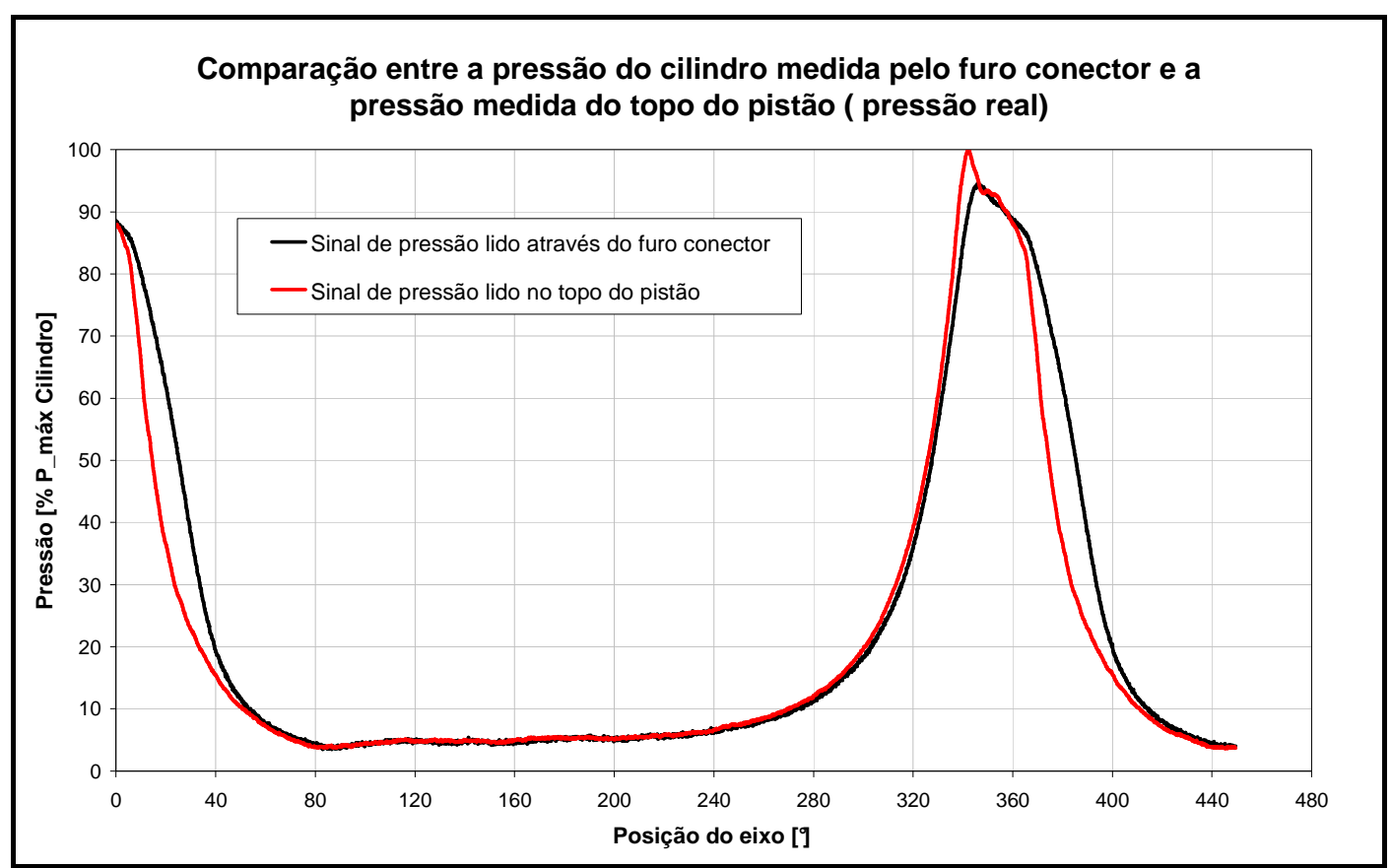

Figura 5.4 - Influência do furo adaptador sobre o sinal medido.

Pode-se verificar que o furo conector atenua em 6\% a pico máximo de pressão registrado durante o ciclo de compressão. Os transientes em alta freqüência também são prejudicados pelo adaptador que ocasiona um erro na medida de pressão de até $25 \%$ durante o retorno do pistão, momento em que posição angular do eixo de rotação está posicionado à 20 graus em relação a referência (ponto morto superior). A pressão medida pelo furo adaptador apresentou boa concordância com o sinal real entre 60 e 300 graus angulares do eixo, justamente onde não ocorrem mudanças bruscas na pressão do cilindro. 
Baseado nos resultados encontrados, as medidas de pressão durante 0 ciclo de compressão foram realizadas utilizando um segundo cabeçote, e assim monitorando a pressão diretamente no topo do pistão. Os dados foram então coletados em dois instantes distintos: O primeiro com a configuração utilizando o furo adaptador e o cabeçote 1 que permitiu monitorar o funcionamento das válvulas, e o segundo utilizando o cabeçote 2 que permitiu medir a pressão diretamente no topo do pistão. Apesar de realizar a troca dos cabeçotes este fato não alterou a característica das medidas, uma vez que as condições de testes foram controladas e o segundo cabeçote era semelhante ao primeiro. A figura 5.5 mostra a concordância entre as medidas de pressão, realizadas em ensaios distintos.

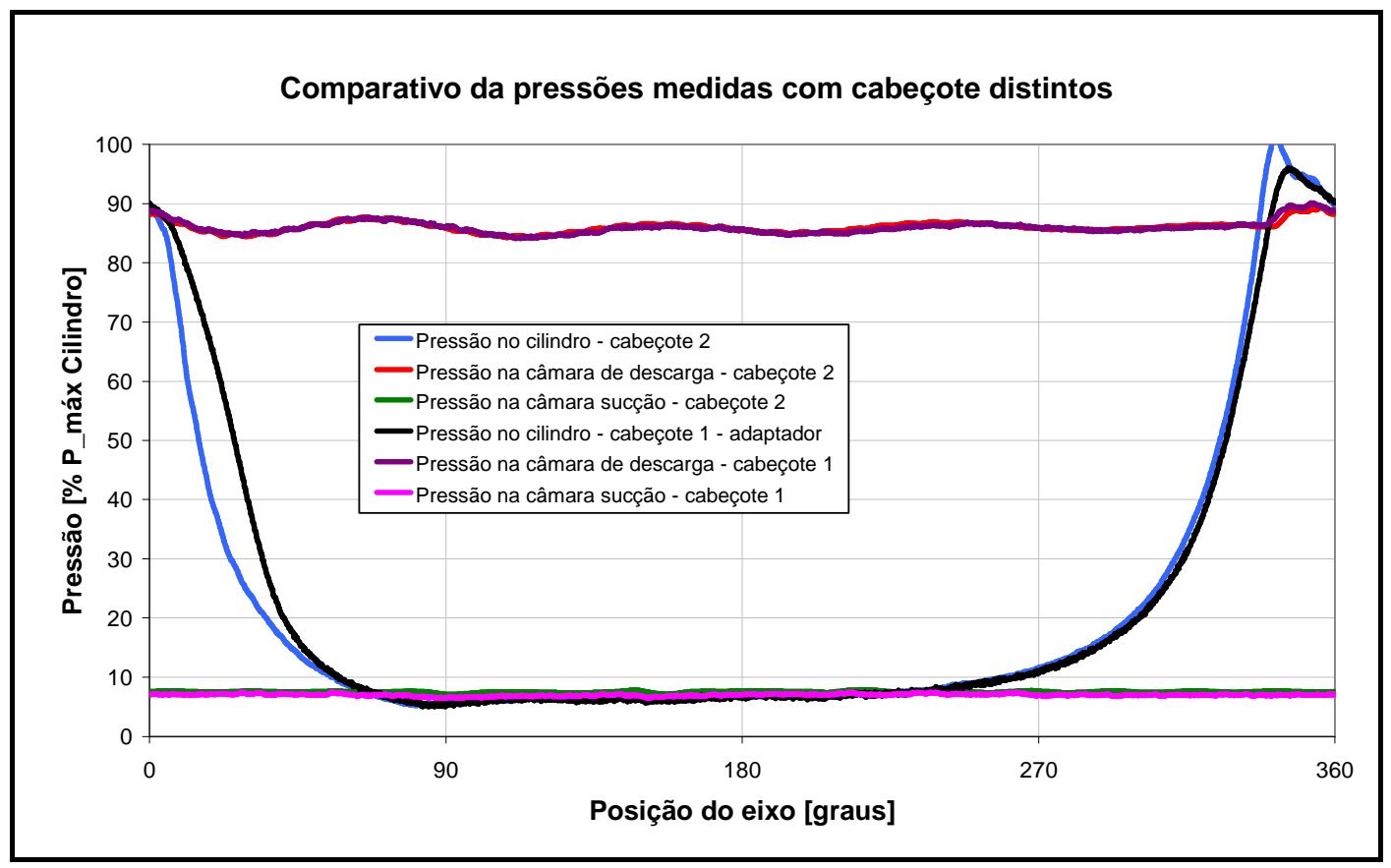

Figura 5.5 - Comparação entre as medidas de pressão usando cabeçotes distintos.

Pode-se observar que não existe diferença entre as curvas da pressão de sucção e de descarga entre os cabeçotes 1 e 2, fato que comprova a não alteração do comportamento dessas pressões, devido mudança dos cabeçotes. A diferença apontada na figura 5.5 está na pressão do cilindro, conforme já discutido anteriormente, devido a utilização do furo adaptador. 
O sincronismo entre as medidas foi garantido pelo pulso de referência do encoder, que não precisou ser desmontado para a troca dos cabeçotes.

Portanto os dados de pressão no cilindro considerado neste trabalho são os obtidos com o cabeçote 2, pois este tem uma resposta mais rápida e não atenua o pico, conforme mostram as figuras 5.4 e 5.5 , em torno dos $22^{\circ}$ e $342^{\circ}$ da posição do eixo, respectivamente. O uso do furo adaptador para extrair as informações de pressão do cilindro foi descartado.

A figura 5.6 mostra as curvas de pressão no cilindro, pressão na câmara de descarga e pressão de sucção em função da posição angular do eixo de rotação durante um ciclo do compressor.

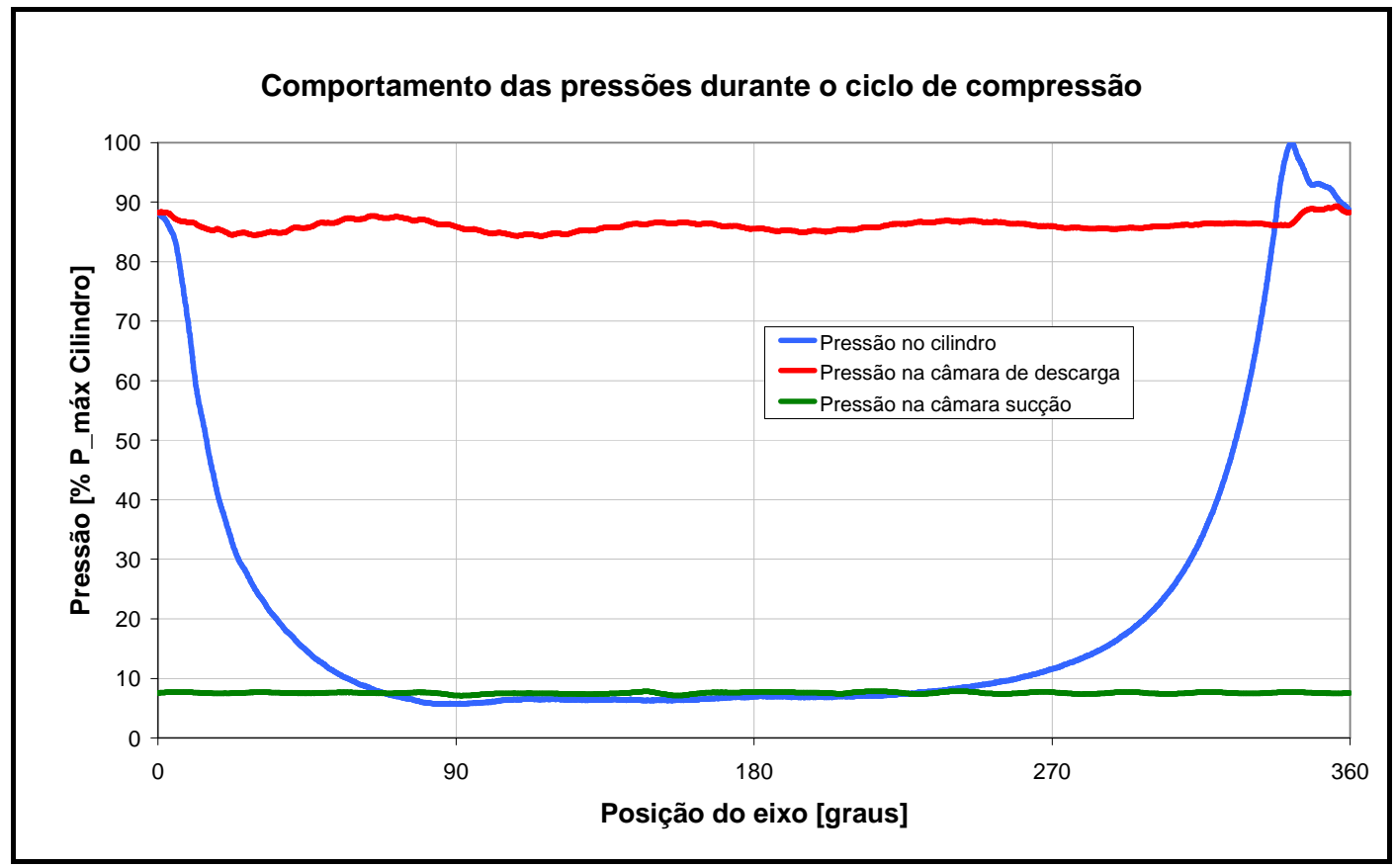

Figura 5.6 - Comportamento das pressões durante o ciclo de compressão de um compressor hermético.

Pode-se verificar que a curva da pressão no cilindro cruza, em determinado instante, a pressão de descarga e a pressão de sucção, proporcionando assim o diferencial de pressão necessário para a abertura das válvulas de sucção e de descarga.

Nos compressores herméticos, os movimentos do pistão são determinados pelo sistema biela-manivela do conjunto mecânico. Com a 
informação da posição angular, obtida pelo sensor de deslocamento angular e conhecendo a excentricidade da manivela e o comprimento da biela é possível calcular o deslocamento do pistão.

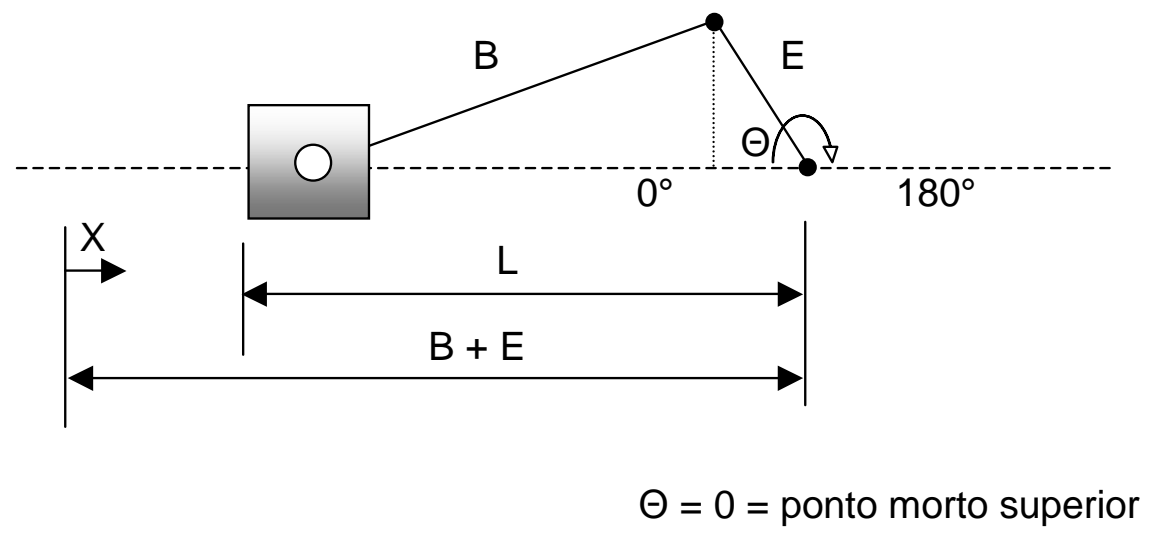

Figura 5.7 - Determinação do deslocamento do pistão em um sistema biela-manivela.

Seja:

$X$ = deslocamento do pistão;

$\mathrm{B}=$ comprimento da biela;

$\mathrm{E}=$ excentricidade da manivela.

O deslocamento do pistão ao longo do eixo x, em função do ângulo de rotação do eixo é:

$X(\Theta)=B+E-L(\Theta)$

Desenvolvendo $L(\Theta)$ :

$\left.L(\Theta)=E \cos (\Theta)+\sqrt{B^{2}-\left(E \cdot \operatorname{sen}(\Theta)^{2}\right.}\right)$

Substituindo (5.2) em (5.1):

$$
\left.X(\Theta)=B+E-E \cos (\Theta)-\sqrt{B^{2}-\left(E \cdot \operatorname{sen}(\Theta)^{2}\right.}\right)
$$

A figura 5.8 mostra a variação de pressão no cilindro comparada ao deslocamento $X(\Theta)$ do pistão. 


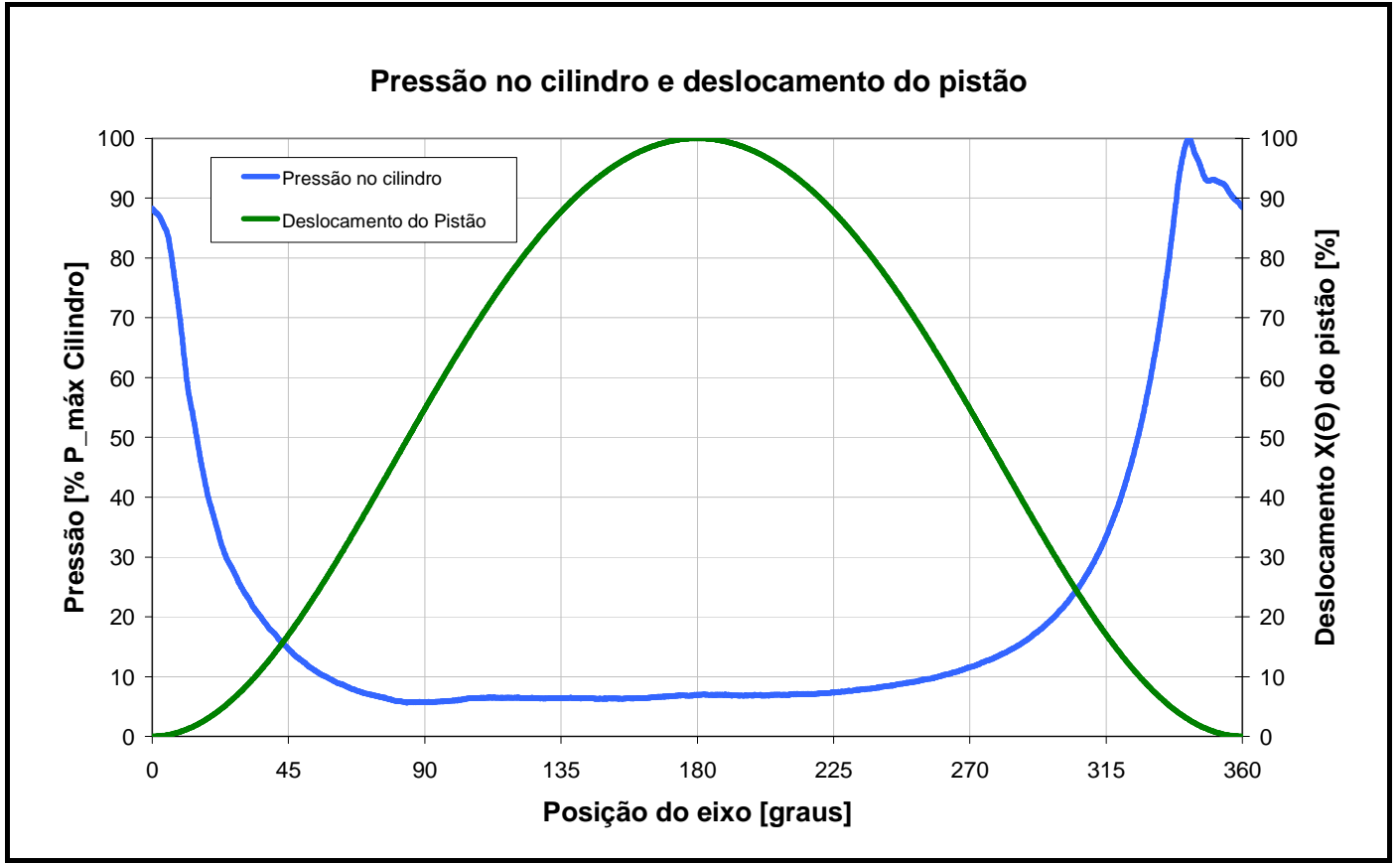

Figura 5.8 - Variação da pressão do cilindro comparada ao deslocamento do pistão.

É possível verificar que na região do ponto morto superior - menor distância entre o pistão e a placa válvula - a pressão é máxima. À medida que o pistão retorna, a pressão dentro do cilindro diminui e chega próximo ao mínimo no momento que o pistão está totalmente recuado - ponto morto inferior.

Com a informação de deslocamento e conhecendo-se o diâmetro do pistão, é possível calcular o volume do cilindro em função da posição angular do eixo de rotação. Um gráfico de pressão em função do volume pode ser criado e assim encontrar o trabalho realizado durante um ciclo através da integral pressão - volume.

A figura 5.9 apresenta o diagrama das pressões contra o volume do compressor. As pressões foram medidas diretamente e o volume determinado indiretamente utilizando a informação da posição angular do eixo do compressor e suas características geométricas. 


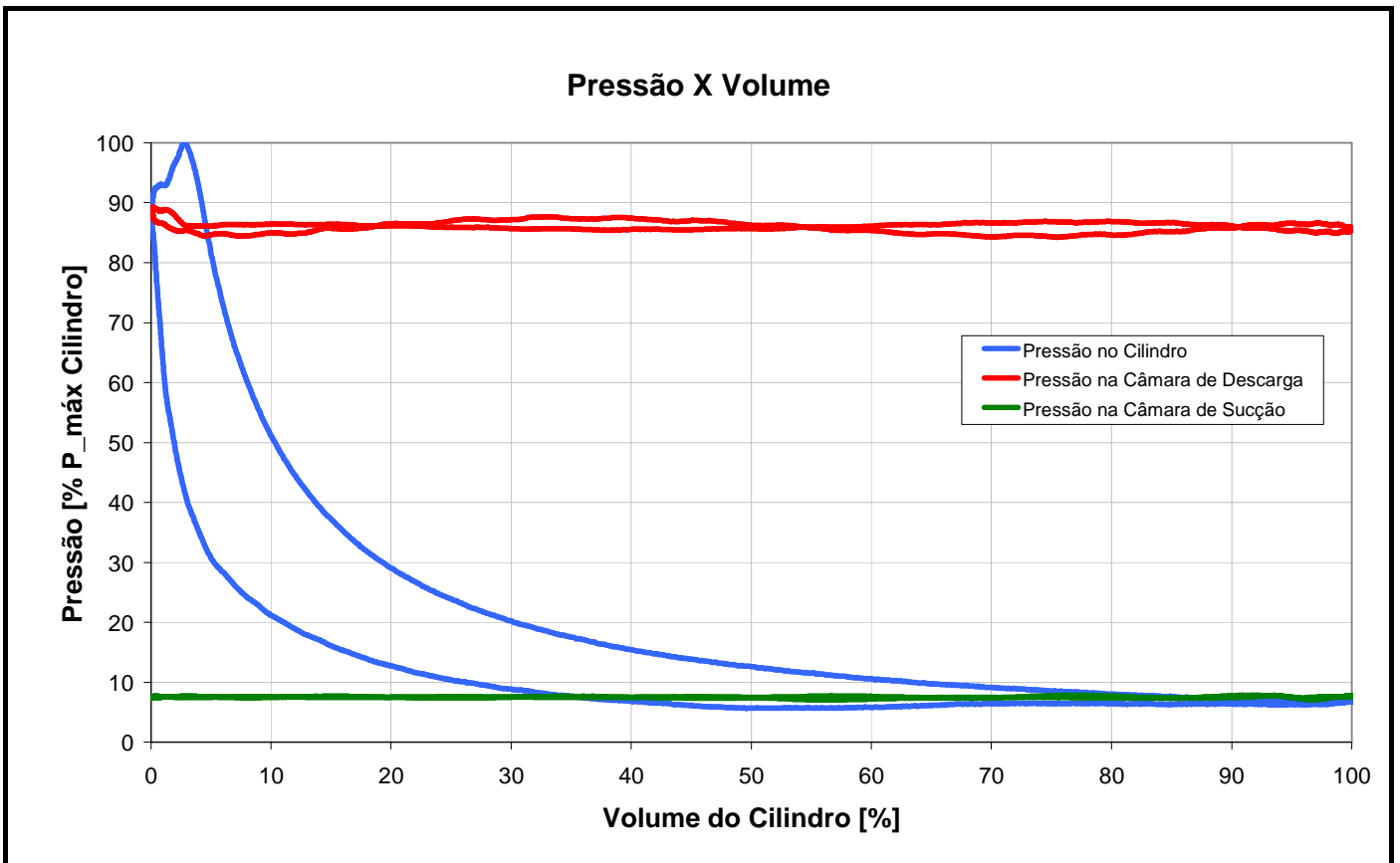

Figura 5.9 - Diagrama das pressões contra o volume de um compressor hermético

Outra informação que pode ser obtida através do sinal de pressão é a componente em freqüência da medida. Através da Transformada de Fourier pode-se extrair as componentes em freqüência das pressões de sucção e descarga e assim, contribuir na identificação de fontes indesejáveis de ruídos nos sistemas de refrigeração. Uma vez que, o conteúdo em freqüência dos pulsos de descarga é transmitido através do fluido refrigerante, pode existir a interação entre a freqüência natural do sistema e a freqüência dos pulsos de descarga, gerando a ressonância do conjunto, e assim prejudicar a qualidade sonora do sistema.

Com a taxa de aquisição de $80.000 \mathrm{~Hz}$ foram coletados 10 ciclos completos das pressões de descarga e de sucção que foram utilizados para calcular a densidade espectral de potência do sinal ("Power Spectrum Density"), através da FFT, com auxílio do software labview®. As figuras 5.10 e 5.11 trazem a densidade espectral de potência da pressão de sucção e descarga durante o funcionamento do compressor. 


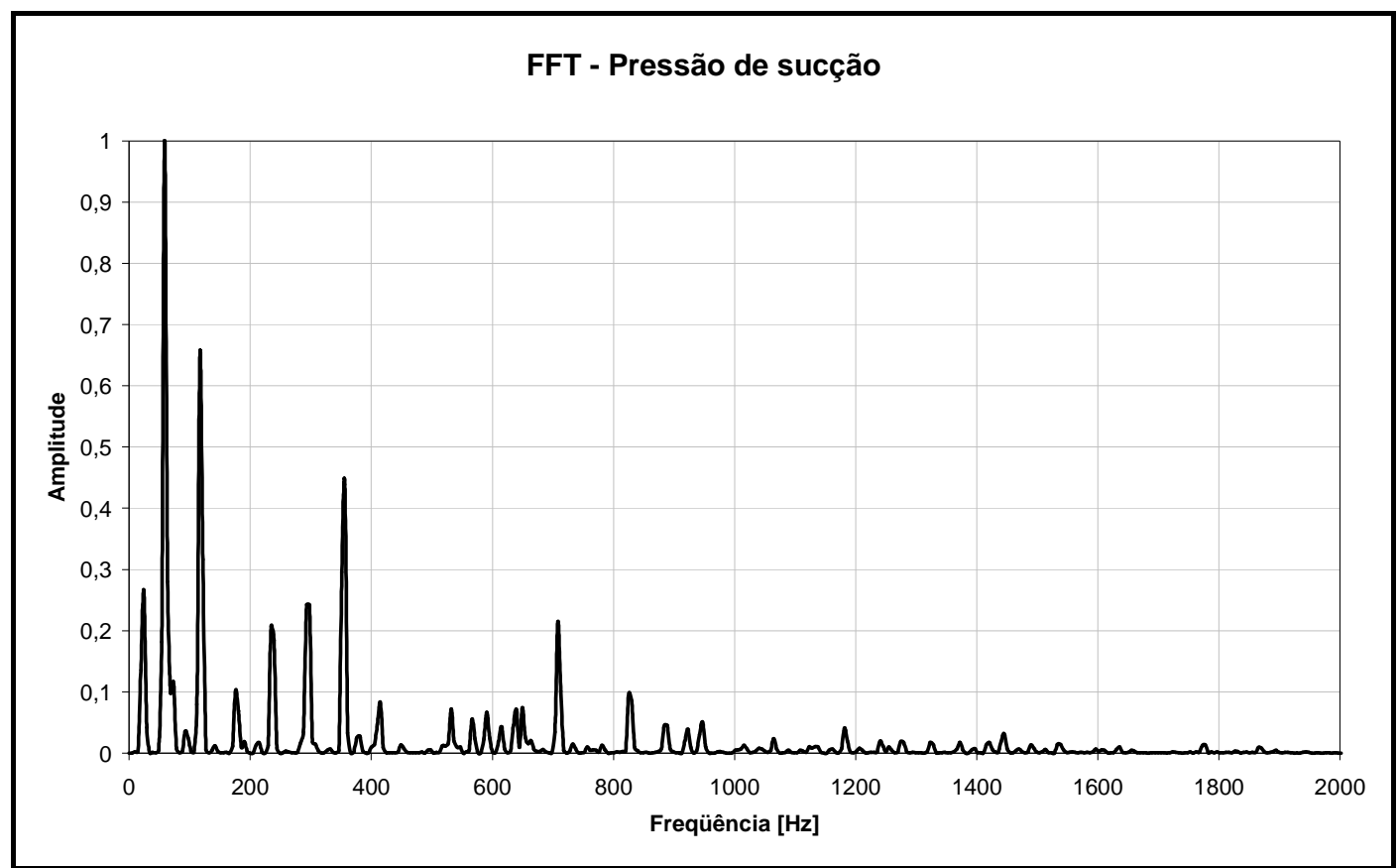

Figura 5.10 - FFT do sinal da pressão de sucção

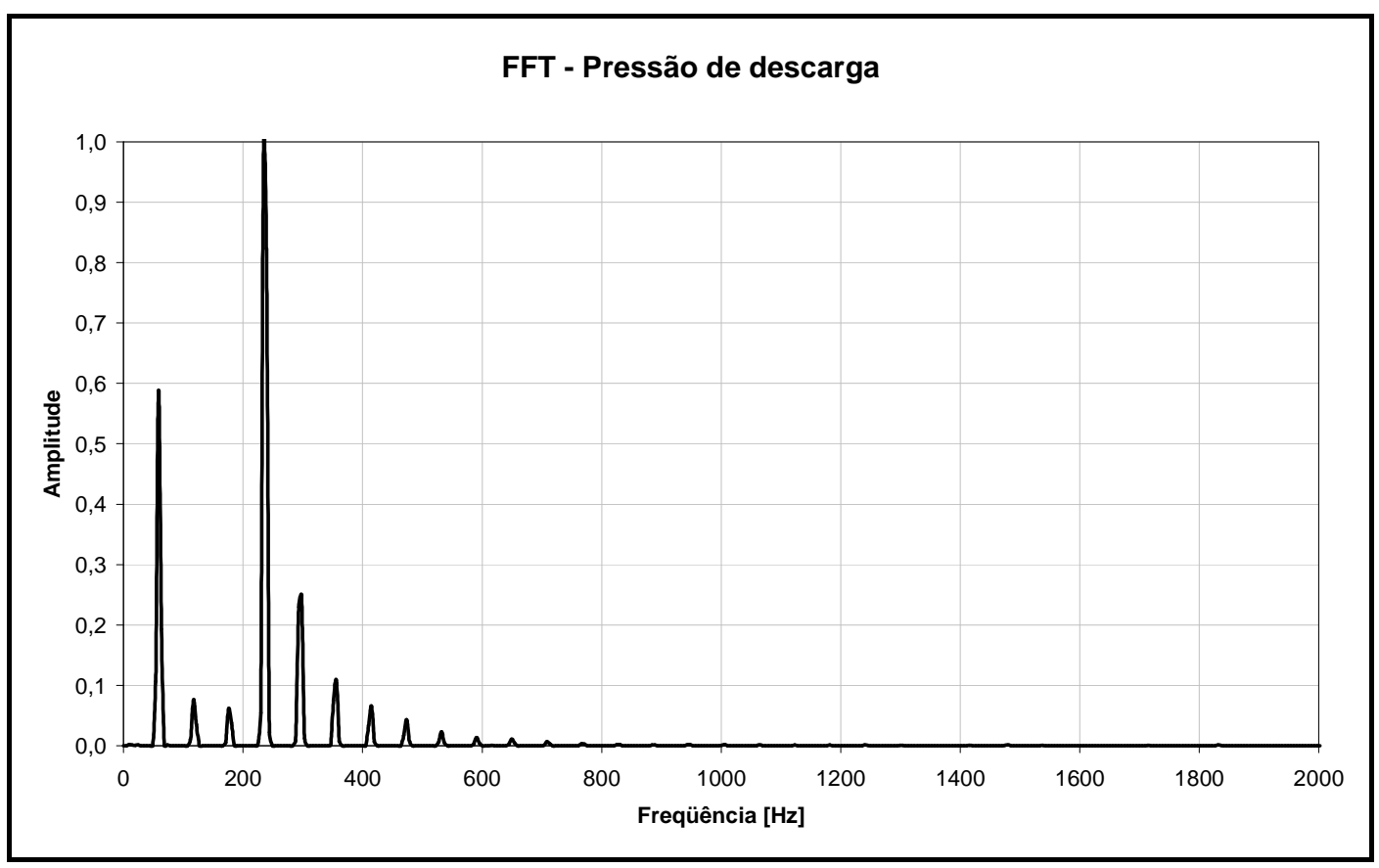

Figura 5.11 - FFT do sinal da pressão de descarga.

O resultado das medições realizadas nas pressões de sucção, cilindro e descarga mostraram-se bastante repetitivas. Tomando-se três medições distintas e sobrepondo-as em um gráfico, fica praticamente impossível 
distinguir a diferença entre as leituras, confirmando assim, a estabilidade do sistema de medida. Esse fato pode ser atribuído a escolha dos sensores de pressão e também pelo fato do compressor estar trabalhando em condições de pressão e temperatura controlada.

A figura 5.12 mostra a sobreposição das curvas de três leituras distintas em diferentes instantes de tempo durante o funcionamento do compressor em condições de teste pré-determinadas.

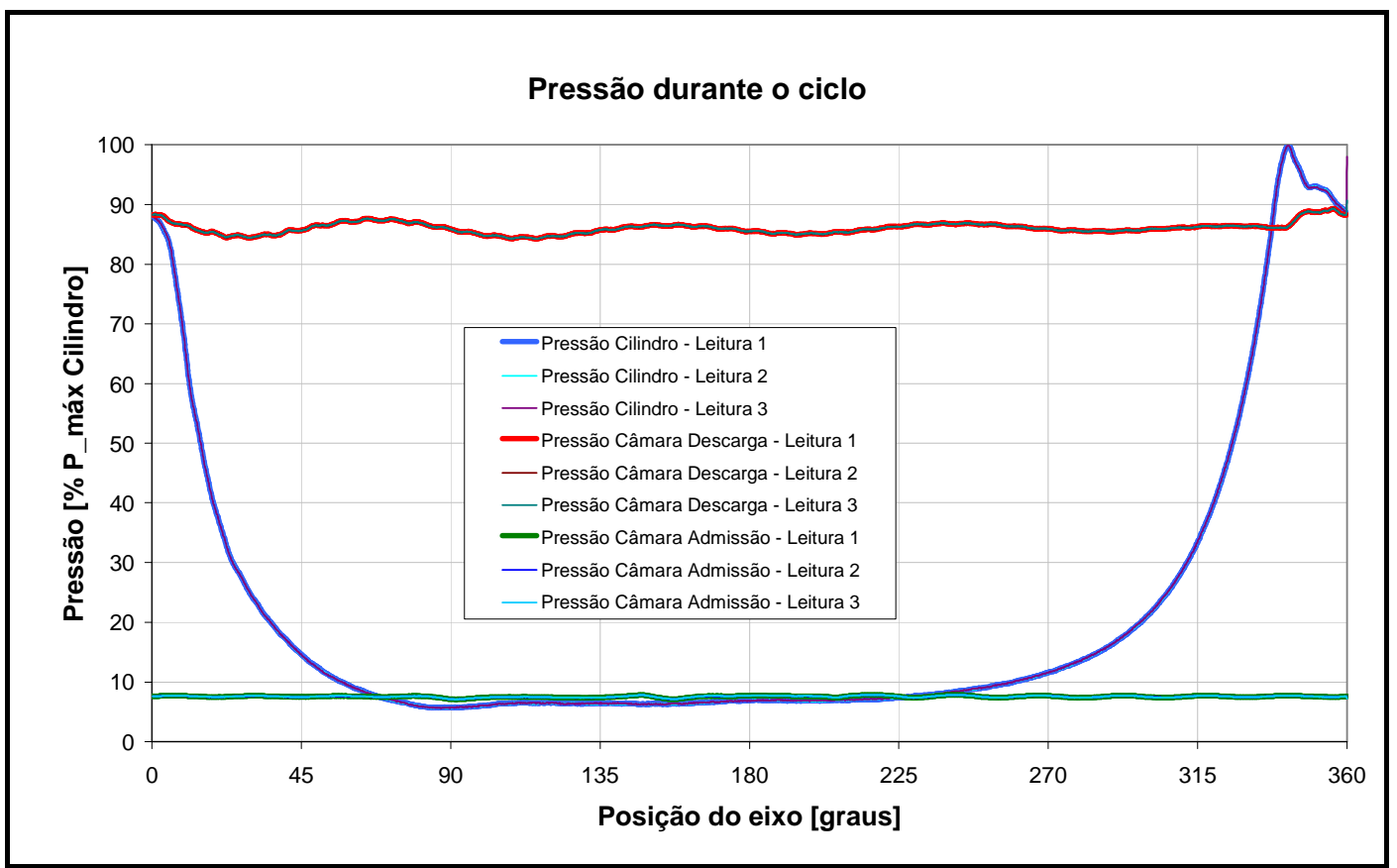

Figura 5.12 - Repetição das leituras do comportamento de pressão durante o ciclo.

\section{3 - COMPORTAMENTO DA VÁLVULA DE SUCÇÃo}

No compressor ensaiado, a válvula de sucção realiza três aberturas durante o ciclo com amplitudes distintas em cada abertura. $O$ fluido refrigerante é admitido para o cilindro do compressor durante essas aberturas. 
A Figura 5.13 mostra o comportamento da válvula de sucção durante o ciclo de compressão.

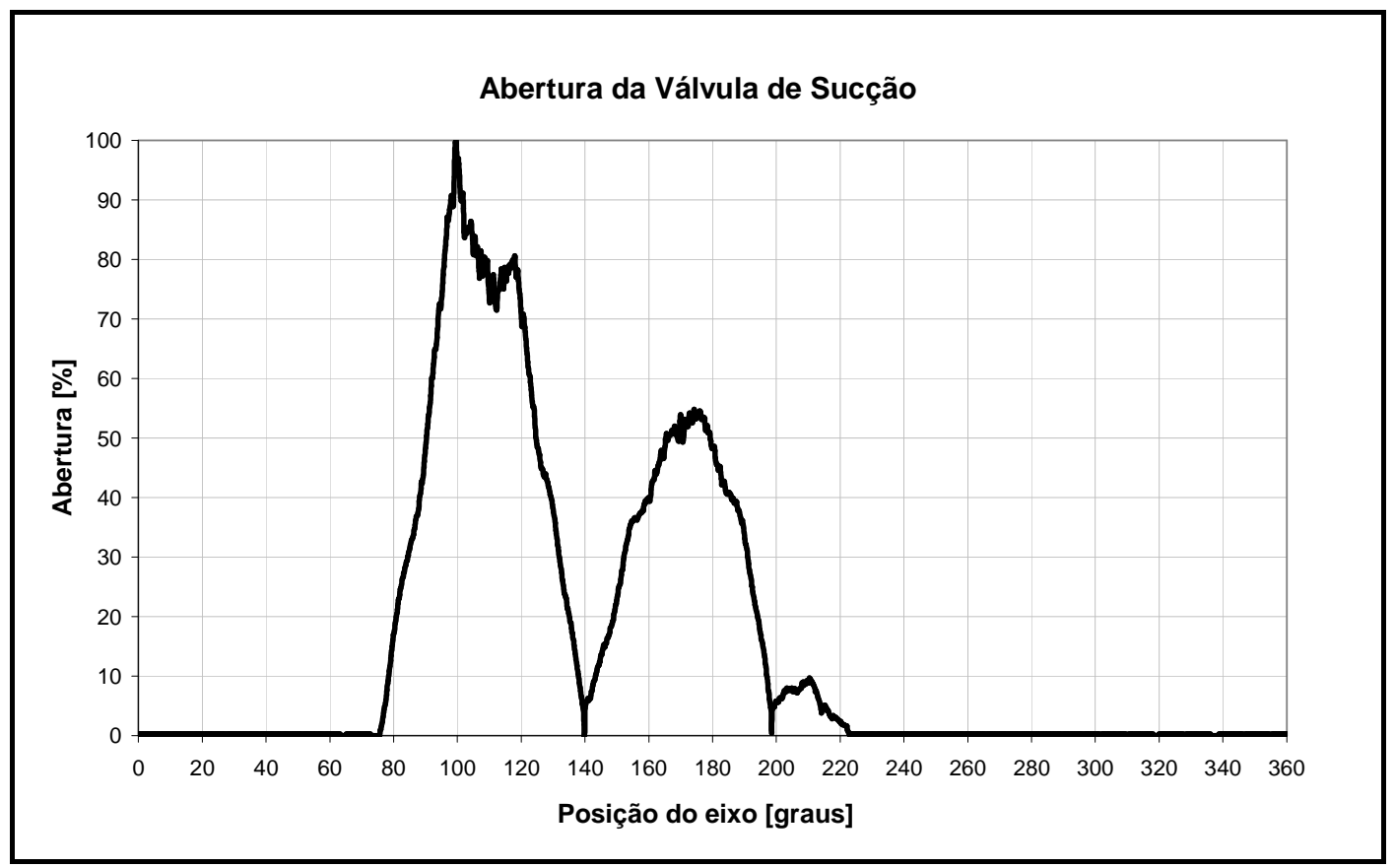

Figura 5.13 - Registro da abertura da válvula de sucção em relação a posição angular do eixo do compressor, durante um ciclo de compressão.

A posição adotada como zero grau, conforme descrita no capítulo 4 , refere-se ao ponto morto superior - menor distância entre o pistão e a placa válvula.

A máxima amplitude de abertura da válvula de sucção durante o ciclo ocorre na primeira abertura da lâmina. As amplitudes das aberturas subseqüentes são, respectivamente, 46 e $90 \%$ menores que a primeira. A máxima amplitude de abertura da válvula é somente atingida uma única vez dentro do ciclo.

A informação sobre o tempo de abertura da válvula de admissão também podem ser extraída dos dados experimentais, conforme mostra a figura 5.14 . 
Tempo de Abertura da Válvula de Sucção

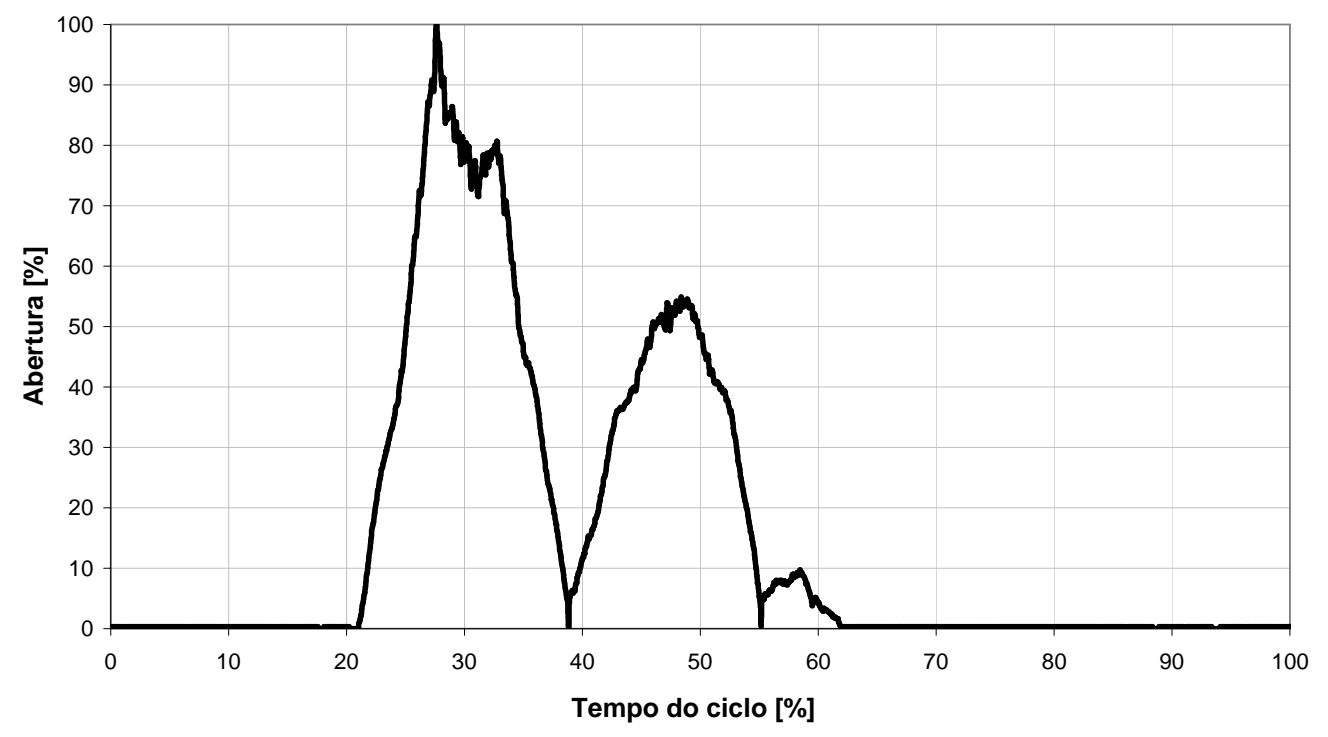

Figura 5.14 - Abertura da válvula de sucção em função do tempo, durante uma revolução.

A válvula de sucção permanece aberta durante aproximadamente $40 \%$ do ciclo.

As duas primeiras aberturas da válvula de sucção são responsáveis por aproximadamente $87,5 \%$ do tempo total de abertura da lâmina. Uma parcela menos significativa, a exemplo da amplitude, está representada pela terceira abertura da válvula.

O flutter da válvula de sucção - movimentos desordenados de abertura e fechamento da válvula - não foi encontrado. Quando os movimentos de abertura da válvula de sucção foram ampliados, observou-se pequenas oscilações de baixa amplitude causadas pela vazão do fluido refrigerante ao passar pela válvula. Esses movimentos da válvula não são suficientemente grandes para caracterizar tal fenômeno e também para perturbar o perfil das pressões de admissão e do cilindro.

A figura 5.15 apresenta um trecho ampliado da abertura da válvula de sucção ilustrando as oscilações encontradas durante um ciclo. 


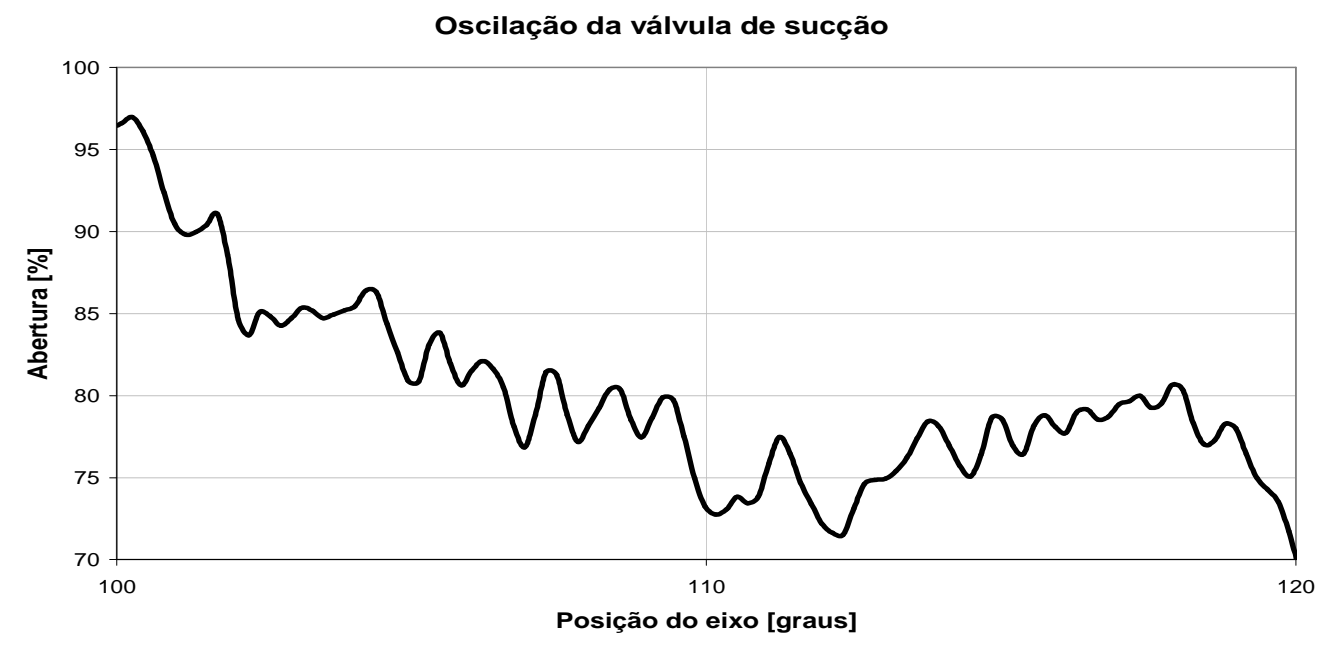

Figura 5.15 - Trecho ampliado que ilustra as oscilações da válvula de sucção na admissão.

Observando a primeira abertura da válvula de sucção entre 100 e 120 graus, as oscilações mensuradas apresentam uma amplitude de aproximadamente 5\% em relação a máxima abertura da lâmina.

O diferencial de pressão necessário para que a válvula de sucção fosse acionada também foi outra característica importante, possível de se quantificar.

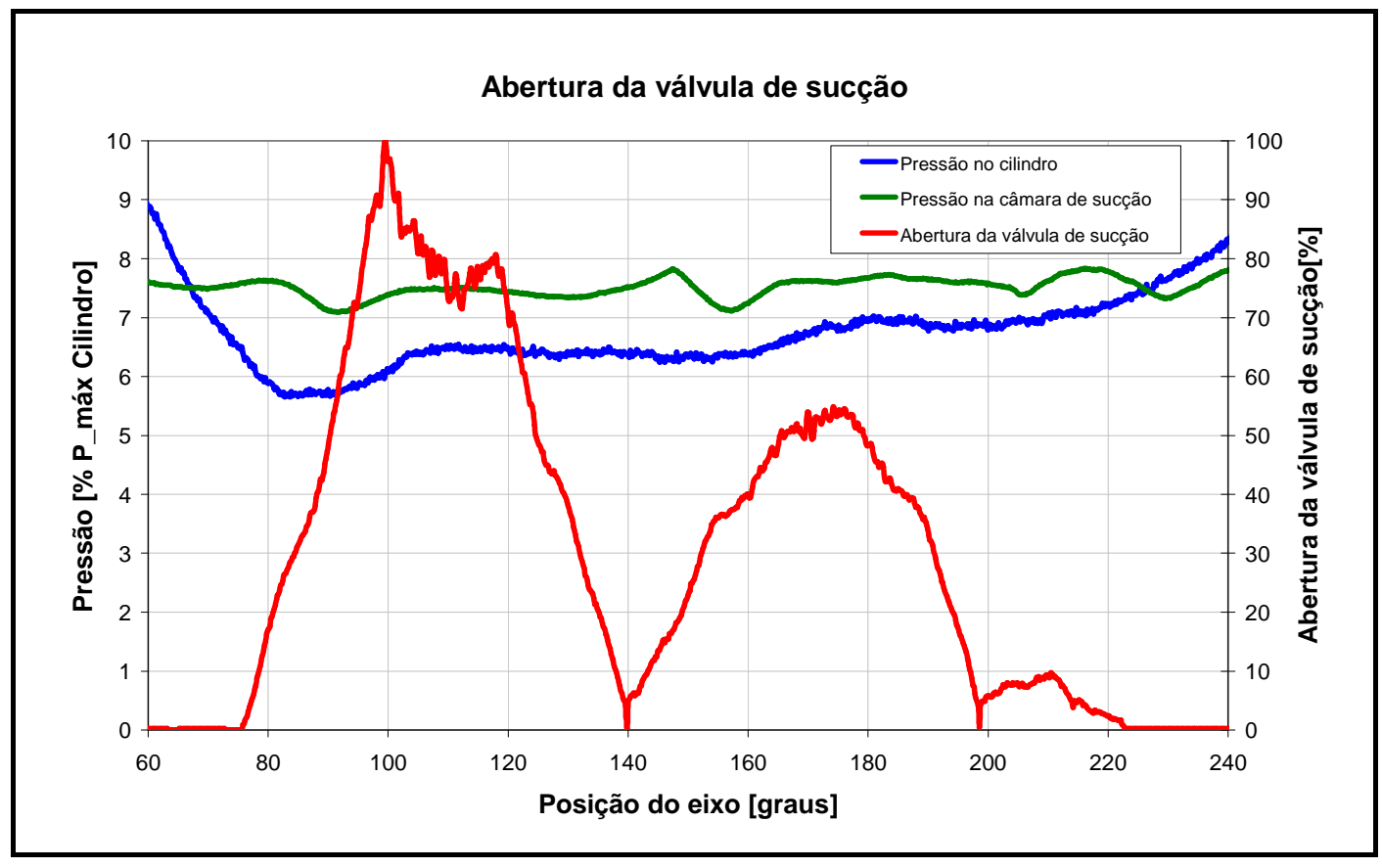

Figura 5.16 - Comportamento das pressões durante abertura da válvula de sucção. 
$\mathrm{Na}$ figura 5.16, pode-se observar o diferencial de pressão que a válvula está submetida no instante da abertura. Neste momento existe uma pequena diferença entre a pressão dentro do cilindro e a pressão na câmara de sucção, aproximadamente de $1 \%$ da máxima atingida no cilindro.

A figura 5.16 mostra ainda que a pressão dentro do cilindro é sempre menor que a pressão de admissão durante o tempo que a válvula de sucção permanece aberta. Com o fechamento da válvula de sucção, a pressão dentro do cilindro passa a ser maior que a de admissão. Pode-se observar também, que as oscilações verificadas na figura 5.15 não comprometem o comportamento das pressões do cilindro e da sucção.

Uma análise no domínio da freqüência foi feita para a abertura da válvula de admissão, através da Transformada de Fourier (FFT), conforme ilustrado na figura 5.17 .

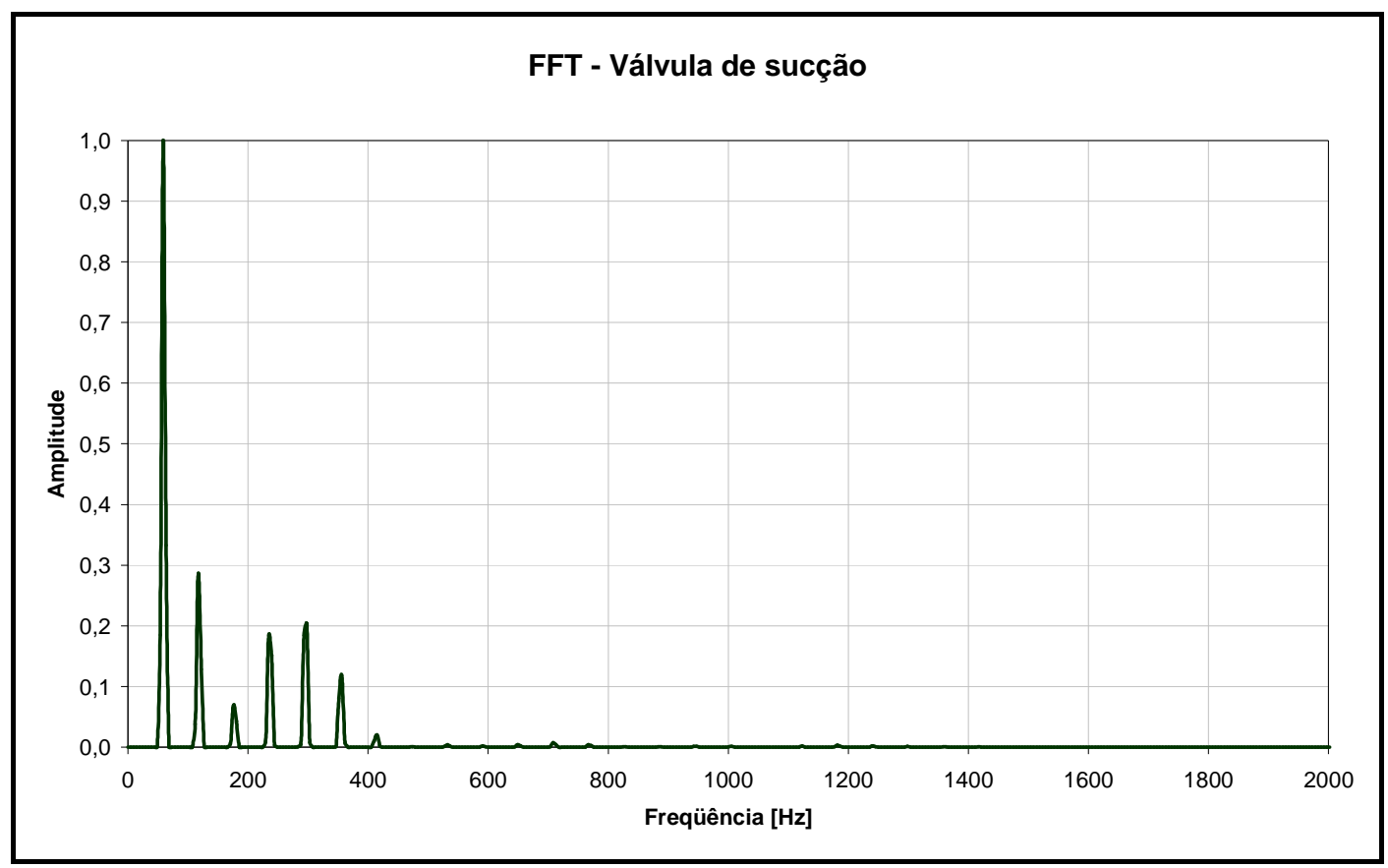

Figura 5.17 - Transformada de Fourier da abertura da válvula de sucção.

Com a taxa de aquisição de $80.000 \mathrm{~Hz}$, foram coletados 10 ciclos completos da abertura da válvula de sucção que foram utilizados para calcular a densidade espectral de potência do sinal ("Power Spectrum Density - PSD"), através da Transformada rápida de Fourier e com auxílio do software labview®. 
É observado na figura 5.17 que as amplitudes mais significantes estão nas freqüências de até $400 \mathrm{~Hz}$.

A análise em freqüência pode ser uma ferramenta muito importante na determinação de fontes de ruído dos compressores. Se ao analisar o espectro sonoro de um compressor hermético for encontrada uma componente em freqüência significativa que se relaciona com uma das freqüências da válvula de sucção ou de descarga, isto pode indicar que as válvulas podem estar contribuindo negativamente na qualidade sonora do equipamento.

As medidas realizadas na válvula de sucção apresentaram boa repetibilidade. A figura 5.18 apresenta a sobreposição de três leituras da abertura da válvula, em instantes distintos, mostrando a repetibilidade das medidas.

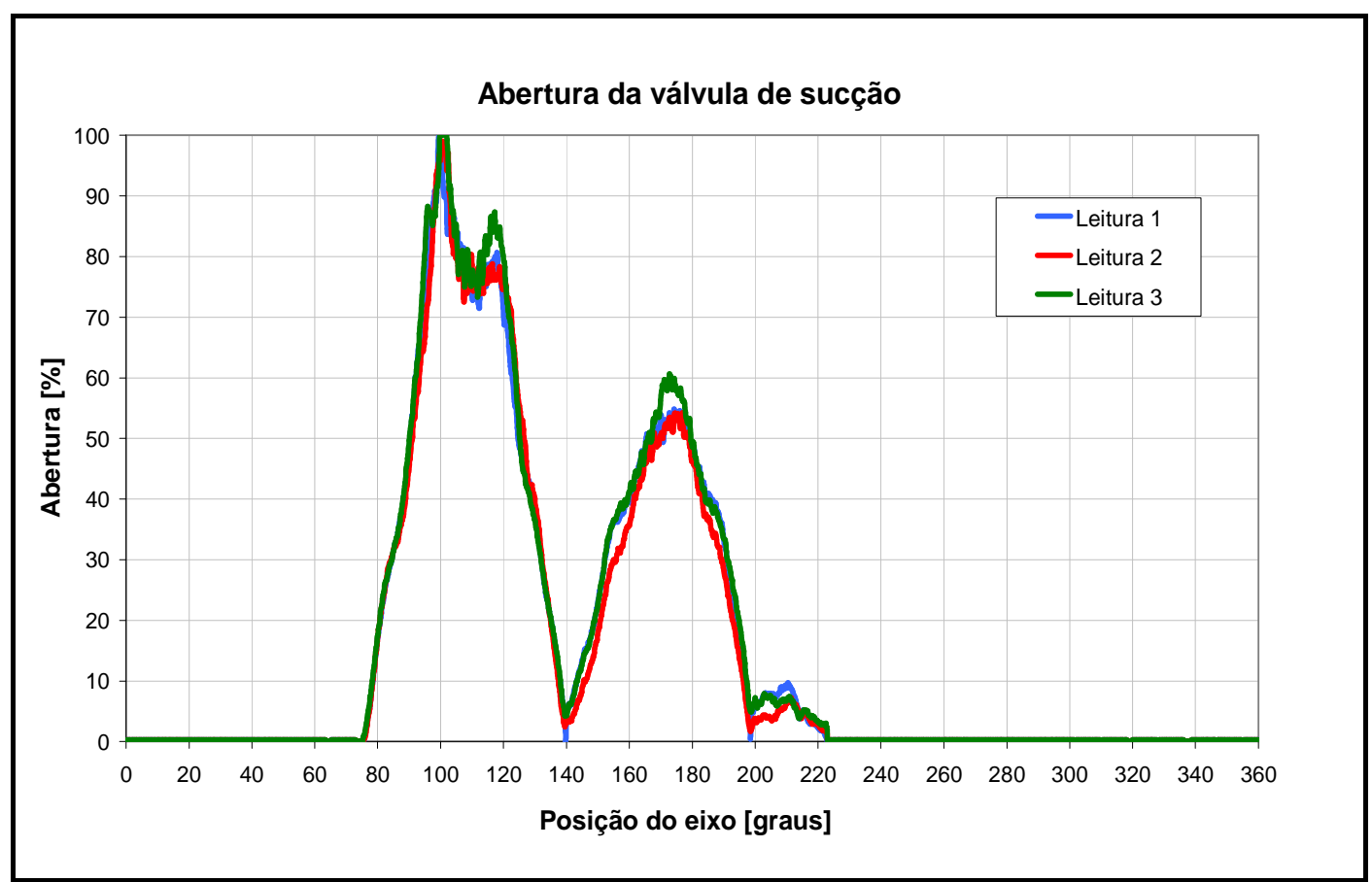

Figura 5.18 - Repetibilidade das leituras da abertura da válvula de sucção. 


\section{4 - COMPORTAMENTO DA VÁLVULA DE DESCARGA.}

A válvula de descarga realiza apenas uma abertura durante o ciclo de compressão. A amplitude máxima de abertura está limitada à distância da válvula ao retentor. A figura 5.19 mostra o comportamento da válvula de descarga durante um ciclo do funcionamento do compressor.

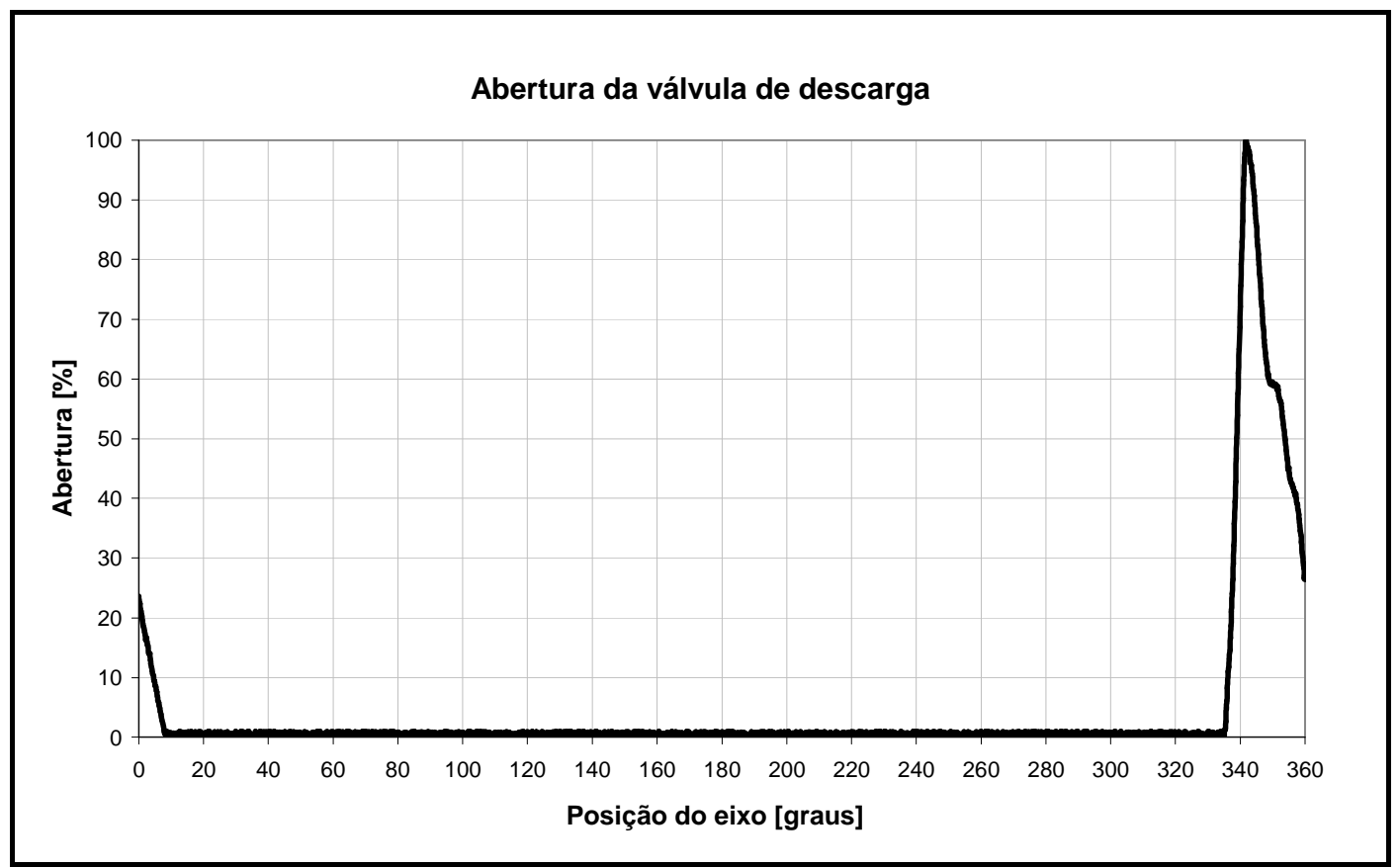

Figura 5.19 - Abertura da válvula de descarga em relação a posição angular do eixo do compressor durante um ciclo.

O início da abertura da válvula de descarga ocorre em um ponto bem determinado e está próxima da posição do ponto morto superior, aproximadamente 335 graus. O tempo de abertura da válvula é muito curto, aproximadamente $9 \%$ do tempo total do ciclo, permanecendo plenamente fechada durante resto do ciclo. A figura 5.20 mostra o tempo de abertura da válvula de descarga. 


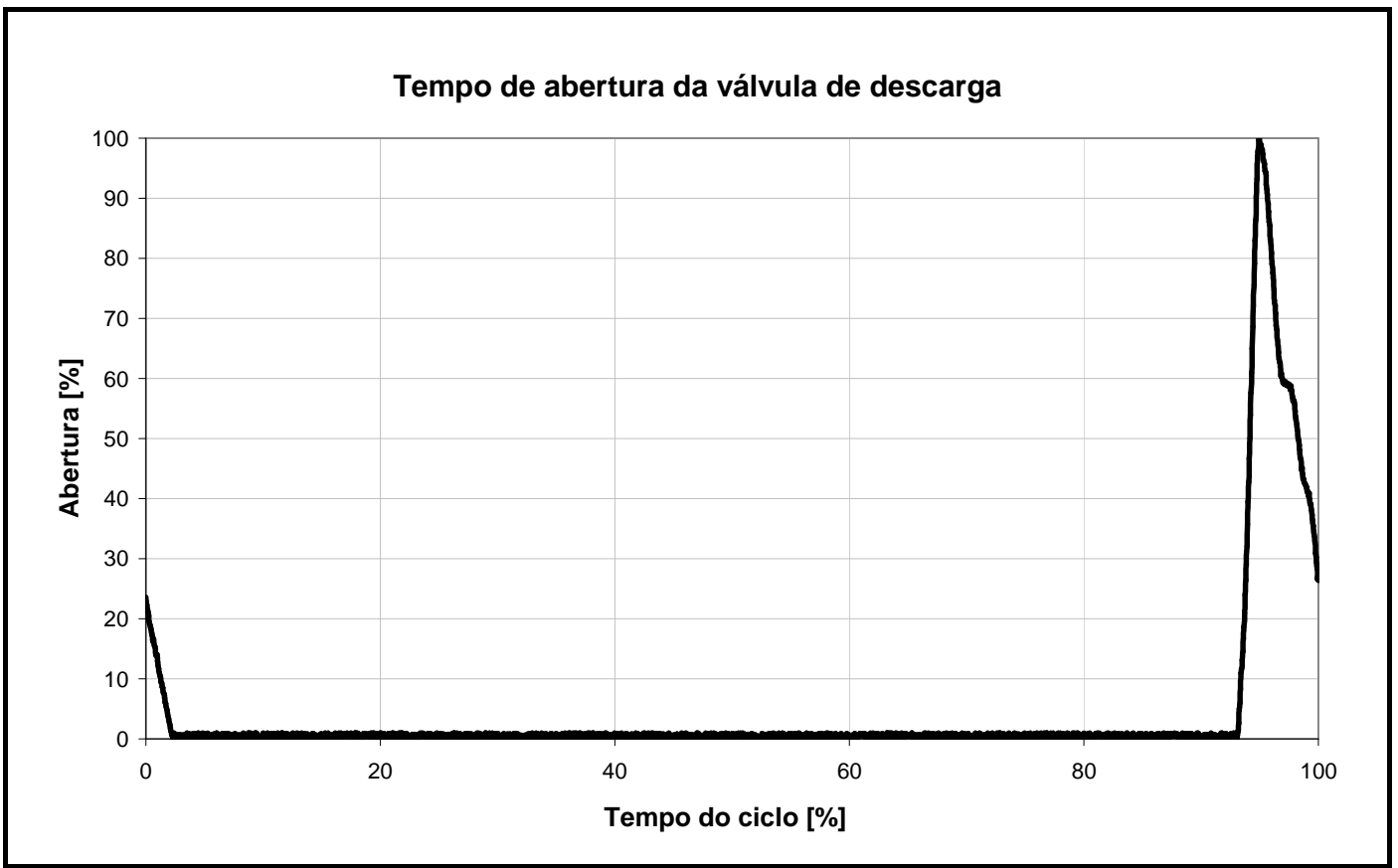

Figura 5.20 - Abertura da válvula de descarga em função do tempo, durante um ciclo.

Não foi observado o flutter da válvula de descarga, a exemplo da válvula de sucção. As oscilações encontradas na válvula de sucção não apareceram na válvula de descarga, conforme pode ser visto na figura 5.21.

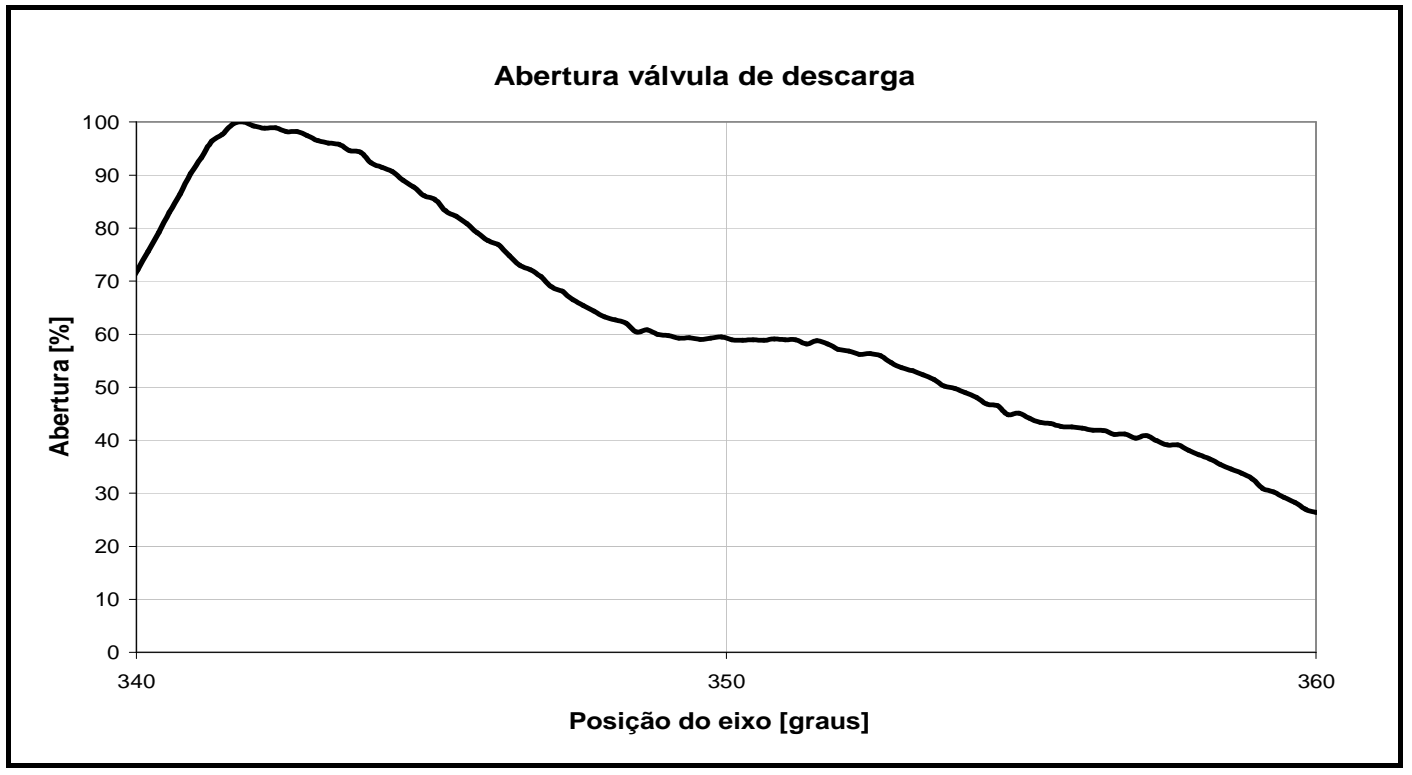

Figura 5.21 - Trecho ampliado ilustrando a ausência de oscilações na válvula de descarga. 
O diferencial de pressão necessário para o inicio da abertura da válvula de descarga é semelhante ao diferencial da válvula de sucção, aproximadamente $1 \%$ do valor máximo da pressão do cilindro. A figura 5.22 mostra em detalhes o movimento de abertura da válvula de descarga e as variações das pressões no cilindro e na câmara de descarga.

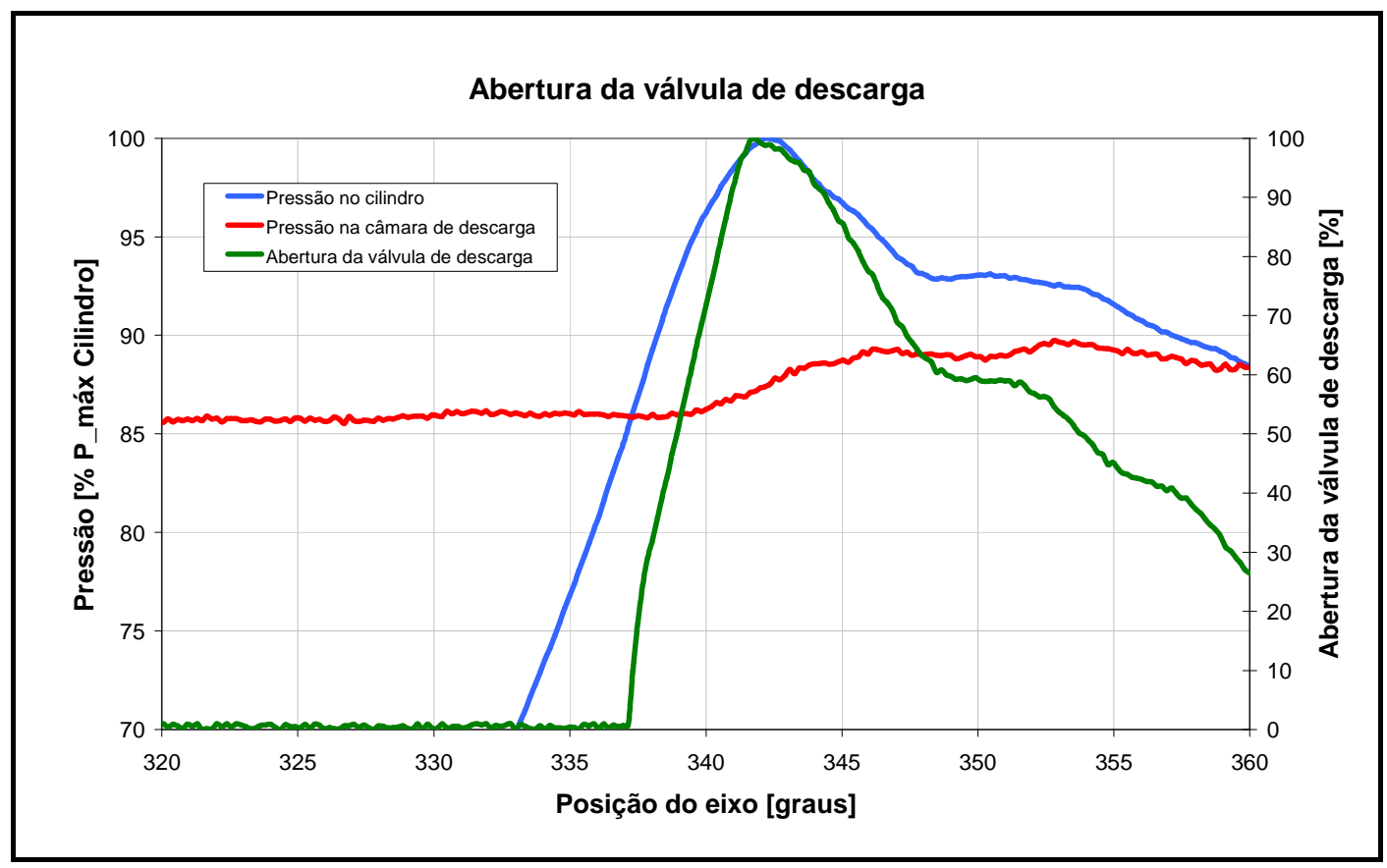

Figura 5.22 - Comportamento das pressões durante a abertura da válvula de descarga, em um ciclo

Pode-se observar que a abertura total da válvula se dá em aproximadamente 5 graus do eixo de rotação do compressor, entre 337 e 342 graus com relação à referência. Dessa forma, é possível conhecer o tempo que a válvula levou para realizar sua abertura total. A pressão na câmara de descarga começa a aumentar após 3 graus de rotação do eixo em relação ao inicio da abertura da válvula. Isso pode ser justificado pelo volume da câmara de descarga do compressor e também pela pequena abertura da válvula durante este período. Com a abertura total da válvula de descarga pode-se verificar uma queda na pressão no cilindro, e neste momento, a pressão dentro da câmara de descarga é elevada próximo ao seu nível máximo. A válvula de descarga permanece aberta por um curto intervalo de tempo. 
Uma análise no domínio da freqüência também foi feita para a válvula de descarga, através da Transformada de Fourier (FFT), conforme ilustrado na figura 5.23 .

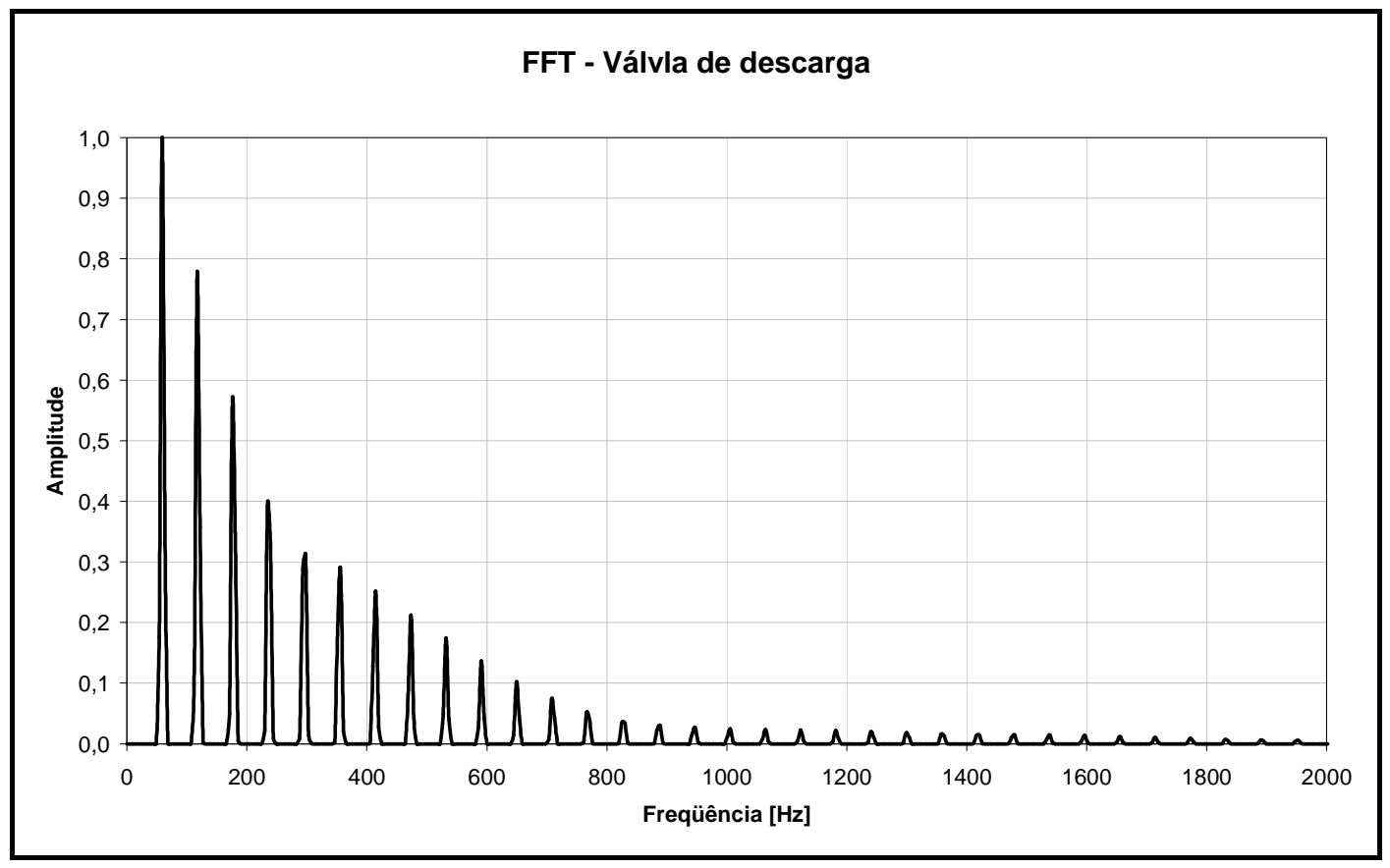

Figura 5.23 - FFT da abertura da válvula de descarga.

Foram coletados 10 ciclos completos da abertura da válvula de sucção com uma freqüência de aquisição de $80.000 \mathrm{~Hz}$. Os dados foram utilizados para calcular a densidade espectral de potência do sinal com auxílio do software labview $\AA^{\circledR}$.

O resultado das medições realizadas na válvula de descarga mostrou-se bastante repetitivo, a exemplo do que foi visto na válvula de sucção. Tomandose três leituras distintas e sobrepondo-as em um gráfico, fica praticamente impossível distinguir a diferença entre as leituras, confirmando a confiança nos resultados encontrados. Esse fato pode ser atribuído à correta escolha dos sensores de deslocamento e também pelo fato do compressor estar trabalhando em condições controladas. A figura 5.24 mostra a sobreposição das curvas de três leituras distintas. 


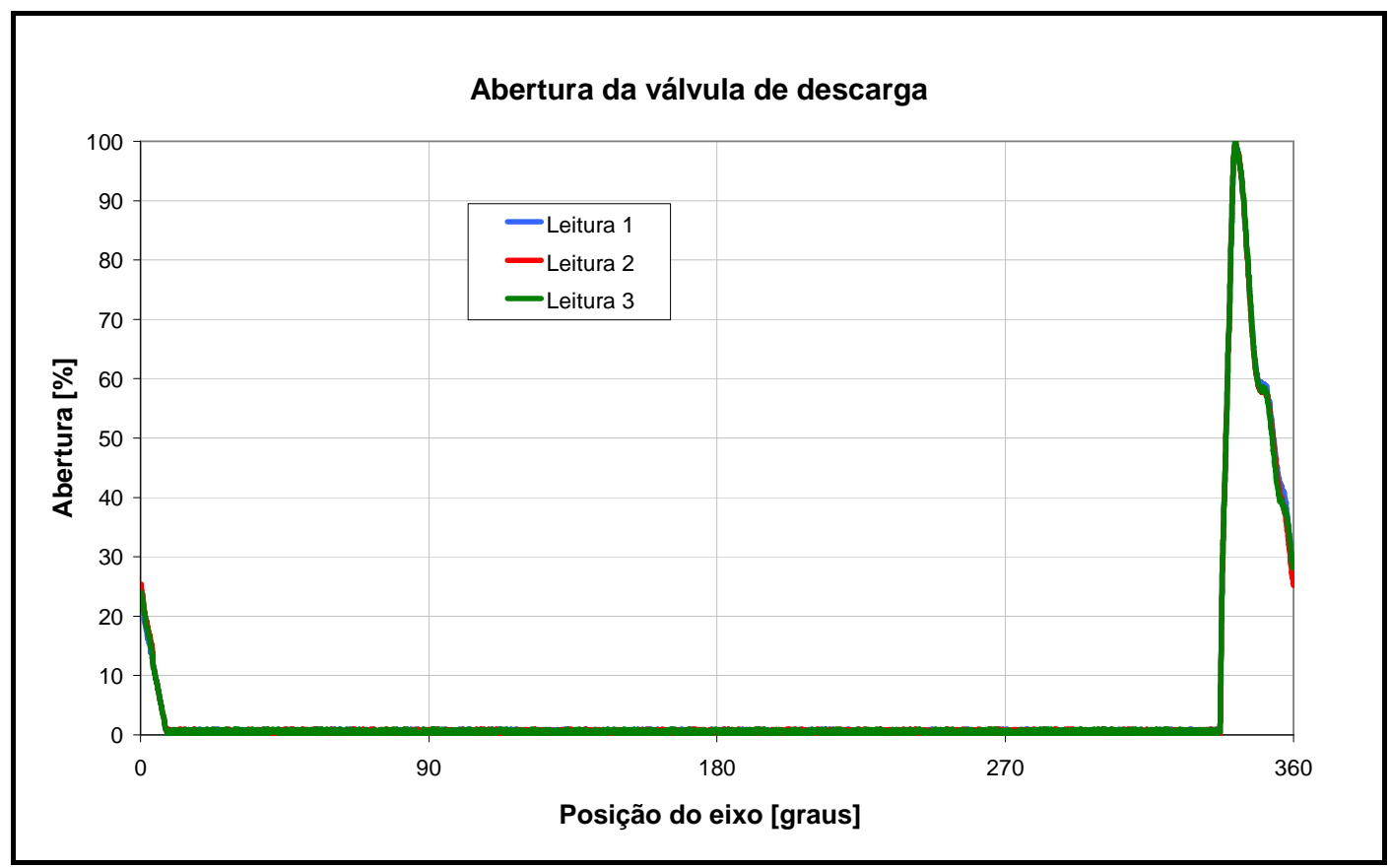

Figura 5.24 - Repetibilidade das leituras da abertura da válvula de descarga.

\section{5 - TEMPERATURA DURANTE O CICLO.}

As medidas de temperatura em determinadas regiões dos compressores herméticos são utilizadas em cálculos para se determinar sua eficiência e também como entrada para determinação de parâmetros físicos, tais como, velocidade do som no fluido refrigerante, viscosidade e densidade. Não é objetivo dessa dissertação realizar cálculos de eficiência do compressor, mas sim desenvolver uma técnica que permita a obtenção dos dados que serão empregados para essa finalidade.

A temperatura média do compressor durante o funcionamento é um dos parâmetros que podem ser extraídos desse trabalho. As temperaturas registradas durante o ciclo compressão, em condições pré-determinadas conforme item 5.1, estão apontadas na figura 5.25. 
TEMPERATURA MÉDIA DO COMPRESSOR HERMÉTICO EM FUNCIONAMENTO

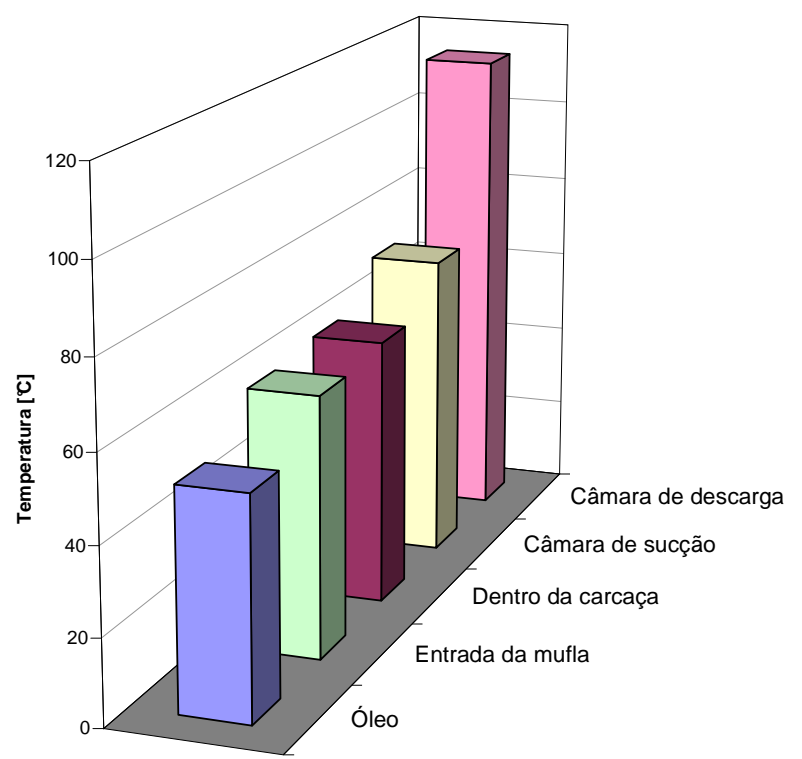

Figura 5.25 - Temperatura do compressor hermético em funcionamento representado em gráfico de barras.

Pode-se verificar que a temperatura na câmara de descarga do compressor é uma das regiões mais quentes durante seu funcionamento. Outra região também bastante aquecida durante o ciclo é o cilindro, que recebe o gás refrigerante vindo da câmara de sucção e o entrega à câmara de descarga. Pode-se afirmar que a temperatura no cilindro durante a compressão, no momento em que a válvula de descarga é aberta, é igual ou superior a registrada na câmara de descarga, uma vez que o fluido que chega a esta câmara foi entregue pelo cilindro. Esta grandeza não foi monitorada para se evitar vazamento de gás durante a compressão e também pelo fato do termopar não possuir resposta rápida às variações de temperatura. Assim, se fosse instalado um termopar no cilindro do compressor, tudo indica que seria obtido a temperatura média do cilindro durante o ciclo, a exemplo das demais temperaturas monitoradas. 


\section{6 - VARIAÇÃO DE ROTAÇÃO NO CICLO.}

Em geral, a rotação dos compressores herméticos está diretamente relacionada com a freqüência da rede de alimentação. Nos compressores utilizados no mercado brasileiro, a freqüência de alimentação é de $60 \mathrm{hz}$, ou seja, 3600 ciclos por minuto. A cada mudança de polaridade da alimentação do motor elétrico ocorre a inversão do pólo do magnético da bobina do compressor ocasionando um giro completo no rotor. Desta forma, o compressor livre de carga deve trabalhar próximo da rotação de $3600 \mathrm{rpm}$. Esta é a ordem de grandeza da velocidade média de rotação dos compressores herméticos, pois durante o ciclo de compressão esta velocidade não permanece constante. Com o motor sem carga a variação de velocidade é desprezível, mas com o aumento da diferença de pressão entre a linha de sucção e a linha de descarga (carregamento) a velocidade média do compressor diminui e as variações de velocidade passam a ser significativas, conforme foi verificado por McConnell e Cohen (1972). Durante a admissão do fluido refrigerante para dentro do cilindro existe um aumento na velocidade do eixo, fato contrário ao observado durante compressão do fluido, que ocorre a diminuição da velocidade devido a pressão presente no topo do pistão.

O estudo da variação de velocidade durante o ciclo de compressão foi realizado manipulando os dados do sinal do sensor de deslocamento angular. Este método consistiu em medir a variação de tempo, $(\Delta t)$, entre dois pulsos consecutivos do sensor de deslocamento angular $(\Delta \Theta)$. Dessa forma, tendo a variação da posição angular pela variação de tempo , foi possível determinar a velocidade instantânea no trecho representado por esses traços do encoder.

A figura 5.26 ilustra o método empregado. 


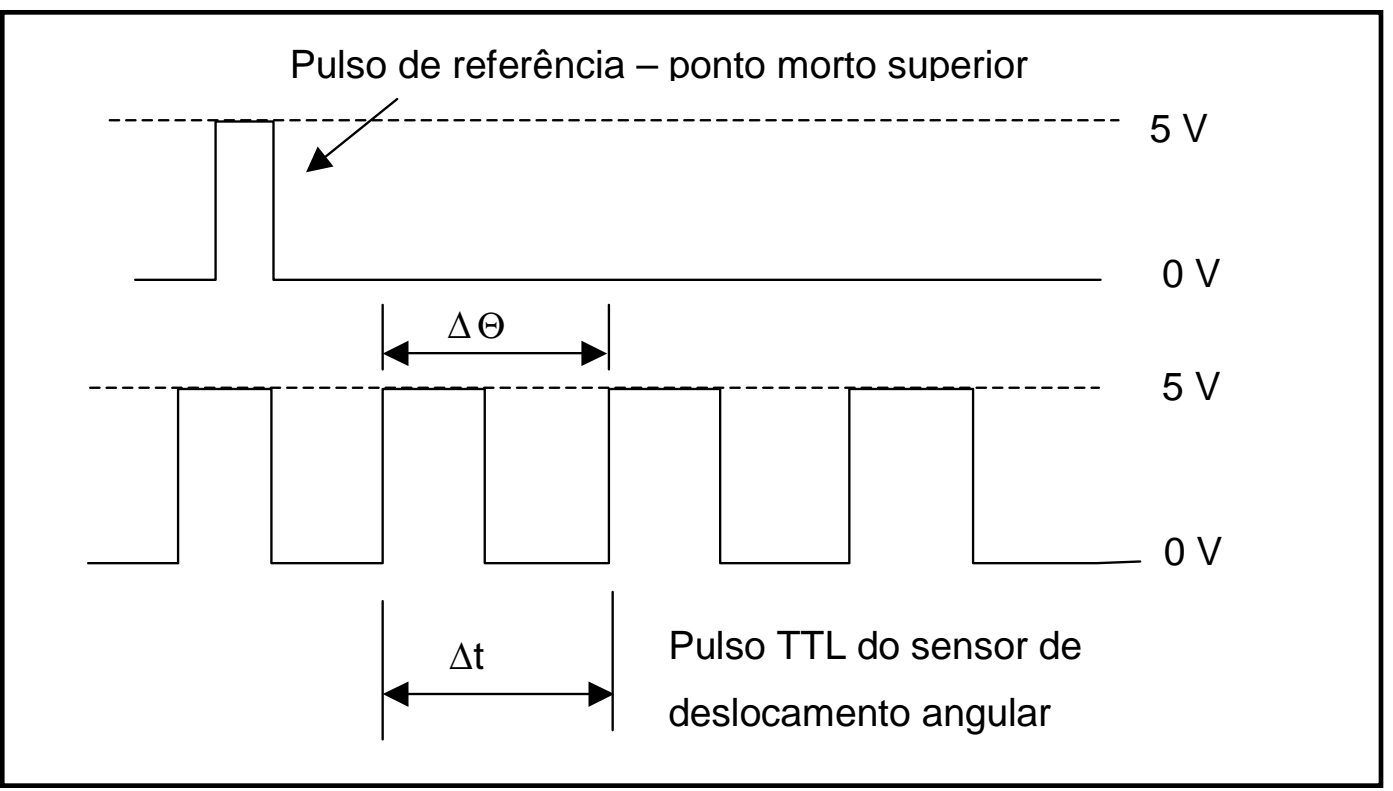

Figura 5.26 - Método empregado para determinar velocidade do eixo de rotação.

A variação do ângulo do eixo de rotação, $\Delta \Theta$, é determinada pelo número de traços que o sensor de deslocamento possui :

$$
\Delta(\Theta)=\frac{n}{n_{t}} \times 360^{\circ}
$$

Onde:

$n=$ número de traços lidos;

$n_{t}=$ número de traços total de traços do encoder.

$\mathrm{Na}$ instrumentação utilizada foi empregado um sensor de deslocamento angular com 2000 traços, portanto a menor variação de posição angular está em $1 / 2000$, ou seja, 0,18 .

Para determinar a variação do tempo entre os pulsos, o sinal do sensor de deslocamento angular foi amostrado com a máxima taxa permitida pela placa de aquisição de dados, 1,25 Mhz. Isto implica que o nível de tensão do sinal foi adquirido com um intervalo de tempo de $8 \times 10^{-7}$ segundos. Considerando a rotação do compressor de $60 \mathrm{rps}$, o tempo total do ciclo de giro é de $1 / 60$ segundos $(0,01667$ s). Se empregado um encoder de 2000 traços, o 
período entre os traços corresponde à $0,01667 / 2000$, ou seja, $8,335 \times 10^{-6}$ segundos. Dessa forma, o pulso referente ao movimento de $0,18^{\circ}$ seria digitalizado por aproximadamente 11 pontos. A figura 5.27 mostra um exemplo da digitalização de $0,18^{\circ}$ do ciclo de compr essão.

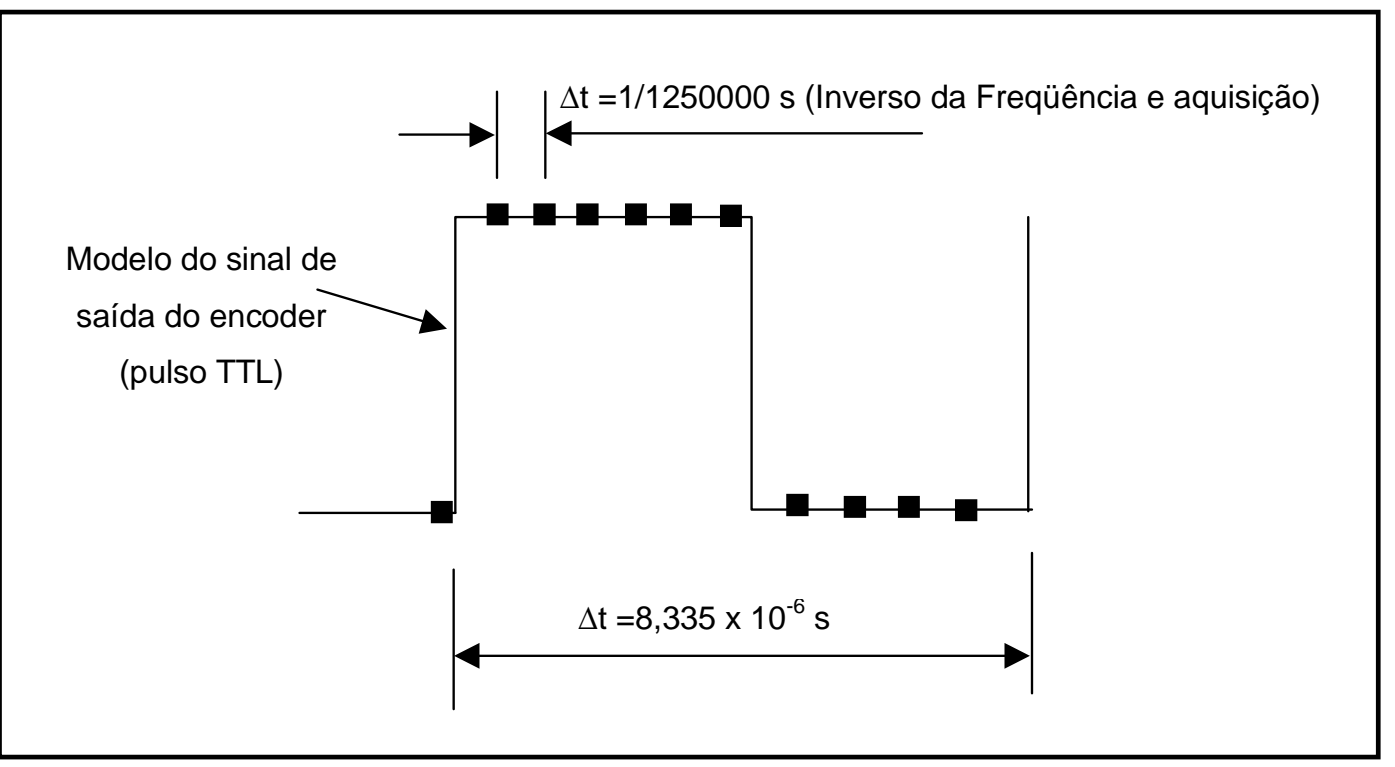

Figura 5.27 - Discretização do sinal do encoder ( sensor de deslocamento angular).

Pode-se notar que o máximo erro entre detectar o nível baixo e o nível alto do sinal do sensor é da ordem de $8 \times 10^{-7}$ segundos, ou seja, $1 / 11$ do tempo do pulso, isso implica em um erro de $9 \%$ no valor da velocidade lida.

Para minimizar o erro foi mensurado o tempo de 20 pulsos, ou seja, um ponto de velocidade a cada $3,6^{\circ}$. Assim, como o erro entre detectar o nível alto e o baixo do pulso continua sendo de $8 \times 10^{-7}$ segundos, o erro no tempo total passa a ser $1 /(11 \times 20)$, que significa um erro de $0,45 \%$ no valor da velocidade média medida dentro do intervalo de $3,6^{\circ}$.

O erro poderia ser ainda menor se aumentado o número de pulsos a serem medidos, mas com esse procedimento seria medido a velocidade média de trechos de deslocamentos angulares muito distantes. Isso prejudicaria a qualidade da informação dinâmica sobre a variação da velocidade durante um ciclo.

Para verificar a variação de rotação, foram utilizados 100 pontos distintos e interpolada uma curva. O resultado está apresentado na figura 5.28. 


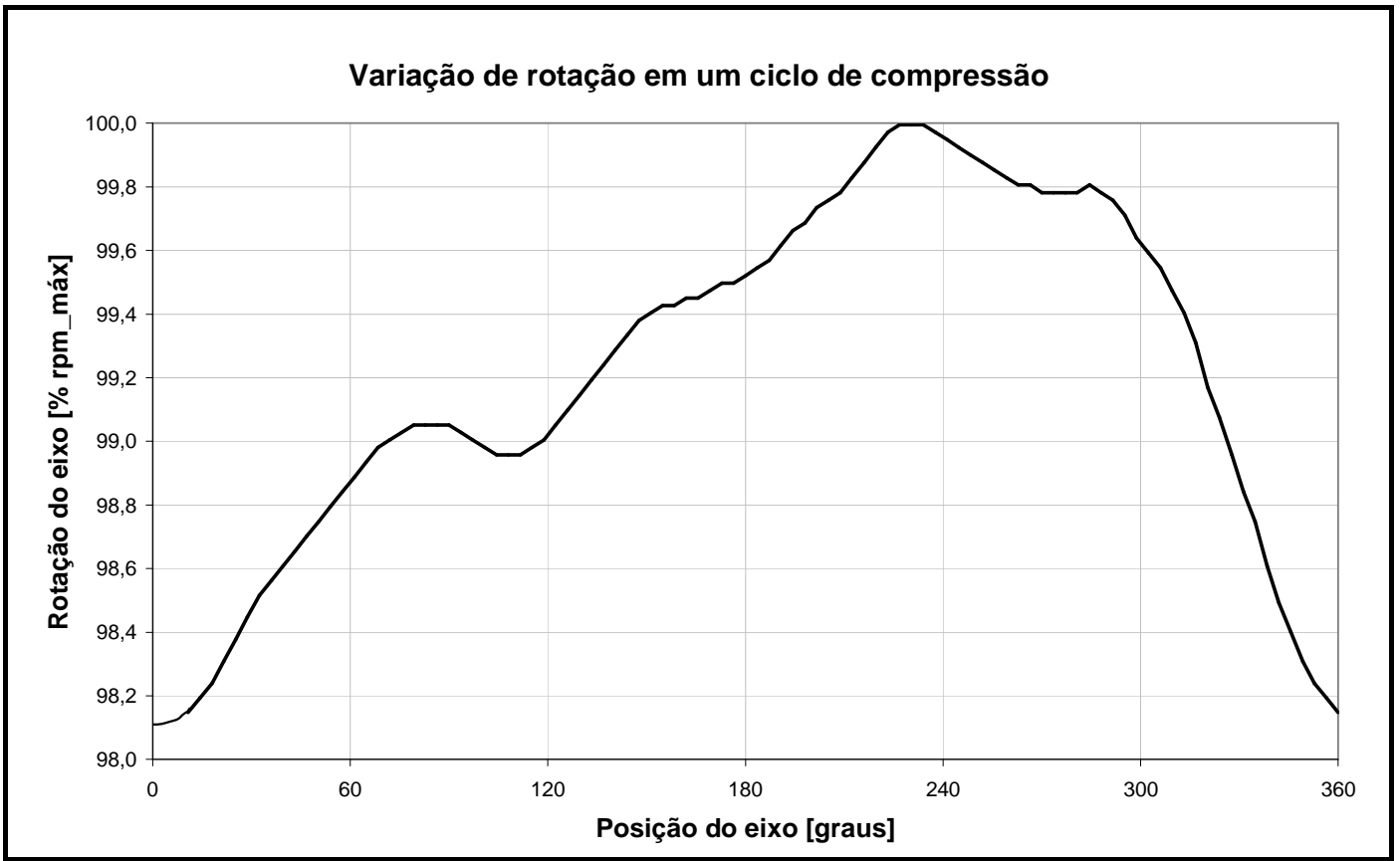

Figura 5.28 - Variação da rotação durante o ciclo de compressão.

A figura 5.29 mostra a variação de rotação e a pressão do cilindro.

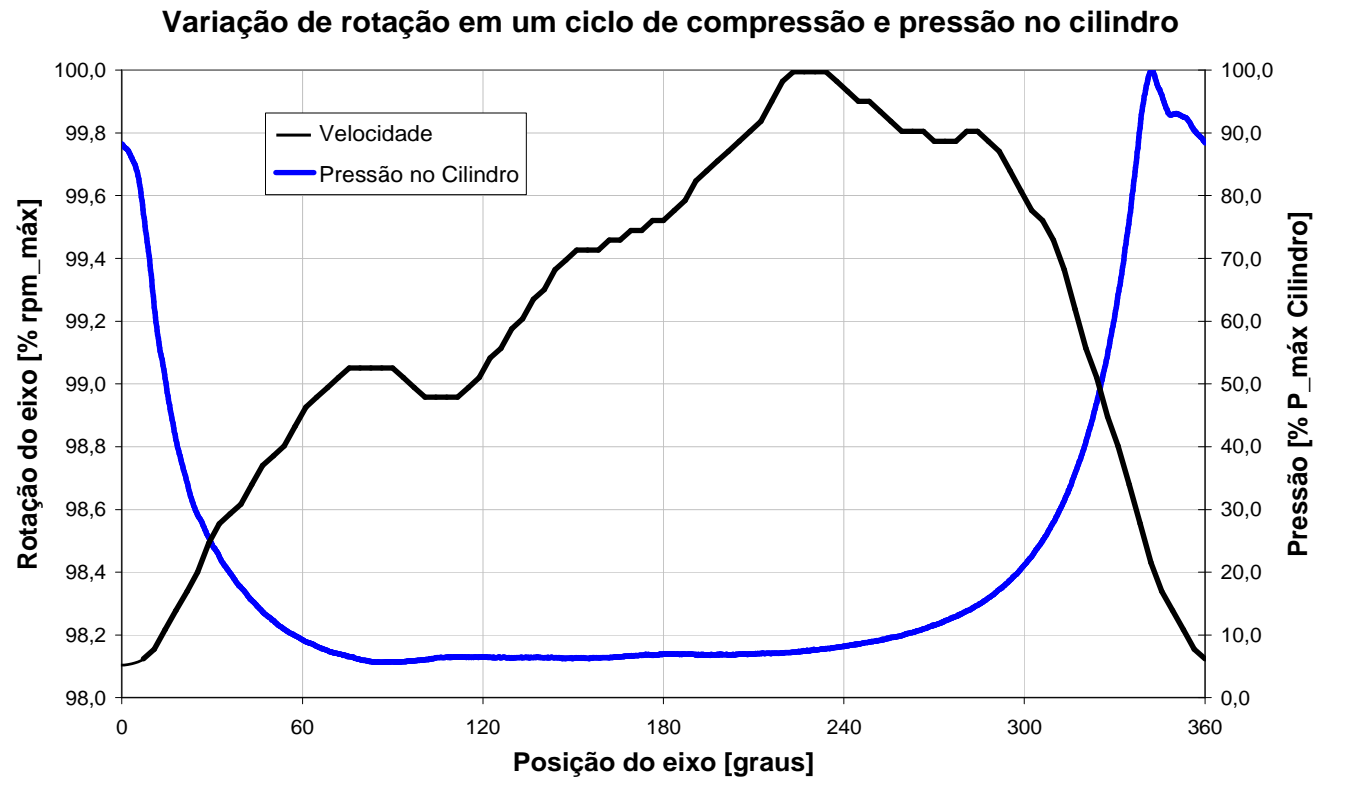

Figura 5.29 - Variação da rotação e pressão no cilindro durante um ciclo. 
A figura 5.30 mostra a variação de rotação e o deslocamento do pistão.

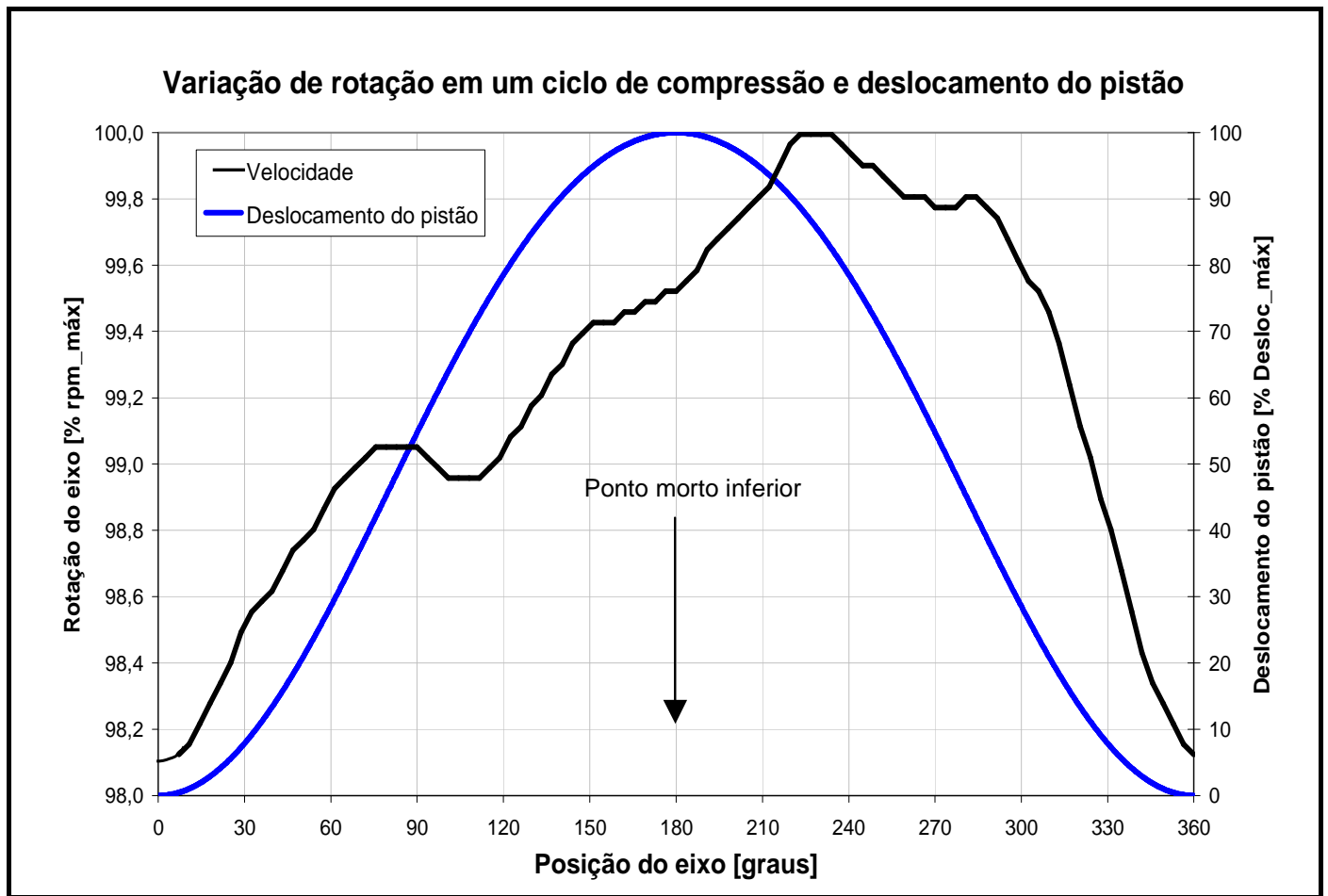

Figura 5.30 - Variação da rotação e deslocamento do pistão durante um ciclo.

Pode-se verificar que a rotação aumenta com o retorno do pistão, instante em que a pressão dentro do cilindro diminui. A sua rotação é máxima após a posição de ponto morto inferior - maior distância entre o pistão e a placa válvula - aproximadamente a 235 graus. Com avanço do pistão, em direção à placa válvula, ocorre o aumento da pressão dentro do cilindro que ocasiona uma diminuição na rotação do compressor, até chegar ao ponto morto superior, momento que a rotação é mínima.

Aplicando este método para determinação da variação de rotação, constata-se boa repetibilidade nos dados.

A figura 5.31 mostra a sobreposição das curvas de três leituras distintas em diferentes ciclos durante o funcionamento do compressor. 


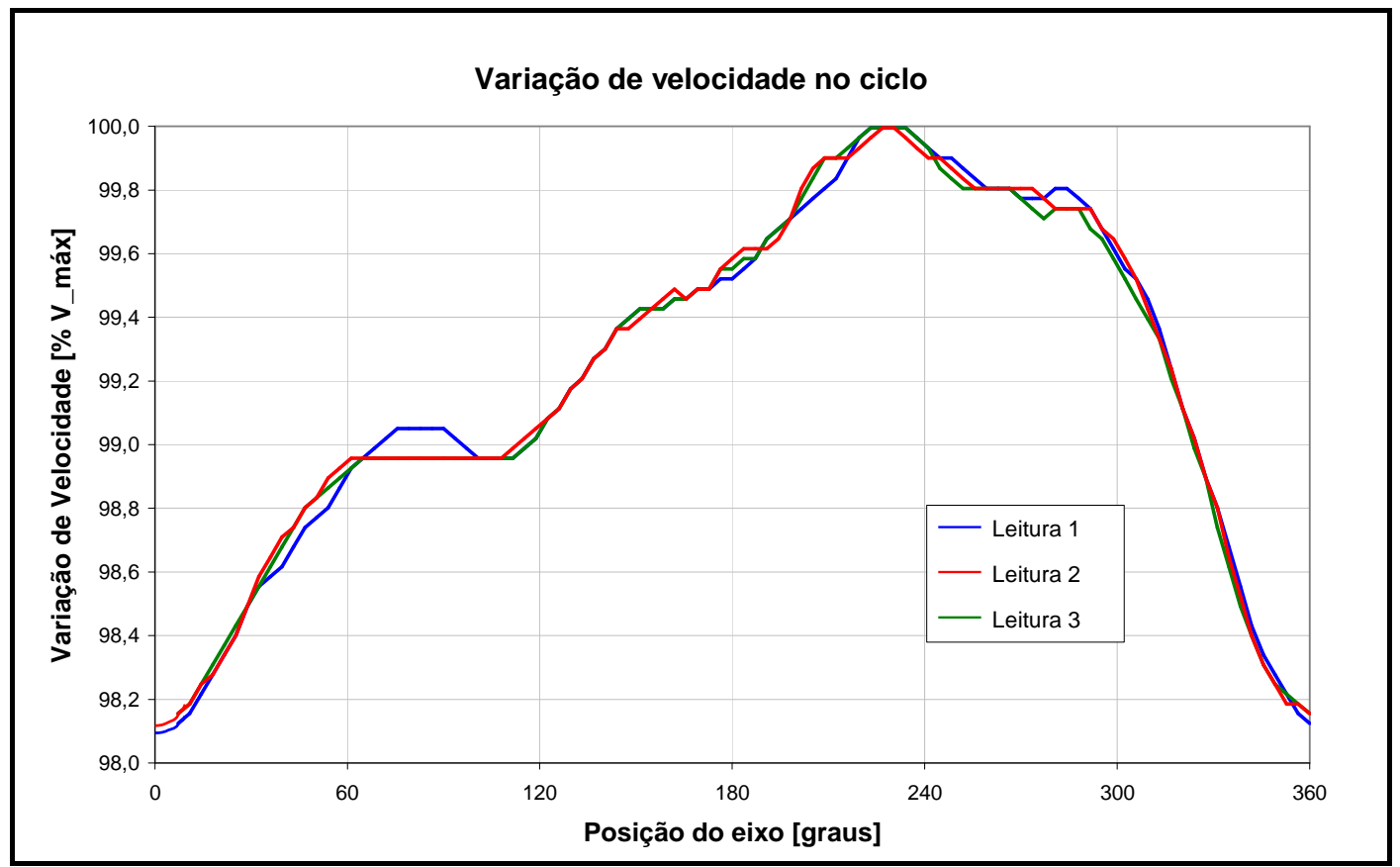

Figura 5.31 - Repetibilidade das leituras do perfil de velocidade durante o ciclo.

Os dados sobre a variação da rotação do motor durante 0 funcionamento do compressor podem contribuir no projeto e no desenvolvimento dos motores elétricos. 


\section{CONCLUSÕES}

Para o desenvolvimento da técnica de medição e obtenção de dados experimentais de pressão envolvidos no ciclo de trabalho dos compressores herméticos foram empregados sensores de pressão piezos-resistivos microprocessados, característica que permitiu a sua instalação dentro de um ambiente agressivo, como o compressor hermético. O sensor pôde ser empregado em uma larga faixa de temperatura sem comprometer a precisão, característica que foi avaliada no desenvolvimento do trabalho. Outro atributo desses sensores é o tamanho miniatura, essencial nesta aplicação devido à restrição de espaço físico do equipamento estudado. A medida de pressão do cilindro foi realizada com auxilio de um furo adaptador e também diretamente do topo do pistão do compressor. A influência desta conexão foi discutida e avaliada, onde o resultado mostrou que o uso do adaptador apresenta perda na informação de pressão, principalmente nos transientes de alta freqüência.

Os sensores de pressão mostram-se bastante eficientes em sua aplicação. Conhecendo a curva de resposta dos sensores, foi possível realizar as leituras de pressão de admissão, pressão de descarga e a pressão dentro do cilindro de compressão com boa precisão.

Os sensores mostraram-se bastante robustos quanto a fontes de ruídos externos, a temperatura e aos agentes químicos presentes nos compressores. Com os resultados apresentados pode-se verificar que os sensores atenderam as necessidades a que foram destinados, mostrando-se capaz de serem utilizados em instrumentações voltados ao estudo das pressões envolvidas no ciclo de trabalhos dos compressores herméticos.

Além das pressões envolvidas no ciclo de compressão dos compressores herméticos, também foram medidas as aberturas das válvulas de admissão e descarga do fluido refrigerante. Essas informações contribuem de forma efetiva no levantamento da eficiência do ciclo de compressão. Para realizar essas medidas foram empregados sensores de deslocamento ópticos, sem contato, diretamente posicionados sobre as válvulas de sucção e descarga do compressor. Um cuidado todo especial foi tomado na escolha desses sensores, uma vez que eles não poderiam estar conectados a válvula, 
pois qualquer contato físico entre o sensor e a válvula poderia deturpar a característica de funcionamento do elemento medido. Sua escolha foi também devido à robustez do sensor, ou seja, capacidade de suportar elevados níveis de pressão e temperatura, além de possuir compatibilidade química com óleo e o fluido refrigerante. A verificação desses sensores necessitou de uma atenção especial. Foi verificada a influência da luz e também a influência da flexão da válvula sobre o sinal medido. Considerando essas características foi possível melhorar a qualidade das medidas. Os resultados foram plenamente satisfatórios.

Os sensores utilizados para medição do deslocamento das válvulas de sucção e descarga mostraram-se bastante eficazes. Utilizando a faixa linear da curva de resposta em escuro dos sensores e considerando o efeito da flexão da válvula, conforme descrito no capitulo 4 , foi possível realizar as leituras de deslocamento das válvulas com boa precisão.

Os sensores mostraram-se bastante robustos quanto a fontes de ruídos externos e ao ambiente agressivo a que foram submetidos. Com os resultados apresentados pode-se verificar que os sensores atenderam as necessidades a que foram destinados, mostrando-se capaz de serem utilizados em instrumentações voltados ao estudo das válvulas em compressores herméticos.

As medidas de pressão do cilindro, de descarga e de sucção e as aberturas das válvulas foram correlacionadas com a posição angular do eixo de rotação, que foi medida através de um sensor de deslocamento angular (encoder) acoplado ao eixo do compressor. Através desse sensor foi também possível verificar a variação de rotação do eixo durante o ciclo de compressão. Com as informações extraídas pelo encoder foi também possível verificar o deslocamento do pistão no ciclo e conseqüentemente, extrair a informação da pressão no cilindro em função do volume.

Todos os sensores empregados neste trabalho mostraram-se bastante robustos e com excelente repetibilidade.

Para o desenvolvimento do trabalho fez-se necessário desenvolver uma carcaça especial que garantisse a hermeticidade do sistema e possibilitasse a montagem dos sensores e passagem dos cabos dos sinais. Dessa forma, foi 
possível realizar as medidas do ciclo de trabalho dos compressores em condições reais de funcionamento, com a presença de pressão, temperatura, fluido refrigerante e óleo.

O hardware para aquisição dos dados foi planejado e montado com sucesso o que possibilitou a aquisição de todas as grandezas físicas propostas no presente trabalho.

O desenvolvimento de um software também fez-se necessário para realização do estudo do ciclo de trabalho do compressor hermético. Com auxilio dessa ferramenta foi possível visualizar as informações em tempo real, gravar em arquivo todas as características mensuradas durante o trabalho, configurar os parâmetros de aquisição de dados e manipular matematicamente os dados adquiridos.

Dessa forma, a instrumentação desenvolvida e empregada nesse trabalho possibilitou a obtenção de dados experimentais envolvidos no ciclo de trabalho dos compressores herméticos alternativos. Este tipo de compressor é amplamente empregado no cotidiano, tendo sua maior aplicabilidade em refrigeradores e freezers. Com a metodologia, técnica e instrumentação desenvolvida nessa dissertação é possível extrair dados que auxiliam no desenvolvimento e projeto de compressores mais eficientes. Não foi foco desse trabalho realizar tal desenvolvimento.

O trabalho atingiu plenamente o objetivo proposto, possui importante aplicação e representa um grande passo para a pesquisa e desenvolvimento tecnológico do nosso país. 


\section{REFERÊNCIAS}

ANSI-ASRHAE Standard 23-1993. Methods of testing for rating positive displacement refrigerant compressors and condensing units.

ANSI-ASRHAE Standard 41.9.1989. A standard calorimeter test method for flow measurement of volatile refrigerant.

BÖSWIRTH, L. (1990). Theoretical and experimental study on valve flutter, part I. In: PROCEEDINGS OF PURDUE, INTERNATIONAL COMPRESSOR CONFERENCE, 1990, Purdue University, Lafayette, EUA, p.674 - 683.

BÖSWIRTH, L. (1990). Theoretical and experimental study on valve flutter, part II. In: PROCEEDINGS OF PURDUE, INTERNATIONAL COMPRESSOR CONFERENCE, 1990, Purdue University, Lafayette, EUA, p.684- 698.

BREDESEN, A.M. (1974). Computer simulation of valve dynamics as an aid to design. In: PROCEEDINGS OF PURDUE, INTERNATIONAL COMPRESSOR CONFERENCE, 1974, Purdue University, Lafayette, EUA, p.171-177.

BUCHHOLZ, A.B. (1978). Investigation of pressure transducer adapter dynamics. In: PROCEEDINGS OF PURDUE, INTERNATIONAL COMPRESSOR CONFERENCE, 1978, Purdue University, Lafayette, EUA, p. $275-282$.

BUKAC, H. (2002). Understanding valve dynamics. In: PROCEEDINGS OF PURDUE, INTERNATIONAL COMPRESSOR CONFERENCE, 2002, Purdue University, Lafayette, EUA, p.C15-3.

BULIGAN, G. et al (2003). The measurement of hermetic compressor valve motion. In: PROCEEDINGS OF 21ST INTERNATIONAL MODAL ANALYSIS CONFERENCE, \#163, Kissimmee, Florida, 2003. 
BULIGAN, G. et al (2002). Valve lift measurement by optical techniques in compressors. In: PROCEEDINGS OF PURDUE, INTERNATIONAL COMPRESSOR CONFERENCE, 2002, Purdue University, Lafayette, EUA, p.C13-5.

CHAU, K.H.L. (1999). Pressure measurement. In: WEBSTER J.G. (1999). The measurement, instrumentation and sensor handbook. Flórida, EUA : CRC press LLC, 1999, p. $26.1-26.11$.

CLAUS, R.O.; BHATIA, V.; WANG, A. (1999). Optical fiber displacement sensors. In: WEBSTER J.G. (1999). The measurement, instrumentation and sensor handbook. Flórida, EUA : CRC press LLC, 1999, p. 6.141-6.156.

DANQING, W.; QI, P.; XIANGXING, S. (1986). The applicaton of a microcomputer in experiment of reciprocating compressor. In: PROCEEDINGS OF PURDUE, INTERNATIONAL COMPRESSOR CONFERENCE, 1986, Purdue University, Lafayette, EUA, p.724 - 735.

DIECK, R.H. (1999). Measurement accuracy. In: WEBSTER J.G. (1999). The measurement, instrumentation and sensor handbook. Flórida, EUA : CRC press LLC, 1999, p. $4.1-4.13$.

DOEBELIN, E. (1990). Measurement systems: application and design. New York, EUA, McGraw-Hill publishing CO, 1990, 3ª edição, p. 37 - 98 e 437 521.

DOSSAT, R.J. (1984). Princípio de Refrigeração. São Paulo, Hemus, 1984.

ELSON, J.P. (1972). Criteria for the design of pressure transducer adapter systems. In: PROCEEDINGS OF PURDUE, INTERNATIONAL COMPRESSOR CONFERENCE, 1986, Purdue University, Lafayette, EUA, p.390 - 394. 
FLIGLIOLA, R.S. (1999). Operational modes of instrumentation. WEBSTER J.G. (1999). The measurement, instrumentation and sensor handbook. Flórida, EUA : CRC press LLC, 1999, p. $2.1-2.7$.

FLIGLIOLA, R.S.; BEASSLEY, D.E. (2000). Theory and design for mechanical measurements. Danvers, EUA, John Wiley and Sons Inc, 2000, $3^{\underline{a}}$ edição, p. 1 $-104,235-278$ e $345-384$.

HANSMAN Jr, R.J. (1999). Characteristics of instrumentation. In: WEBSTER J.G. (1999). The measurement, instrumentation and sensor handbook. Flórida, EUA : CRC press LLC, 1999, p. $1.1-1.8$.

HOUAISS (2001). Dicionário eletrônico da língua portuguesa - versão1.0, dezembro 2001, Distribuído Editora Objetiva Ltda.

IBGE (2003), Produção e vendas dos 100 maiores produtos e/ou serviços industriais, segundo posição e descrições dos produtos - Brasil - 2003, Instituto Brasileiro de Geografia e Estatística.(2005). Disponível em:<http://www.ibge.gov.br/ Acessado em 25/02/05.

JOO,J.M. et al (2000). Optimal valve design for reciprocating compressor. In: PROCEEDINGS OF PURDUE, INTERNATIONAL COMPRESSOR CONFERENCE, 2000, Purdue University, Lafayette, EUA, p.451 - 458.

KILLMANN, I.G. (1972). Investigations on a spring less, low mass compressor valve. In: PROCEEDINGS OF PURDUE, INTERNATIONAL COMPRESSOR CONFERENCE, 1972, Purdue University, Lafayette, EUA, p.415 - 422.

KIM, J.; SOEDEL, W. (1986). On experimental errors in P-V diagrams. In: PROCEEDINGS OF PURDUE, INTERNATIONAL COMPRESSOR CONFERENCE, 1986, Purdue University, Lafayette, EUA, p.698 - 713. 
LUDU, A.; BETTO, A.; REGNER, G. (2000). Endoscope video of compressor valve motion and pressure measurement assist simulations for design improvements. In: PROCEEDINGS OF PURDUE, INTERNATIONAL COMPRESSOR CONFERENCE, 2000, Purdue University, Lafayette, EUA, p. $443-450$.

MACLAREN,J.F.T.; TRAMSCHEK, A.B. (1972). Prediction of valve behavior with pulsating flow in reciprocating compressor. In: PROCEEDINGS OF PURDUE, INTERNATIONAL COMPRESSOR CONFERENCE, 1972, Purdue University, Lafayette, EUA, p.203 - 211.

MEINERS, W.G.; ZHOU, W.; KIM,J. (1996). A new technique to measure experimental pressure diagrams of reciprocating compressors. In: PROCEEDINGS OF PURDUE, INTERNATIONAL COMPRESSOR CONFERENCE, 1986, Purdue University, Lafayette, EUA, p.31 - 35.

MCCONNELL, R.R.; COHEN, R. (1972). A system to measure instantaneous compressor crankshaft speed. In: PROCEEDINGS OF PURDUE, INTERNATIONAL COMPRESSOR CONFERENCE, 1972, Purdue University, Lafayette, EUA, p.386 - 389.

PERKOVICH,M.; KUEHN, T.H.; RAMSEY, J.W. (1994). Experimental testing and computer simulation of a reciprocating refrigeration compressor. In: PROCEEDINGS OF PURDUE, INTERNATIONAL COMPRESSOR CONFERENCE, 1994, Purdue University, Lafayette, EUA, p.387 - 392.

PRASAD, B.G.S.; WOOLLATT,D. (2000). Valve dynamic measurements in a vip compressor. In: PROCEEDINGS OF PURDUE, INTERNATIONAL COMPRESSOR CONFERENCE, 2000, Purdue University, Lafayette, EUA, p.361- 368 . 
REED, R.P. (1999). Thermocouple thermometers. In: WEBSTER J.G. (1999). The measurement, instrumentation and sensor handbook. Flórida, EUA : CRC press LLC, 1999, p. $32.41-32.74$.

RICHARDSON, H.; GATECLIFF, G. W.; GRINER, G. C. (1980). Verification of flapper suction valve simulation program. In: PROCEEDINGS OF PURDUE, INTERNATIONAL COMPRESSOR CONFERENCE, 1980, Purdue University, Lafayette, EUA, p.180 - 184.

RIGOLA, J.; et al (2002). Experimental studies of hermetic reciprocating compressor with special emphasis on P-V diagram. In: PROCEEDINGS OF PURDUE, INTERNATIONAL COMPRESSOR CONFERENCE, 2002, Purdue University, Lafayette, EUA, p.C4-1.

SPEICH, C. F. (1972). Dynamic measurements in reciprocating refrigerant compressors. In: PROCEEDINGS OF PURDUE, INTERNATIONAL COMPRESSOR CONFERENCE, 1972, Purdue University, Lafayette, EUA, p.362- 368 .

STOECKER, W. F.; JONES, J. W. (1985). Refrigeração e ar condicionado. São Paulo, McGraw - Hill do Brasil , 1985, p. 227 - 310 e 327 - 338.

SYDENHAM, P.H. (1999). Static and dynamic characteristics of instrumentation. In: WEBSTER J.G. (1999). The measurement, instrumentation and sensor handbook. Flórida, EUA : CRC press LLC, 1999, p. 3. 1 - 3.22.

TIPLER, P. A. (2000). Física para cientistas e engenheiros, V1. Rio de Janeiro, LTC , 2000, p. $504-600$.

WOOLLATT, D. (1972). Some practical applications of modern compressor valve technology. In: PROCEEDINGS OF PURDUE, INTERNATIONAL COMPRESSOR CONFERENCE, 1972, Purdue University, Lafayette, EUA, p.170 - 179. 
ANEXO A - Dados complementares sobre os sensores utilizados. 


\section{SENSOR DE PRESSÃO}

Modelo : ETL-76M-190-500A.

Faixa de pressão: 0 - 500 Psia (pressão absoluta).

Alimentação: $12 \pm 4$ VDC.

Sinal de saída: 0 - 5 VDC.

Erro total: $0.25 \%$ (histerese, repetibilidade e efeitos térmicos).

Faixa de freqüência: $0-2500 \mathrm{~Hz}$.

Resolução: Infinitesimal.

Temperatura de operação: $-40^{\circ} \mathrm{C}$ a $140^{\circ} \mathrm{C}$.

Peso: 10 gramas.

Torque de montagem: 15 lb.pol

Princípio de funcionamento: Piezoresistivo.

Mais informações: http://www.kulite.com

\section{SENSOR DE DESLOCAMENTO.}

Modelo: RC100 / RC171.

Fonte de luz: LED, 880nm.

\section{Amplificador:}

Alimentação: 12 a 30 VDC.

Sinal de saída: 0 - 5 VDC.

Faixa de freqüência: $0-20 \mathrm{KHz}$.

Temperatura de operação: 0 a $70^{\circ} \mathrm{C}$.

Peso: $0.6 \mathrm{Kg}$.

Erro: $<0.1 \%$.

\section{Ponta do sensor:}

Temperatura de operação: $-45^{\circ} \mathrm{C}+200^{\circ} \mathrm{C}$.

Pressão: 250 psig.

\section{Cabo:}

Temperatura de operação: $-40{ }^{\circ} \mathrm{C}+105^{\circ} \mathrm{C}$.

Raio de flexão: $12 \mathrm{~mm}$ mínimo.

Mais informações: http://www.philtec.com 
SENSOR DE DESLOCAMENTO ANGULAR (ENCODER).

Alimentação: 5 VDC $\pm 10 \%$.

Sinal de saída: TTL; 0 - 5 VDC.

Numero de linhas: 2000.

Máxima freqüência: $300 \mathrm{Khz}$.

Velocidade máxima: $10000 \mathrm{rpm}$.

Momento de inércia: $0.5 \times 10^{-6} \mathrm{kgm}^{2}$

Temperatura de operação: -40 a $100^{\circ} \mathrm{C}$.

Peso: $0.1 \mathrm{~kg}$

Mais informações: http://www.heidenhain.com 
ANEXO B - Dados complementares hardware de aquisição de dados. 


\section{HARDWARE DE AQUISIÇÃO}

\section{Placa de aquisição de dados}

Modelo: NIPCI-6251 - National instruments.

Número de canais: Analógico: 8 canais (diferencial) ou 16 (comum)

Digital: 24 canais

Resolução: 16 Bit

Taxa de amostragem: 1,25Mhz 1 canal / 1 Mhz multicanais

Acuracidade: 50 ppm da taxa de amostragem.

Resolução de tempo: 50 ns

Entrada: 0 - 10V

Trigger Analógico: 1

Número de contadores: 2 - 32 Bits - 80Mhz

Mais informações: http:// www.ni.com/pdf/manuals/371291c.pdf

\section{Chassis}

Modelo: SCX1-1000

informação: http://www.ni.com/pdf/products/us/4scxisc333_334_335_336.pdf

\section{Modulo de entrada analógico:}

Modelo: SCXI -1125

informação: http://www.ni.com/pdf/products/us/4scxisc296_ETC_196.pdf

\section{Modulo de Temperatura:}

Modelo: SCXI -1102

informação: http://www.ni.com/pdf/products/us/4scxisc278_ETC_196.pdf

\section{Bloco conector:}

Modelo: SCXI - 1180

Informação:

http://www.ni.com/pdf/products/us/4scxisc337_338_339_340_341.pdf

\section{Terminal Bloco}

Modelo: SCXI-1300, SCXI-1302 e SCXI-1313

Informação: http://www.ni.com/pdf/products/us/4scxisc326_ETC_332.pdf 